\title{
ENHANCED GREEN PRODUCTION OF BIOBUTANOL BY NOVEL FUSANTS OF TWO AND THREE CLOSTRIDIA
}

\author{
by \\ BANAFSHEH MOHTASEBI \\ B.Sci. in Microbiology \\ Islamic Azad University of Tehran, Tehran, Iran, 2000 \\ A Thesis \\ presented to Ryerson University \\ in partial fulfilment of the requirements \\ for the degree of
Master of Applied Science
in the Program of \\ Environmental Applied Science and Management
}

Toronto, Ontario, Canada, 2013

(C) Banafsheh Mohtasebi, 2013 


\section{AUTHOR'S DECLARATION FOR ELECTRONIC SUBMISSION OF A THESIS}

I hereby declare that I am the sole author of this thesis. This is a true copy of the thesis, including any required final revisions, as accepted by my examiners.

I authorize Ryerson University to lend this thesis to other institutions or individuals for the purpose of scholarly research.

Banafshel

$\overline{\text { Banafsheh Mohtasebi }}$

I further authorize Ryerson University to reproduce this thesis by photocopying or by other means, in total or in part, at the request of other institutions or individuals for the purpose of scholarly research.

I understand that my thesis may be made electronically available to the public.

Banafshel

Banafsheh Mohtasebi 


\begin{abstract}
Enhanced Green Production of Biobutanol By Novel Fusants of Two and Three Clostridia

\author{
Banafsheh Mohtasebi \\ Master of Applied Science \\ Environmental Applied Science and Management \\ Ryerson University
}

2013

Protoplast fusion, which is a novel genetic engineering approach, was developed between mesophilic and thermophilic butanol producing bacteria to enhance production of biobutanol as a green energy resource. Three strains of anaerobic gram-positive clostridia were fused through a protoplast fusion technique to produce biobutanol from wheat straw as a feedstock during the process of Simultaneous Saccharification and Fermentation (SSF). These strains have the natural enzymatic ability for biobutanol production, and include Clostridium beijerinckii (ATCC BA101), Clostridium thermocellum, and Thermoanaerobacterium saccharolyticum. The objective of the present study was to increase enzymatic activity during saccharification by raising the temperature of fermentation to increase biobutanol production. Results showed that protoplast fusion of thermophilic and mesophilic clostridia have led to improving thermostability in a fermentation medium at $45^{\circ} \mathrm{C}$. This represents the optimum temperature for enzymatic hydrolysis. Results also showed that the fused strain produced essential hydrolysis enzymes, which eliminated the need to add any enzymes during the hydrolysis step. Furthermore, results in the present study demonstrated that the fused culture of bacteria was able to tolerate the elevated concentration of acetone, butanol, and ethanol during production, which resulted in higher biobutanol production of $13.8 \mathrm{~g} / \mathrm{L}$. This study included a comparison to the coculture as a benchmark to account for the effects of protoplast fusion.

Keywords: Biobutanol; Novel Fusants; Two and Three Clostridia; Simultaneous Saccharification and Fermentation (SSF); Co-culture 


\section{ACKNOWLEDGMENTS}

I would like to express my sincere gratitude to my supervisor, Dr. Yaser Dahman of the Department of Chemical Engineering at Ryerson University, for his guidance, assistance, and financial support throughout the successful completion of this study.

I would also like to acknowledge Dr. Ronald Pushchak, whose comments, advices and suggestions immensely benefitted this research; Dr. Michael Bardecki, Elias Chu, Isabella Fernandes, and Alison MacLeod, Ryerson University staff, for their support and guidance during my studies; Ali Hemmati, Daniel Boothe, and Tondar Tajrobehkar, Engineering Technologists of the Department of Chemical Engineering, for their technical support and assistance on my experimental setup and further experiments.

Furthermore, I would like to thank my colleagues Kashif Seyed, Hamza Nakhoda, Wahib Al Abdallah, and Ciro LeCompte for many times of enlightenment and entertainment, as well as their help in troubleshooting, support and advice. A special thanks is due to Miranda Maki, a PhD student in the Department of Biology at Lakehead University for performing genetic stability studies for the strains.

I would also like to express my sincere appreciation to my lovely parents and sisters for their unconditional help and guidance whose advices and encouragements helped me to become a better person. Finally, I would like to acknowledge the unconditional love and support I received from my husband, Mohammadreza Davoudpour, during my years of studying at Ryerson University. 
AUTHOR'S DECLARATION FOR ELECTRONIC SUBMISSION OF A THESIS.............................. ii

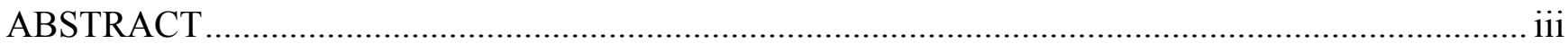

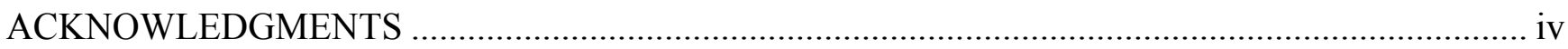

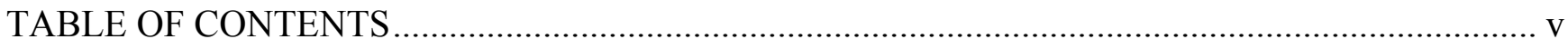

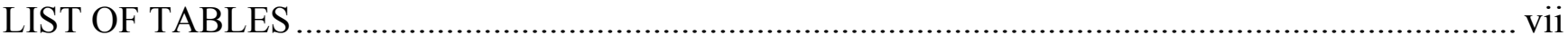

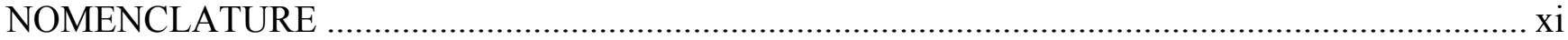

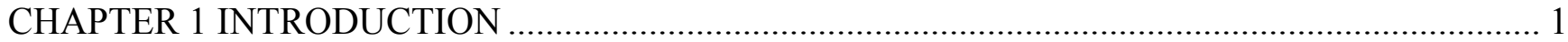

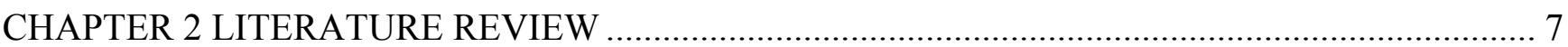

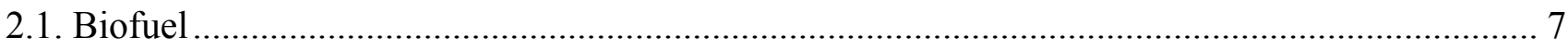

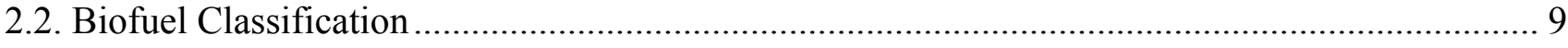

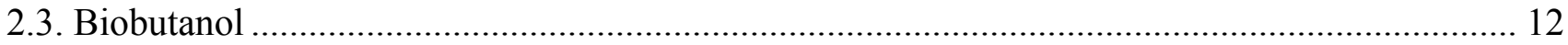

2.4. Agricultural Biomass....................................................................................................... 13

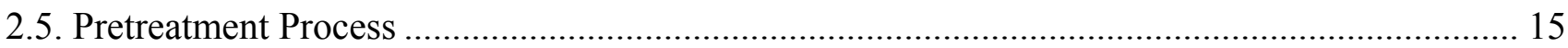

2.6. Biobutanol Fermentation and Metabolic Pathways of Gram-positive Bacteria............................ 18

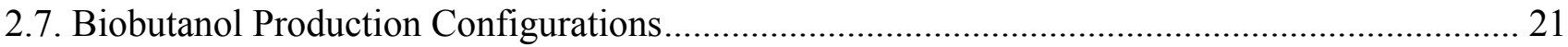

2.8. Protoplast Fusion and Cell Wall Regeneration …………......................................................... 23

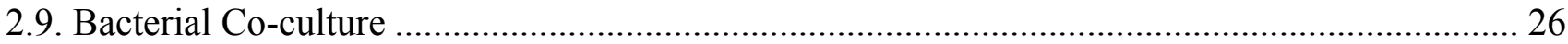

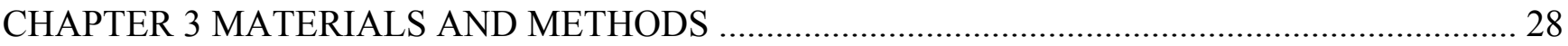

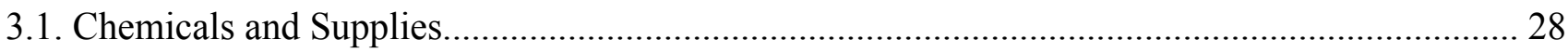

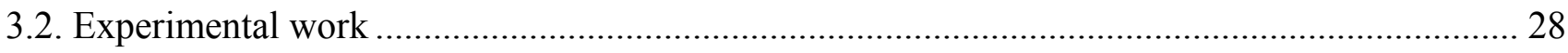

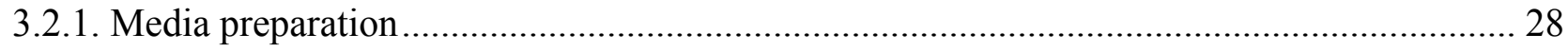

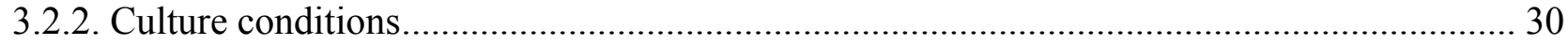

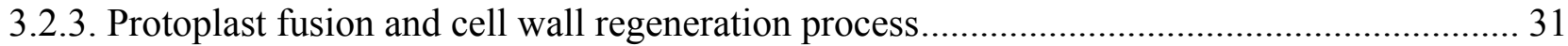

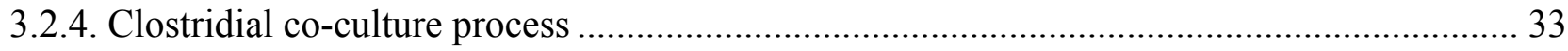

3.2.5. Wheat straw pre-treatment....................................................................................... 34

3.2.6. SSF experiment using fused and co-culture clostridia ...................................................... 35

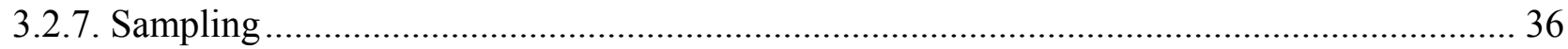

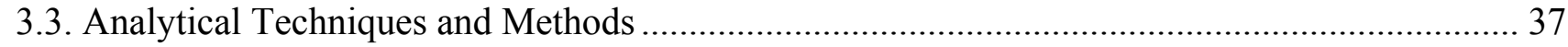




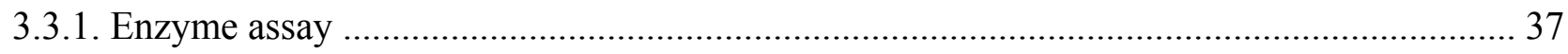

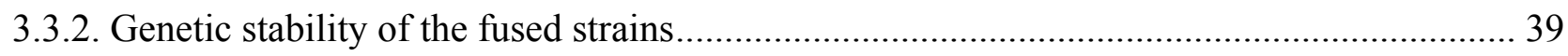

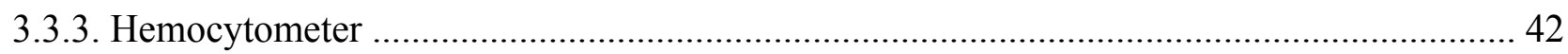

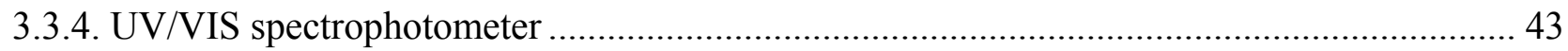

3.3.5. High performance liquid chromatography (HPLC)............................................................... 44

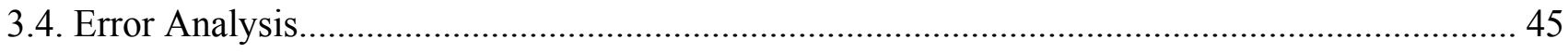

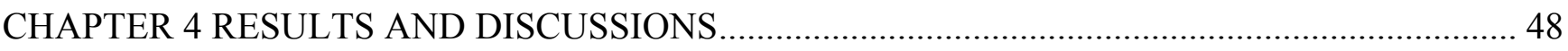

4.1. Protoplast Formation and Cell Wall Regeneration of Wild Strains ............................................. 48

4.2. Results of the Genetic Stability Test of CbCt and CbCtTs Fused Strains .................................... 49

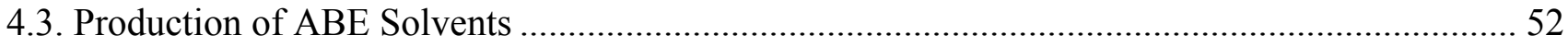

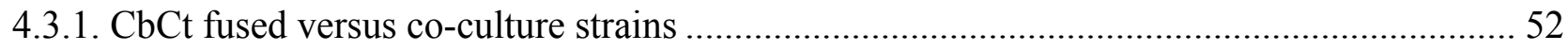

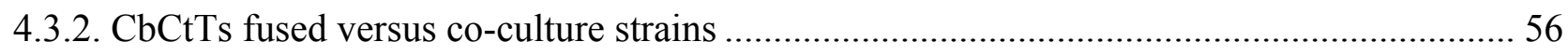

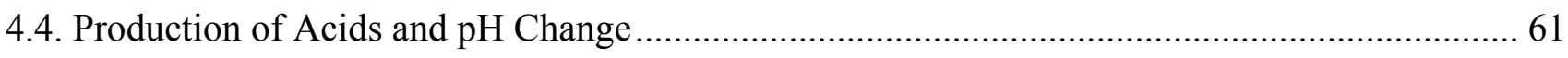

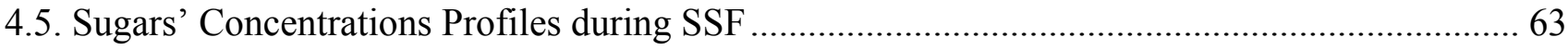

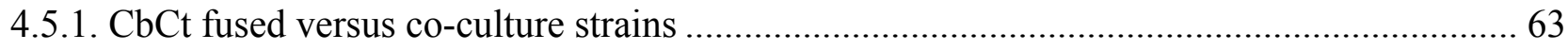

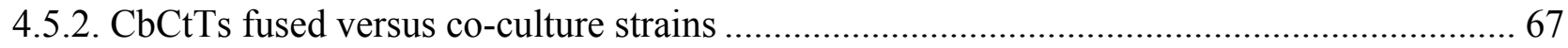

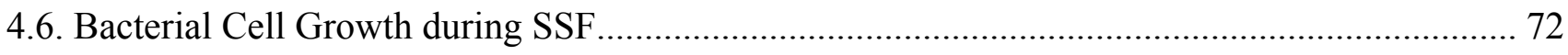

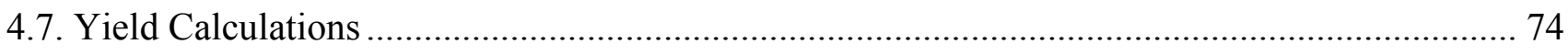

4.8. Enzyme Assay Evaluation .................................................................................................... 76

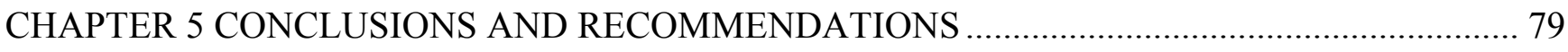

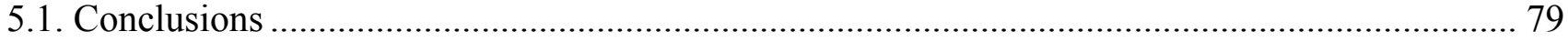

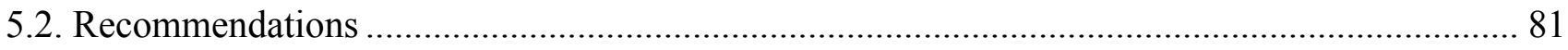

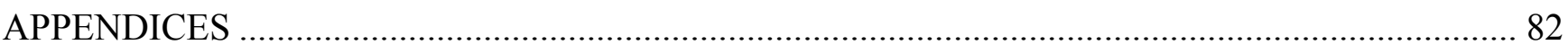

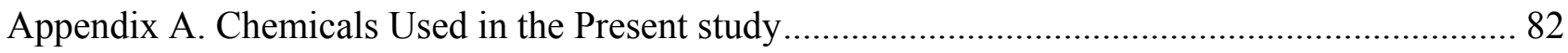

Appendix B. Glucose Standard Curve and Filter Paper Assay Analysis ........................................... 84

Appendix C. Raw Data for ABE and Acids from three SSF Experiments ......................................... 86

Appendix D. Raw Data for Total Sugar Consumption during SSF ................................................... 87

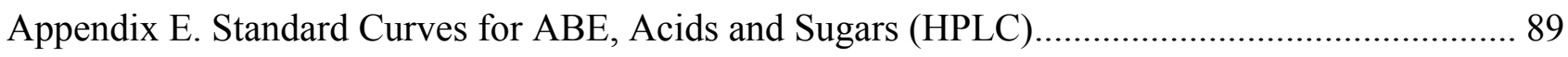

Appendix F. Raw Data for Biobutanol Concentration Profile during SSF Experiments.................... 94

Appendix G. Cell Growth Profile for all Fused and Co-culture Strains ............................................ 96

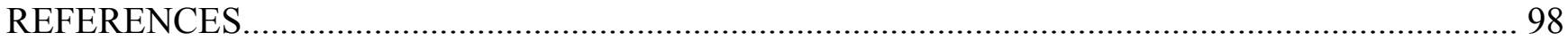




\section{LIST OF TABLES}

Page

Table 2.1. Comparison of biofuel properties and gasoline (Adapted from Lee et al., 2008).............. 13

Table 2.2. Sugar concentration of different agricultural wastes. ................................................... 16

Table 2.3. Biobutanol concentrations (g/L) using different sources of biomass. .............................. 22

Table 3.1. Primer sequences and product size for biomarker genes. .............................................. 41

Table 4.1. Regeneration of C. beijerinckii, C. thermocellum and T. saccharolyticum $(\mathrm{CFU} / \mathrm{mL}) \ldots \ldots \ldots .48$

Table 4.2. ABE and acid concentrations for all fused and co-cultured strains during SSF................. 53

Table 4.3. Concentration of sugar consumption and average cell proliferation rate for all strains........55

Table 4.4. Individual and total sugars concentrations during SSF for $C b C t$ fused strains. .................. 63

Table 4.5. Individual and total sugars concentrations during SSF for $C b C t$ co-culture strains............. 66

Table 4.6. Individual and total sugars concentrations during SSF for $C b C t T s$ fused strains............... 68

Table 4.7. Individual and total sugars concentrations during SSF for $C b C t T s$ co-culture strains......... 72

Table 4.8. Total ABE and individual yields for all fused and co-culture strains.............................. 76

Table 4.9. Concentrations of released glucose from samples and enzyme activity for $C b C t$ and $C b C t T s$

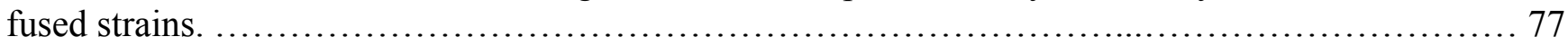

Table A.1. List of chemicals used in the present study............................................................. 82

Table B.1. Glucose standards dilutions and UV absorbance at $540 \mathrm{~nm}$..................................... 84

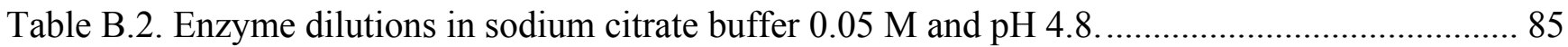

Table C.1. ABE concentration from three SSF experiments for all fusants................................... 86

Table C.2. Final acid concentration from three SSF experiments for all fusants. ............................ 86

Table D.1. Raw data for total sugars during SSF for $\mathrm{CbCt}$ fused strains. ...................................... 87

Table D.2. Raw data for total sugars during SSF for $C b C t$ co-culture strains................................. 87

Table D.3. Raw data for total sugars during SSF for CbCtTs fused strains....................................... 88

Table D.4. Raw data for total sugars during SSF for $C b C t T s$ co-culture strains .............................. 88

Table F.1. Biobutanol concentration profile for $C b C t$ fused strains during SSF experiments. ............ 94

Table F.2. Biobutanol concentration profile for $\mathrm{CbCt}$ co-culture strains during SSF experiments....... 94

Table F.3. Biobutanol concentration profile for $\mathrm{CbCtTs}$ fused strains during SSF experiments. ......... 95 
Table F.4. Biobutanol concentration profile for $C b C t T s$ co-culture strains during SSF experiments.... 95

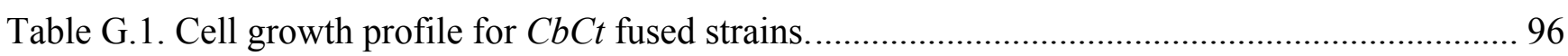

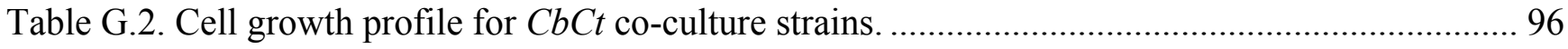

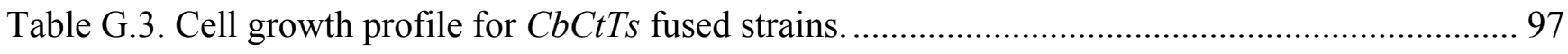

Table G.4. Cell growth profile for $C b C t T s$ co-culture strains. ................................................... 97 


\section{LIST OF FIGURES}

Figure 2.1. Global biofuel production (Adapted from Marcacci, 2012)......................................... 8

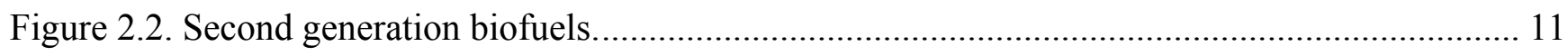

Figure 2.3. Molecular structure of lignocellulosic biomass (Adapted from Kahar, 2013)................. 14

Figure 2.4. Pretreatment of lignocellulosic biomass (Mosier et al., 2005)...................................... 17

Figure 2.5. Metabolic pathways of C. acetobutylicum (Jin et al., 2011)........................................ 19

Figure 2.6. (a) C. beijerinckii on BLM medium; (b) reverted L-colonies to the bacillary form (Birrer et

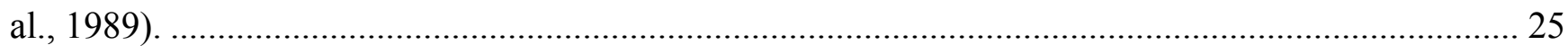

Figure 2.7. The Clostridial co-culture process (Adapted from Maki et al., 2009)............................ 27

Figure 3.1. Glove box (Terra Universal, Canada) used for the anaerobic environment...................... 31

Figure 3.2. Hammer mill used for wheat straw preparation (Retsch GmnH Inc., USA).................... 35

Figure 3.3. Agarose gel electrophoresis apparatus (BioRad Laboratories). .................................... 42

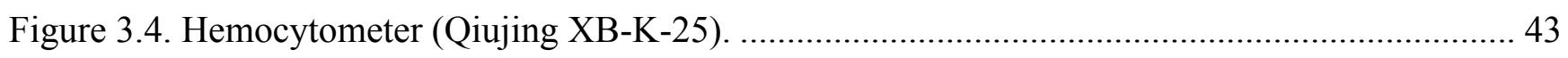

Figure 3.5. GENESYS 10S UV/VIS spectrophotometer (Thermo Fisher Scientific, USA)................ 44

Figure 3.6. HPLC (model \# 600 by Perklin Elmer) equipped with refractive index (model \# HP1047 A,

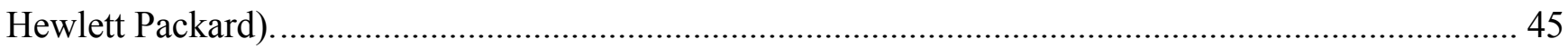

Figure 4.1. Agarose gel electrophorosis of PCR products for biomarkers. From left: generations 1 to 5 and 10 (G1-G5 and G10); first band (solid line) and second band (dotted line) are bglA and ald gene, respectively, representing $C t$ and $C b$, positive and negative controls as designated.......................... 50

Figure 4.2. A) Agarose gel electrophoresis of PCR products for biomarkers. From left: Generations 1 and 2 (G1, G2); third band in each generation: ald, respectively, representing C. beijerinckii. B)

Positive (band present) and negative controls (no bands) for the presence/absence of biomarkers in each corresponding strain as labeled.

Figure 4.3. ABE concentration profile during SSF using $C b C t$ fused strains at $45^{\circ} \mathrm{C}$ (Average RSD: $0.6 \%$ ).

Figure 4.4. ABE concentration profile during SSF using $C b C t$ co-culture strains at $35^{\circ} \mathrm{C}$ (Average RSD: $0.9 \%$ ). 56

Figure 4.5. ABE concentration profile during SSF using $C b C t T s$ fused strains at $45^{\circ} \mathrm{C}$ (Average RSD: $0.29 \%)$ 58

Figure 4.6. ABE concentration profile during SSF using $C b C t T s$ co-culture strains at $35^{\circ} \mathrm{C}$ (Average RSD: $0.24 \%)$ 
Figure 4.7. $\mathrm{pH}$ Changes during SSF for all fused and co-culture bacterial strains (Average RSD: 3.4\%).

Figure 4.8. Individual sugar's concentrations with respect to total sugars during SSF for $C b C t$ fused strains (Average RSD: 1.65\%).

Figure 4.9. Individual sugar's concentrations with respect to total sugars during SSF for $\mathrm{CbCt}$ coculture strains (Average RSD: 1.3\%).

Figure 4.10. Individual sugar's concentrations with respect to total sugars during SSF for CbCtTs fused strains (Average RSD: 0.8\%).

Figure 4.11. Individual sugar's concentrations with respect to total sugars during SSF for CbCtTs coculture strains (Average RSD: 0.36\%)......

Figure 4.12. Changes in cell concentration for $C b C t$ fused and $C b C t$ co-culture strains during SSF (Average RSD: $3.4 \%$ ).

Figure 4.13. Changes in cell concentration for $C b C t T s$ fused and $C b C t T s$ co-culture strains during SSF (Average RSD: $4.1 \%$ ). 75

Figure B.1. Glucose calibration curve for filter paper assay analysis at $540 \mathrm{~nm}$ using UV-VIS. 84

Figure B.2. Determining enzyme concentration that release $2 \mathrm{mg}$ of glucose by plotting liberated

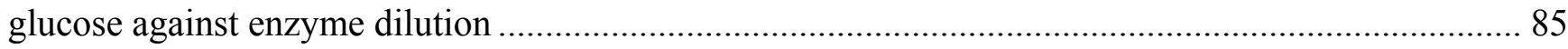

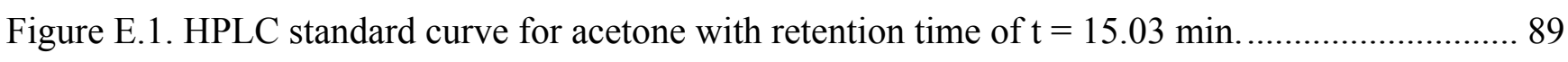

Figure E.2. HPLC standard curve for butanol with retention time of $\mathrm{t}=15.54 \mathrm{~min}$.................... 89

Figure E.3. HPLC standard curve for ethanol with retention time of $\mathrm{t}=13.69$ min. ….................. 90

Figure E.4. HPLC standard curve for Acetic acid with retention time of $\mathrm{t}=11.71 \mathrm{~min} . \ldots \ldots \ldots \ldots \ldots \ldots . . . . . . . . .90$

Figure E.5. HPLC standard curve for butyric acid with retention time of $\mathrm{t}=12.38 \mathrm{~min}$.................. 91

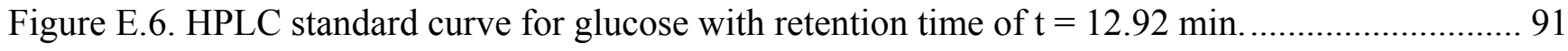

Figure E.7. HPLC standard curve for xylose with retention time of $\mathrm{t}=14.02 \mathrm{~min} \ldots \ldots \ldots \ldots \ldots \ldots \ldots \ldots . . . \ldots 2$

Figure E.8. HPLC standard curve for Mannose with retention time of $\mathrm{t}=9.38 \mathrm{~min} . \ldots \ldots \ldots \ldots \ldots \ldots \ldots . . . \ldots \ldots 2$

Figure E.9. HPLC standard curve for arabinose with retention time of $\mathrm{t}=21.61 \mathrm{~min} \ldots \ldots \ldots \ldots \ldots \ldots \ldots . . . \ldots 3$ 


\section{NOMENCLATURE}

\begin{tabular}{|c|c|}
\hline$\% \mathrm{RSD}$ & percent relative standard deviation \\
\hline$\Delta T$ & the change in temperature $\left({ }^{\circ} \mathrm{C}\right)$ \\
\hline$a$ & CFU of cells before protoplasting (units $/ \mathrm{mL}$ ) \\
\hline Ack & acetate kinase \\
\hline Adh & alcohol dehydrogenase \\
\hline ald & aldehyde dehydrogenase gene \\
\hline Aldh & acetaldehyde dehydogenase \\
\hline$b$ & $\mathrm{CFU}$ of regenerated protoplasts after $48 \mathrm{~h}$ (units $/ \mathrm{mL}$ ) \\
\hline bglA & $\beta$-glucosidase A gene \\
\hline$c$ & CFU of the non-protoplasted units (units/mL) \\
\hline $\mathrm{Cb}$ & Clostridium beijerinckii \\
\hline$c_{h}$ & the specific heat $\left(\mathrm{J} / \mathrm{g} \cdot{ }^{\circ} \mathrm{C}\right)$ \\
\hline$C t$ & Clostridium thermocellum \\
\hline$[E]$ & concentration of enzymes releasing $2 \mathrm{mg}$ glucose. \\
\hline$F P U$ & filter paper activity (units/mL) \\
\hline$m$ & mass of the substance $(\mathrm{g})$ \\
\hline$n$ & sample size \\
\hline Pta & phosphate acetyltransferase \\
\hline$Q$ & heat of a measured substance $(\mathrm{J})$ \\
\hline$T s$ & Thermoanaerobacterium saccharolyticum \\
\hline$x$ & data point \\
\hline $\bar{x}$ & sample mean value \\
\hline$x y l B$ & $\beta$-xylosidase $\mathrm{B}$ \\
\hline
\end{tabular}

\section{Acronyms}

$\mathrm{ABE}$

BS

CBM acetone-butanol-ethanol

barely straw

clostridium basal medium 


\begin{tabular}{ll} 
CBP & consolidated bioprocessing \\
CF & corn fibre \\
CFU & colony forming units \\
CGM & clostridium growth medium \\
CMM & cooked meat medium \\
CS & corn stover \\
DDGS & distiller's dried grains with solubles \\
FPA & filter paper Assay \\
GHG & greenhouse gas \\
HMF & hydroxymethyl furfural \\
HPLC & high performance liquid chromatography \\
MTC & medium for thermophilic clostridia \\
NBRC & national biological resource centre \\
PEG & polyethylene glycol \\
PPM & protoplasting medium \\
RM & regeneration medium \\
SG & switch grass \\
SSF & simultaneous saccharification and fermentation \\
STDEV & standard deviation \\
WS & wheat straw \\
\hline
\end{tabular}




\section{CHAPTER 1}

\section{INTRODUCTION}

The growing consumption of fossil fuels has been one of the main sources of greenhouse gas emissions that lead to undesirable damage to air quality. High prices of oil coupled with instability of barrel supplies have initiated a considerable interest in alternative and renewable energy sources. Factors which include environmental, economic, and geopolitical issues, play important roles in the current interest in sustainable energy production (Dellomonaco et al., 2010).

Over the last decade, biofuels such as bioethanol, biobutanol, and biodiesel have been promoted as a promising alternative to petroleum; thus, as an effective solution to mitigate climate change. The first generation of biofuels was made from edible sources such as wheat, corn, and sugars by the action of microorganisms. However, this generation was not successful, since it threatened traditional food supplies as well as biodiversity. In contrast, the second generation of biofuels, derived from lignocellulosic crops, has achieved a lot of attention, because it is produced from residual non-food crops or agricultural residues which are sustainable resources. Finally, the third generation of biofuel that is made from algae, has attracted lots of attentions due to its ability to be cultured on unsuitable lands for agriculture (Hartman, 2008).

Butanol is a solvent that is used in the paint-and-varnish industry, as well as in the production of resins and plastics, and in the synthesis of many organic substances. It can be also used as an alternative to 
traditional fuels for transportation vehicles or industry. Biobutanol is a biofuel that can be produced from renewable resources or biomass through different chemical and biological techniques. Biological butanol synthesis served as a great feedstock for industrial purposes until the 1950s. However, with an increase in the cost of substrates and the availability of cheap raw oil for the petrochemical industries reduced the importance of the acetone-butanol-ethanol (ABE) fermentation process. The 1974 oil crisis, which resulted in a high cost for crude oil along with its environmental impacts, created a renewed interest in the biological production of butanol by using microorganisms, which have the potential to produce cellulolytic enzymes (Dürre, 1998).

There have been many attempts to produce alternative biofuels and chemical feedstocks from sustainable resources. In 2006, a remarkable advance in the production of advanced biofuels, especially biobutanol through the fermentation process, was achieved by the joint efforts of British Petroleum (BP) and DuPont (Energy Industry, 2012). Further, Environmental Energy Inc. (EEI) established a biobutanol production unit in the United States.

Biobutanol, as a clean energy alternative has some advantages over other biofuels, especially ethanol. Due to its physical properties, butanol can be mixed with gasoline; it also has the potential to replace gasoline to a larger extent than ethanol, without any adjustments to automobile engines (Zverlov et al., 2006). However, ethanol can only be used as an additive to gasoline after engine modifications and with the maximum content of $85 \%$. Butanol can also generate higher amounts of clean energy per operating cycle compared to ethanol by $25 \%$ and gasoline by $10 \%$. Therefore, butanol is more costeffective in comparison with ethanol, as it improves the efficiency of automobile fuel and increases distance run per unit of consumed fuel. Moreover, the rate of evaporation of butanol is six times lower than that of ethanol, with its volatility being 13.5 times less than that of gasoline. Hence, butanol is safer to be used as an oxygenate without any considerable variation in proportions during summer or 
winter seasons. In addition, butanol is capable of transportation through existing fuel pipelines since it is a less aggressive substance compared to ethanol (Zverlov et al., 2006). In terms of ecological issues, butanol combustion releases no sulphur or nitrogen oxides into the environment. Moreover, biobutanol can be produced from the same renewable sources as ethanol. In the past, traditional substrates such as starch, glucose, molasses, and whey permeate have been used for butanol production. However, because of the high costs of the substrates affecting the price of butanol, the use of economically available substrates, including agricultural residues and wastes (wheat straw, corn fibre, rice straw, hardwood, waste paper, and annual and perennial crops), is being examined (Qureshi et al., 2007). It should be also noted that pretreatment of some agricultural residues such as corn fibre might produce fermentation inhibitors.

Renewable resources, such as lignocellulosic biomass, are sustainable resources that can be used without depletion. For instance, biomass remains a significant part of Canada's energy picture, supplying around $4.7 \%$ of the primary energy demand, being the second energy source after hydroelectricity (Government of Canada, 2009). Wheat straw (WS), used in the current study, is a potential substrate for butanol production using bacterial strains. It is composed of cellulose, hemicellulose, and a relatively low lignin content, noticeable in the process of bioconversion to biofuel. WS makes the process of $\mathrm{ABE}$ production economically attractive because of its sustainability and cost-effectiveness. In Canada, the energy potential associated with WS is about $0.12 \mathrm{EJ} / \mathrm{year}$ from 7.46 million oven-dried tonnes per year (M ODT/year) of WS. However, the total production of WS is 26.7 M ODT/year (Wood et al., 2003). Therefore, due to large-scale production of wheat crops in Canada, one might realize the need to invest in wheat straw as the substrate for biofuel production. According to the Food and Agriculture Organization (FAO) of the United Nations (UN), the United States (US) produced $51.0 \times 10^{6}$ tonnes of WS in 2006. This is a large amount compared to the WS production worldwide, which was approximately $616 \times 10^{6}$ tonnes for the same year (FAO, 2010). 
Biobutanol can be produced by anaerobic fermentation of sugar components by using various species of Clostridia. Cellulolytic and solventogenic Clostridia species such as C. thermocellum, $C$. saccharobutylicum, C. cellulolyticum, and C. acetobutylicum are among the best-studied biomassmetabolizing bacteria which have a significant potential to produce sustainable biofuel via consolidated bioprocessing (CBP). Among them, Clostridium beijerinckii and Clostridium acetobuylicum are the best-known strains for butanol fermentation, which have the ability to produce solvents from carbohydrates via two-stage fermentation. The advantage of using these strains is related to their ability to utilize both hexoses and pentoses sugars available in biomass compared to traditional ethanolproducing yeast strains which are incapable of utilizing lignocellulosic hydrolysate sugars (Qureshi and Blaschek, 2006).

The flexibility of solventogenic Clostridia to utilize carbon sources makes them valuable for developing a biobutanol fermentation process. Thermoanaerobacterium saccharolyticum ( $T$. saccharolyticum) is another thermophilic anaerobic Clostridium that has the ability to directly ferment primary sugars into biofuels, especially five carbon sugars, such as xylose in cellulosic biomass (Joe Shaw et al., 2008). Due to the production of cellulase and hemicellulase enzymes by thermophilic anaerobic bacteria, Clostridia are of prime interest in fermenting biomass, without the addition of external high-priced hydrolytic enzymes. This makes the biomass conversion process more cost effective.

The main problem facing the enzymatic activity of $C$. beijerinckii and $C$. acetobutylicum during Simultaneous Saccharification and Fermentation (SSF) is the low temperature of fermentation, which is around $35^{\circ} \mathrm{C}$; whereas, the optimum temperature for enzymatic hydrolysis is $45^{\circ} \mathrm{C}$. This reduces the efficiency of enzymes, especially cellulase, thus, leading to lower productivity of butanol and higher 
cost of fermentation (Qureshi et al., 2007). Protoplast fusion of bacterial strains is one of the several novel technological ways to enhance the concentration of biobutanol. It is applied to develop interspecific, intraspecific, and intrageneric superhybrids with higher tolerance and stability than their parental strains.

The main objective of the present study is to enhance butanol production from non-edible agricultural biomass by improving the thermal stability (i.e., thermostability) of the biobutanol producing mesophilic bacterial strain (i.e., C. Beijerinckii), and to enhance metabolism to break down longer sugar chains. Improvement of the bacterial strains through protoplast fusion with the more thermal stable clostridial species, C. Thermocellum, was initially examined. Protoplast fusion, which is a genetic manipulation method, between $C$. beijerinckii as a butanol producing strain and $C$. Thermocellum $(\mathrm{CbCt})$ was studied at the higher temperature of $45^{\circ} \mathrm{C}$, where $45^{\circ} \mathrm{C}$ is the optimum temperature of enzymatic hydrolysis essential for saccharification. In order to enhance biobutanol production, a second attempt at protoplast formation between the three strains: C. beijerinckii, $C$. thermocellum and $T$. saccharolyticum $(C b C t T s)$ was examined at $45^{\circ} \mathrm{C}$. It was expected $T$. saccharolyticum would metabolize longer sugars to produce biobutanol. In both cases, protoplast fusion was applied between mesophilic and thermophilic gram-positive bacteria. However, in the second experiment, genetic manipulation was induced between one mesophilic and two thermophilic strains of Clostridia.

There have been many reports of protoplast formation and regeneration of gram-positive bacteria such as Clostridia strains. However, there has been no study found in the literature with regard to fusing the protoplasts of two or three different species of Clostridia strains. This would eliminate the need to add high priced enzymes, and thus reduce the total cost of production. It would also lead to producing outstanding amounts of biobutanol, the main goal of this study. 
Biobutanol production was also examined using clostridial co-cultures. In these experiments, the same bacterial strains as the protoplast fusion strains were applied. The main aim of the co-culture experiment was to compare the production of biobutanol using fused strains to that produced by their corresponding co-culture strains. In the last part of the present study, the genetic stability of the fused strains was examined using the PCR method. The objective was to confirm the genetic stability of the fused strains through several growth cycles.

Although C. beijerinckii, C. thermocellum, and T. saccharolyticum can produce enzymes to hydrolyze wheat straw, they are not able to hydrolyze fibre-rich agricultural residues efficiently. Therefore, an economically feasible pretreatment method was developed in order to hydrolyze agricultural biomass into simple sugars for subsequent fermentation. Dilute sulphuric acid pretreatment was applied to hydrolyze much of the hemicellulose in cellulosic biomass into pentose sugars (Saha, 2003). 


\section{CHAPTER 2}

\section{LITERATURE REVIEW}

\subsection{Biofuel}

In today's era of rapid environmental deterioration, biofuels are considered an attractive alternative to petroleum based fuels because of their adaptability to existing transportation technology, and more importantly, their sustainability and their contribution to reducing greenhouse gas emissions. Until the 1950s, biofuels were considered as feasible fuels for transportation, but the low price of fossil fuels impeded their development. Again in the mid-1970s, renewed interest in commercial production of biofuels for transportation arose. Several countries took advantage of this growing market when Brazil started to produce ethanol from sugarcane, soon followed by the US. This was followed by increased biofuel production worldwide over the last decade, which was supported by impressive government policies. Today, biofuels provide around $3 \%$ of the total fuel required for road transportation globally and significantly higher shares are achieved in certain countries (IEA, 2011).

The US, Brazil, and the European Union (EU) are the three largest biofuel markets, representing 85\% of the global production in 2010. North America leads the world production of biofuels with $48 \%$ of the global market. Figure 2.1 shows the world market of biofuel production from 2011 to a projected level in 2021. According to this figure, rapid growth in biofuel production would be expected between 2017 and 2021 due to higher oil prices, new feedstock availability, and advanced technology. It is projected that by 2021, the total global biofuel production will reach 65.7 billion gallons per year. 


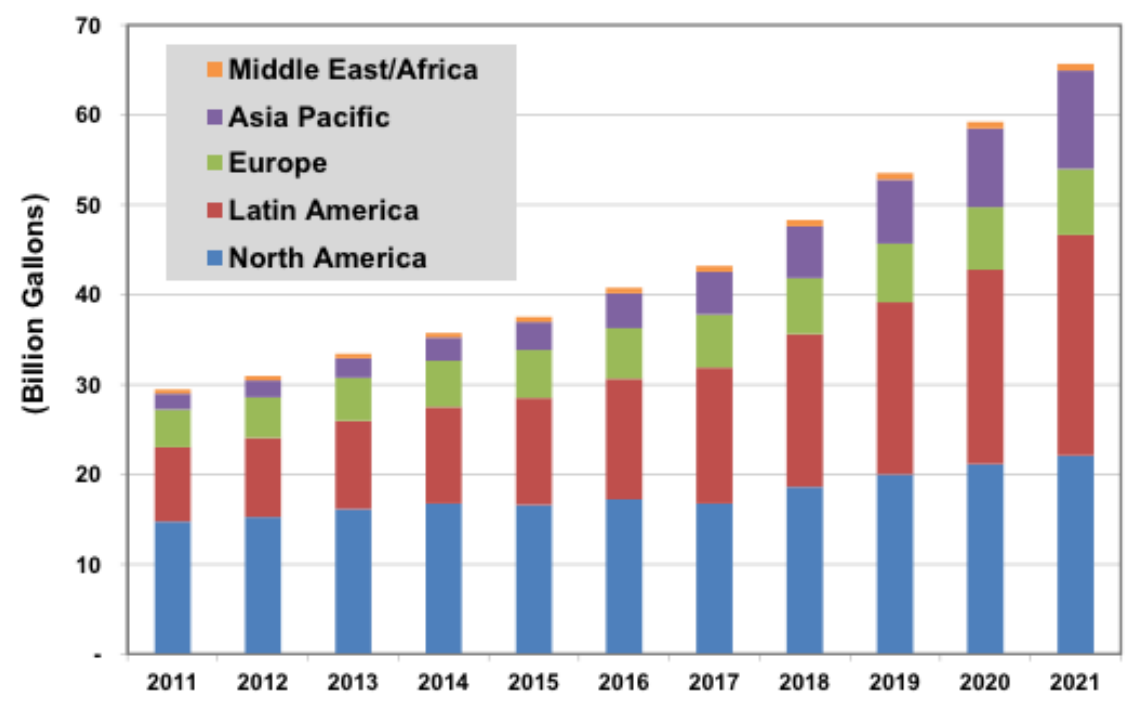

Figure 2.1. Global biofuel production (Adapted from Marcacci, 2012).

For biofuel synthesis, discarded cellulosic biomass, mostly derived from forestry, agriculture, and municipal sources has a strong potential to be used. However, the crystalline structure of cellulose makes it difficult to be hydrolyzed. Biofuels can replace the consumption of fossil fuels, which can lead to a reduction of carbon emissions. Biofuel production generates other benefits taking into account that extraction, processing, and combustion of fossil fuels create many hazards to the environment and public health by polluting soil, air, and water (Levin et al., 2006).

The widely acknowledged world food crisis has limited the use of biomass for producing biofuels, especially crops that can be used for food such as corn and sugar, because of their negative effects on food security. Moreover, biofuels have received lots of criticism for their environmental impact on deforestation, since clear-cutting forests to plant crops used for energy production has a detrimental impact on biodiversity, local economies, and climate change. However, significant advances in the development of biofuels in favour of more sustainable practices over the last decade have led to different methods of biofuel production that have been classified into three generations. 
Current strategies to produce fuel from cellulosic biomass, including Simultaneous Saccharification and Fermentation (SSF) or Simultaneous Saccharification, and Co-fermentation (SSCF), have attracted lots of attention during the last decade (Lynd et al., 2002) (Lynd et al., 2005). However, both strategies require pretreatment of cellulosic feedstock and the addition of high cost cellulolytic enzymes to release glucose monomers, which are required for fermentation. Therefore, Consolidated Bioprocessing (CBP) using microorganisms containing cellulolytic enzymes, is an attractive approach, with outstanding potential for biofuel production in which cellulose production, substrate hydrolysis, and fermentation take place in one step (Lynd et al., 2005).

\subsection{Biofuel Classification}

First generation biofuels commonly come from edible sources such as wheat, corn and sugar. Ethanol, which is the most produced biofuel worldwide, especially in the USA and Brazil, is mainly made from either corn or sugar cane. First generation biofuels have some benefits in terms of $\mathrm{CO}_{2}$ mitigation and improving domestic energy security (Naik et al., 2010). On the other hand, many concerns exist with regard to sourcing of feedstocks that have some impacts on land use and biodiversity, and competition with food crops. First generation biofuels such as bioethanol, biodiesel, and biogas are mostly characterized by their capability to be mixed with petroleum-based fuels, distributed through existing infrastructure, and by their use in existing combustion engines or in an alternative vehicle technology such as natural gas vehicles.

First generation biofuel production is highly commercial today, with around 50 billion liters produced per year. However, its environmental impacts and carbon balances have limited first generation increased production through this route. Moreover, the recent debate about food security versus fuels is considered the main disadvantage of first generation biofuels since one of the reasons for the increase in food prices is due to the diversion of food crops to production of these fuels. On the other hand, it is 
also claimed that biodiesel has not been assessed as a cost-effective technology for emission abatement (Laursen, 2006).

In terms of greenhouse gas (GHG) abatement, second generation biofuels are produced as a more efficient alternative from non-edible resources based on conventional technologies. They are produced from biomass as a sustainable feedstock with neutral or even negative carbon impact on $\mathrm{CO}_{2}$ concentrations. A carbon negative aim is achieved when a portion of the biomass is used for carbon sequestration. They are mostly made from lignocellulosic non-food plant materials such as leaves, stems, and husks, which are both cheap and abundant. They can be also produced from agricultural residues such as corn stover, switch grass, wheat straw and cereals (Inderwildi and King, 2009). Figure 2.2 shows second generation biofuels from cellulosic feedstocks. Lignocellulosic materials referred to as feedstocks are hydrolyzed and fermented into biofuels. The goal of producing this generation of biofuels, which is the main focus of this study, is to enhance the amount of biofuel that can be produced from renewable biomass with great environmental benefits.

It should be also mentioned that valuable co-products such as heat, electricity, and various chemicals, which are produced while using $2^{\text {nd }}$ generation biofuels offer the potential to enhance overall revenue by making the conversion process more economical. Moreover, co-benefits including rural development, employment, carbon sequestration, and energy security need to be taken into account in market assessments of biofuels (Sims et al., 2010).

In terms of policy development, second generation biofuel promotion may assist in providing solutions to several policy issues such as economic development in rural communities, energy security and diversification, GHG mitigation, and reduction of environmental impacts of other transport fuels. Therefore, policies that are well designed for first generation biofuels can be applied by industries for 
second generation biofuels, as an opportunity to grow along with that of the first generation in order to reduce the overall costs.

In contrast, third generation biofuels are considered to be the most sustainable biofuels since they are algae-based fuels. Third generation biofuels have attracted significant attention because of their ability to produce up to 300 times more fuel per acre compared to first generation sources, such as corn and soybeans (Hartman, 2008).

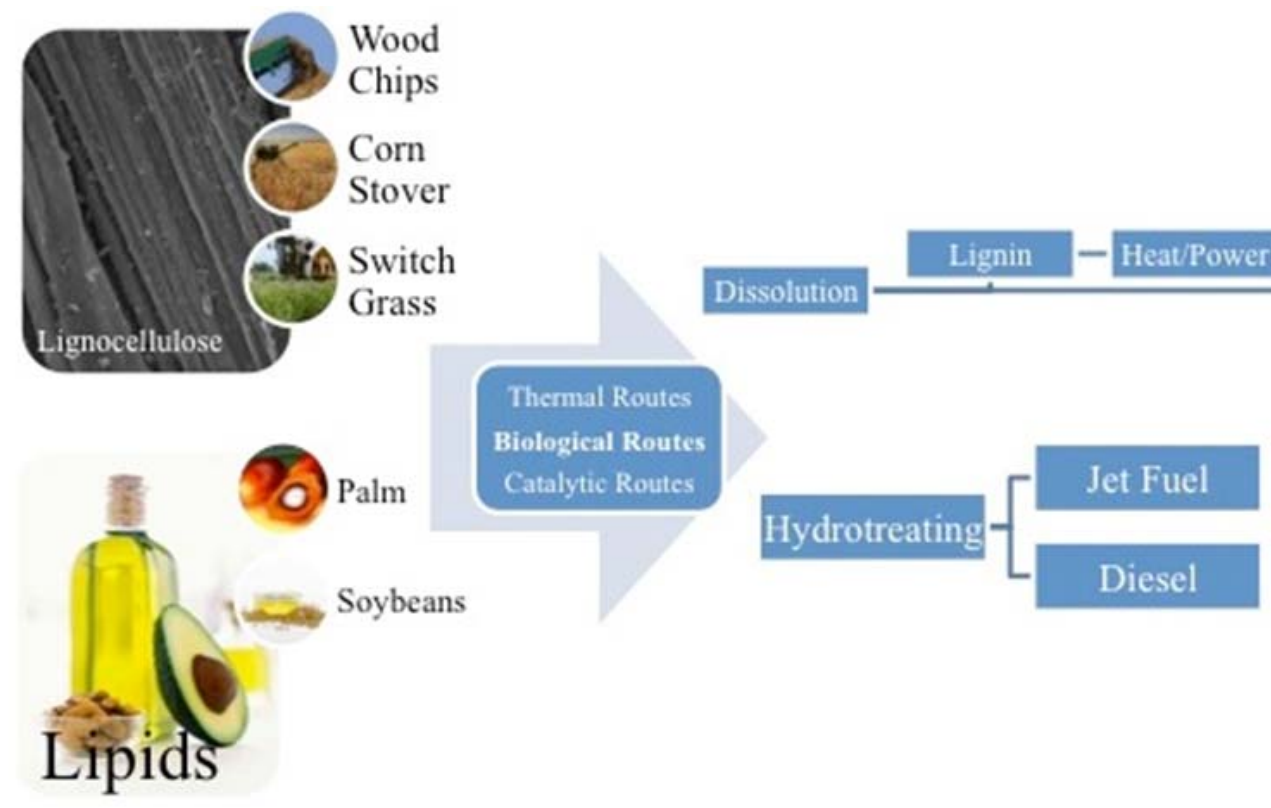

Figure 2.2. Second generation biofuels (Inderwildi and King, 2009).

Moreover, from an environmental standpoint, microalgae are very attractive as a source of biofuel since they use carbon dioxide and grow on marginal land, consuming salt water or waste (Radakovits et al., 2010). Furthermore, biofuel derived from algae sources will not compete with the necessary resources for agricultural food production, provided that recycling method for inorganic constituents and saltwater- based cultivation techniques are developed. 
However, in terms of commercialization, more studies are required. Many governmental agencies and companies are making efforts to decrease capital and operating cost of algae fuel production to make it commercially feasible (GBEP, 2009). Many technical barriers, such as developing low-energy methods to harvest algae cells, the presence of invasive algae species in large ponds, the lack of cost-effective techniques for bioenergy carrier extraction, and difficulties in biomass production at a large scale in variable outdoor conditions, should be overcome before using algae as an economically viable biofuel feedstock (Pienkos and Darzins, 2009).

\subsection{Biobutanol}

In the past, butanol has been produced via chemical synthesis. As a product of traditional acetone-butanol-ethanol (ABE) fermentation, butanol has numerous industrial applications. It is an important feedstock chemical in the plastic industry, a food-grade extract in the food and flavour industry, and a fuel extender (Formanek et al., 1997). Nowadays, biobutanol can be produced through biochemical techniques by applying butanol-producing bacterial strains that have the ability to produce butanol from renewable sources of biomass such as agricultural wastes (Ezeji et al., 2007b). The usage of bacteria, which generate enzymes to convert sugars into alcohol, is well known; however, butanol itself is toxic to the bacteria and acts as an inhibitor, which results in low concentration of butanol in the medium, and consequently increases cost of production. One of the solutions to reduce its toxicity is the simultaneous removal of $\mathrm{ABE}$ which would keep butanol toxicity levels under control. Some techniques such as gas stripping, adsorption, liquid-liquid extraction, and reverse osmosis have been applied to remove the end-products (Qureshi and Ezeji, 2008).

As a choice for green energy, biobutanol contains $22 \%$ oxygen which makes it a superior fuel extender and it combusts cleaner than ethanol. It has a higher energy density almost $30 \%$ more than ethanol, enhanced hydrophobic properties and the capability of mixing with gasoline at any ratio. Butanol also 
has a higher heating value that qualifies it as a replacement for gasoline without engine modifications. Moreover, as a fuel, it is more cost-effective and safer than ethanol (Zverlov et al., 2006).

Table 2.1 displays the properties of common biofuels with respect to gasoline as a traditional fuel. It is clear that butanol has superior fuel properties compared to other biofuels. Thus, commercial interests have returned to investigate butanol fermentation through advanced biotechnology and bioprocessing methods.

Table 2.1. Comparison of biofuel properties and gasoline (Adapted from Lee et al., 2008).

\begin{tabular}{|c|c|c|c|c|}
\hline Fuel & Air/fuel ratio & $\begin{array}{c}\text { Energy density } \\
(\mathbf{M J} / \mathbf{L})\end{array}$ & $\begin{array}{c}\text { Boiling point } \\
\left({ }^{\circ} \mathbf{C}\right)\end{array}$ & $\begin{array}{c}\text { Heat of vaporization } \\
\mathbf{( M J} / \mathbf{k g})\end{array}$ \\
\hline Butanol & 11.20 & 29.20 & 117.7 & 0.43 \\
\hline Ethanol & 9.00 & 19.60 & 78.3 & 0.92 \\
\hline Methanol & 6.50 & 16.00 & 64.7 & 0.20 \\
\hline Gasoline & 14.60 & 32.00 & $37-204$ & 0.36 \\
\hline
\end{tabular}

\subsection{Agricultural Biomass}

There are different sources of biomass including agricultural crops and residues, forestry crops and residues, industrial residues, animal residues, municipal solid waste, and sewage. Butanol is an excellent fuel that can be produced from biomass derived from different agricultural products, byproducts, and waste products. Several methods that use cellulose and hemicellulose available from agricultural products and wastes have been developed (Zverlov et al., 2006). Biomass, which is derived from agro-forest residues, plants, grasses, trees, and crops, is a versatile and a significant renewable resource for chemical industries. 
As shown in Figure 2.3, biomass structure is composed of cellulose, hemicellulose, and lignin. It contains approximately 40\% cellulose, 25\% hemi-cellulose, and 25\% lignin, with ash and miscellaneous compounds that make up the remaining 10\% (Lignofuel, 2011). Cellulolosic biomass, which is called lignocellulosic biomass, usually contains from 55 to $75 \%$ carbohydrates by dry weight. Cellulose is a polymer of glucose. However, polymer chains existing in the structure of cellulose are tightly packed, which makes the structures highly crystalline, unstable in water, and resistant to polymerization (Mosier et al., 2005). Hemicellulose, which is the other carbohydrate element in lignocellulosic biomass, and depending on the species, is a polymer of xylose, galactose, arabinose, fructose, and mannose. Hemicellulose forms a network that gives the backbone structure to the plant cell wall, which is established through hydrogen bonding with cellulose microfibrils. Both cellulose and hemicellulose are considered as potential sources of fermentable sugars for biofuel production. However, lignin that is present in the cell wall hinders enzymatic hydrolysis of the carbohydrates. Pretreatment of biomass is a method that is applied to remove lignin.

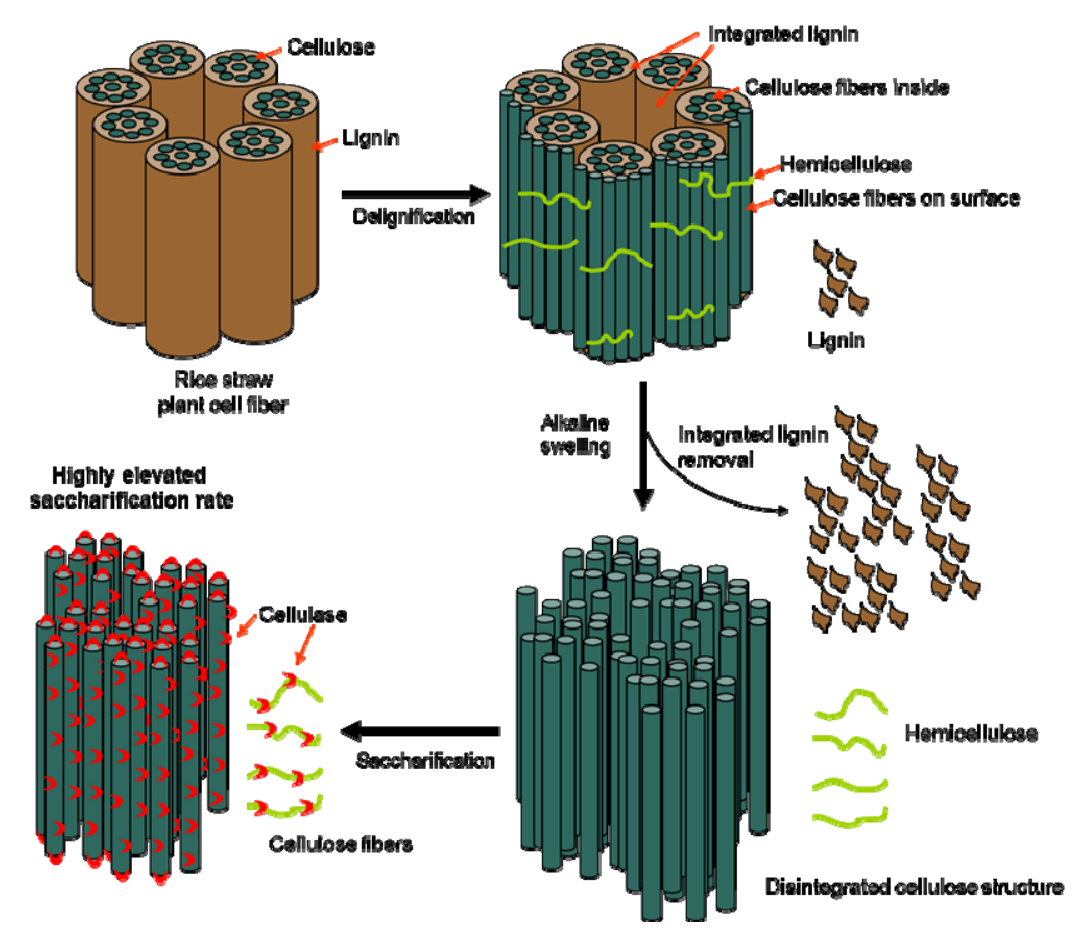

Figure 2.3. Molecular structure of lignocellulosic biomass (Adapted from Kahar, 2013). 
During the Simultaneous Saccharification and Fermentation (SSF) process, sugars derived from cellulose and hemicellulose are converted into biofuels using microorganisms. Consolidated Bioprocessing (CBP) that is applied in this study is a biomass conversion technique in which both the biofuel and enzymes are produced by a single bacterial community. By reducing the high cost of enzymes required for the biochemical processing of biomass, this method can lessen the cost of energy and make it more economical.

It is well known that a cheaper sugar mixture can be obtained from agricultural residues such as wheat straw (WS), corn fibre (CF), and distiller's dried grains with solubles (DDGS), which can be widely utilized in fermentation for butanol production. Recent technologies for agricultural biomass conversion (through their hydrolysate solutions) have proven that agricultural wastes have enough carbon to produce value-added bio-based products (Dahman et al., 2010). It has been also identified that WS is a successful industrial substrate for butanol production (Qureshi et al., 2007). WS contains about $35-40 \%$ cellulose, $30-35 \%$ hemicellulose, and low amounts of lignin (less than 20\%) that makes it noticeable among agricultural residues (Harper and Lynch, 1981). Table 2.2 shows the sugar concentrations and percentages in different agricultural residues.

\subsection{Pretreatment Process}

In order to extract sugar from biomass (agricultural residues) for the purpose of fermenting it into biofuel, a pretreatment process is required. When the experimental data are available, economic analysis should be done carefully to determine the best option for a pretreatment process of a specific feedstock and product opportunity. The main aim of pretreatment is to improve the enzymatic digestibility by solubilizing hemicellulose into monomeric sugars, disrupting the crystallinity of cellulose, and breaking the lignin seal (Sun and Cheng, 2005). Figure 2.4 shows a schematic of goals of pretreatment on lignocellulosic material. 
Table 2.2. Sugar concentration of different agricultural wastes.

\begin{tabular}{|c|c|c|c|c|c|c|c|c|}
\hline & \multicolumn{2}{|c|}{ WS } & \multicolumn{2}{c|}{ DDGS } & \multicolumn{2}{c|}{ CF } & \multicolumn{2}{c|}{ Molasses } \\
\hline Sugars & $\begin{array}{c}\text { Actual } \\
(\mathbf{g} / \mathbf{L})\end{array}$ & $\begin{array}{c}\mathbf{w t} / \mathbf{w t} \\
\mathbf{( \% )}\end{array}$ & $\begin{array}{c}\text { Actual } \\
\mathbf{( g / L )}\end{array}$ & $\begin{array}{c}\mathbf{w t} / \mathbf{w t} \\
\mathbf{( \% )}\end{array}$ & $\begin{array}{c}\text { Actual } \\
\mathbf{( g / L )}\end{array}$ & $\begin{array}{c}\mathbf{w t} / \mathbf{w t} \\
\mathbf{( \% )}\end{array}$ & $\begin{array}{c}\text { Actual } \\
\mathbf{( g / L )}\end{array}$ & $\begin{array}{c}\mathbf{w t} / \mathbf{w t} \\
\mathbf{( \% )}\end{array}$ \\
\hline Glucose & 28.9 & 48 & 23.6 & 44.9 & 37.2 & 53.4 & 14 & 25 \\
\hline Xylose & 20.1 & 33.4 & 16.7 & 31.7 & 17.6 & 25.3 & 0 & 0 \\
\hline Arabinose & 5 & 8.3 & 10.3 & 19.6 & 11.3 & 16.2 & 0 & 0 \\
\hline Galactose & 3.5 & 5.8 & 1.2 & 2.3 & 3.6 & 5.1 & 0 & 0 \\
\hline Mannose & 2.7 & 4.5 & 0.8 & 1.5 & 0 & 0 & 0 & 0 \\
\hline Sucrose & 0 & 0 & 0 & 0 & 0 & 0 & 28 & 50 \\
\hline Fructose & 0 & 0 & 0 & 0 & 0 & 0 & 14 & 25 \\
\hline Total sugar & 60.2 & $100 \%$ & 52.6 & $100 \%$ & 69.6 & $100 \%$ & 56 & $100 \%$ \\
\hline References & \multicolumn{2}{|c|}{2007} & \multicolumn{2}{|c|}{2007} & \multicolumn{2}{c|}{2008} & \multicolumn{2}{c|}{1983} \\
\hline
\end{tabular}

Note: WS, Wheat straw; DDGS, Dry Distiller Grain and Soluble; CF, Corn Fiber

Several pretreatment methods such as steam explosion, AFEX, APR, Liquid hot water, and acid or alkaline have been considerably investigated. However, among all of them, dilute acid pretreatment has been studied extensively since it is both an effective and inexpensive method. Moreover, it is especially useful to convert xylan in hemicellulose to xylose, in comparison with other pretreatment methods, which can be fermented to biofuels by many microorganisms (Wyman, 1996). For the pretreatment of wheat straw, studies have shown that at $140^{\circ} \mathrm{C}$ for 1 hour around $80 \%$ of xylan was removed. This increased the enzymatic digestibility of cellulose up to $80 \%$ (Torget et al., 1990). 


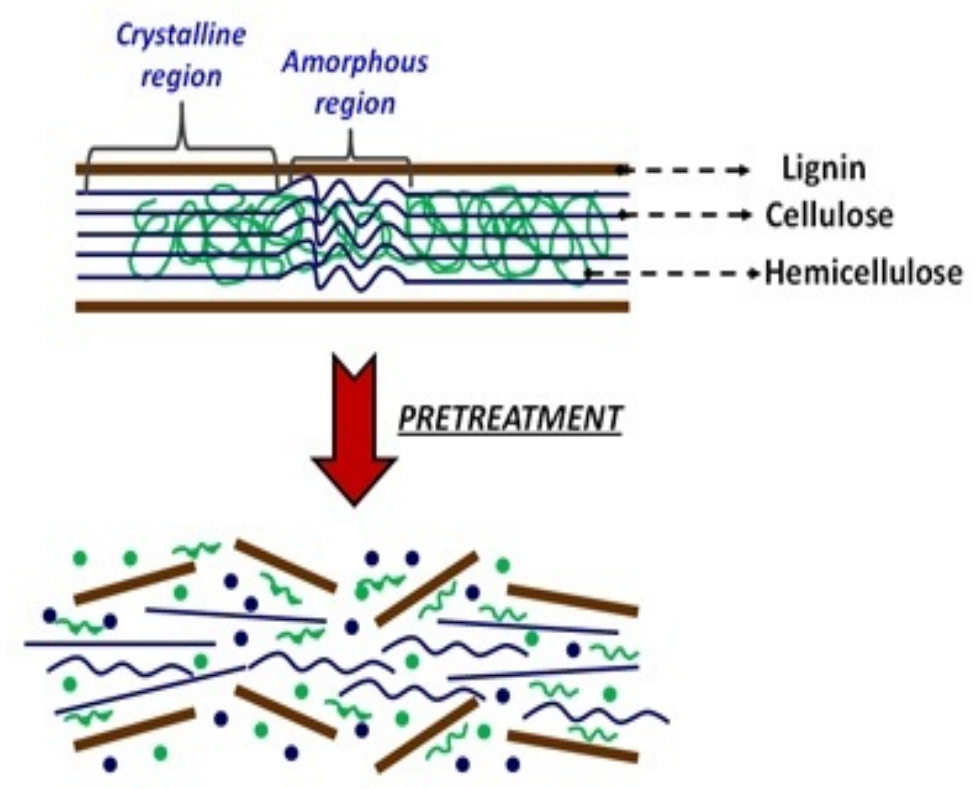

Figure 2.4. Pretreatment of lignocellulosic biomass (Mosier et al., 2005).

It is possible that during acid pretreatment, a complex mixture of bacterial inhibitors such as furfural and hydroxymethyl furfural (HMF) would be generated; however, it could be substrate-specific (Ebener et al., 2003). Furfural is not an inhibitor to C. beijerinckii but it affects the growth of the microorganisms and the biobutanol yield (Ezeji et al., 2007). However, in this study, the amount of these inhibitors was too small to be measured.

An alternative approach for biomass pretreatment is using liquid hot water, based on maintaining the $\mathrm{pH}$ between 4-7. In this method, water can go through the biomass cell structure under high pressure in order to hydrate cellulose and remove hemicellulose (Wyman et al., 2005). The benefit of using this method is that extraneous reagents are not required. By using this method and subsequent enzymatic hydrolysis, cellulose and hemicellulose will be converted completely. 
During the steam explosion pretreatment method, some of the monosaccharaides released from hemicellulose may be degraded to elements such as weak acids, furfural from xylose, and phenolic compounds from lignin that are inhibitory to both cellulase enzymes and the microorganisms during subsequent steps of fermentation (Palmqvist and Hahn-Hägerdal, 2000) (Dien et al., 2006). However, these inhibitory chemicals are not involved in pretreatment by hot water.

Although using alkaline chemicals such as sodium hydroxide, lime, and other bases has been considered to improve digestibility of cellulose by removing lignin, these chemicals are very expensive and too difficult to be recovered and recycled to be feasible for biofuel production (Taherzadeh and Karimi, 2008). Besides, this method takes a relatively long time and needs high concentrations of chemicals. Studies have shown that alkaline pretreatment is more effective in treating agricultural residues rather than wood materials.

\subsection{Biobutanol Fermentation and Metabolic Pathways of Gram-positive Bacteria}

It is well known that cellulolytic and solventogenic bacterial species such as C. thermocellum, C. saccharobutylicum, C. cellulolyticum, and C. acetobutylicum have the potential to ferment carbohydrates into acetone, butanol, and ethanol (ABE) via Consolidated Bioprocessing, which is attractive for economic and environmental reasons (Formanek et al., 1997). The most important economic factor is the utilization of agricultural residues or by-products as cheap substrates for fermentation by Clostridia species.

Clostridia are obligate anaerobe, gram-positive, sporulating firmicutes that include both pathogenic species to humans and animals, and non-pathogenic species relevant to the commercial conversion of renewable resources into biofuels and other chemicals (Jones and Woods, 1986). Among them, Clostridium beijerinckii and Clostridium acetobuylicum are the best-known strains for butanol 
fermentation which have the ability to produce solvents from lignocellulosic biomass via Simultaneous Saccharification and Fermentation (SSF). During the acidogenic stage, acetic and butyric acid are produced; then in the solventogenic stage, microorganisms produce acetone, butanol, and ethanol at a $\mathrm{pH}$ of around 4-5. After solvents start forming, the butyrate decreases to extremely small levels, and $\mathrm{CO}_{2}$ and $\mathrm{H}_{2}$ are produced as co-products of the fermentation (Ladisch and Svarczkopf, 1991).

Figure 2.5 shows the direction of metabolic pathways for Clostridia in the acidogenic and solventogenic phases. In the first phase of fermentation, bacteria grow exponentially along with acetate and butyrate formation, which leads to a reduction of $\mathrm{pH}$ to 4.5 . Then during the glycolysis pathway, pyruvate-consuming glucose is converted to acetyl-CoA which is the major precursor for acetate, butyrate, acetone, butanol, and ethanol synthesis anaerobically. During the acid producing stage, acetate and butyrate are produced via two steps from acetyl-CoA and butyryl-CoA, respectively.

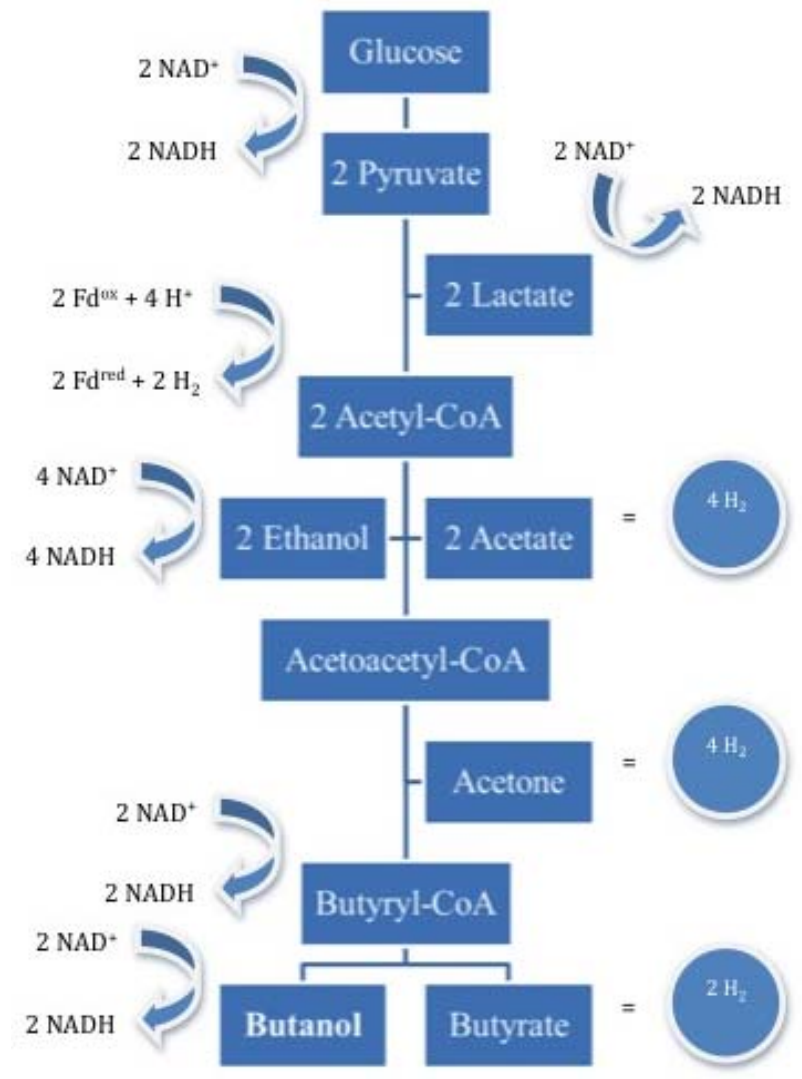

Figure 2.5. Metabolic pathways of C. acetobutylicum (Jin et al., 2011). 
For acetate synthesis, phosphate acetyltransferase and acetate kinase enzymes are implicated; whereas, for butyrate formation, phosphate butyltransferase and butyrate kinase are involved. As can be seen in Figure 2.5, four enzymes are active in catalyzing butyryl-CoA synthesis from acetyl-CoA (Kumar and Gayen, 2011) (Jin et al., 2011). In order to compensate for the adverse effect of low $\mathrm{pH}$ at the end of acidogenesis stage, the metabolic activity of bacteria shifts to the solventogenesis phase.

During the solventogenic stage, the biosynthesis of acetone and butanol, from consumption of acetate and butyrate as substrates is observed without any growth of the organism. Studies show that the highest butanol yield from butyrate occurs in a medium rich in glucose (Tashiro et al., 2007). During this pathway, acetaldehyde and butyraldehyde are produced as intermediates in the presence of two dehydrogenase sets. Butanol production from butyryl-CoA is mediated by butyraldehyde dehydrogenase and butanol dehydrogenase. For the conversion of acetyl-CoA into butanol, six enzymes and seven genes were known and investigated in several microorganisms. It should be mentioned that in $C$. actobutylicum and $C$. beijerinckii, butanol dehydrogenase activity is mostly dependent on Nicotinamide adenine dinucleotide phosphate (NADPH) as a reducing agent; Compared to acetone and butanol, ethanol production was observed in small amounts.

One of the major hurdles limiting biobutanol fermentation is the toxicity of butanol produced by the microorganisms, which leads to a reduction in butanol production (Liu and Qureshi, 2009). One of the most attractive approaches to overcome this hurdle is the manipulation of bacteria through genetic engineering techniques in order to enhance their butanol tolerance limit. Moreover, the use of these techniques may lead to more energy production through more cost-effective techniques.

Thermoanaerobacterium saccharolyticum is a thermophilic anaerobic bacterium that grows in high temperatures, in the range of $45-65^{\circ} \mathrm{C}$, and at a $\mathrm{pH}$ of 4.0 to 6.5 . It has the ability to ferment 
hemicellulose and xylan polymers directly. Moreover, it can consume cellobiose, glucose, mannose, xylose, galactose, and arabinose as primary sugars in cellulosic biomass to produce alcohols (Joe Shaw et al., 2008). T. saccharolyticum has attracted attention due to its genetic system development that has enabled expression of a heterologous gene and a gene knockout. It has been demonstrated that $T$. saccharolyticum can produce high amounts of ethanol through the L-lactate dehydrogenase, phosphate acetyltransferase, and acetate kinase genes.

During the fermentation pathways, fractions of pyruvate are fermented to end-products, such as acetic acid and ethanol, after growing on xylose. Acetate production includes the activity of two enzymes, phosphate acetyltransferase (Pta) and acetate kinase (Ack), along with a co-expression of the genes that are located adjacent to each other on the genome. For ethanol production from acetyl-CoA, acetaldehyde dehydrogenase (Aldh), alcohol dehydrogenase (Adh), and two moles of NAD(P)H are required (Shaw et al., 2009). It should be mentioned that $T$. saccharolyticum enzymes have the ability to use both NADPH and NADH, which is consistent with the high activity of the cofactor FNOR that is specific in this microorganism.

\subsection{Biobutanol Production Configurations}

Several studies have been implemented to produce biobutanol from lignocellulosic substrates, such as wheat straw (WS), corn fibre (CF), barely straw (BS), corn stover (CS), and switch grass (SG) hydrolysates. Table 2.3 shows biobutanol production from different sources of agricultural residues using C. beijerinckii P260 through batch fermentation. From Table 2.3 it is suggested that wheat straw is a superior fermentation substrate, compared with several other agricultural wastes (Ezeji et al., 2004). For this reason, some experiments were conducted to mix BS and WS, as well as WS and CS hydrolysates in a 1:1 ratio. Biobutanol production using batch fermentation is a traditional method with ABE fermentation. However, butanol toxicity limits the higher concentration of product. It should be 
mentioned that a concentration of about 10-13 $\mathrm{g}$ butanol/L can lead to cell growth inhibition and early termination of fermentation. The toxicity of these products will result in low concentration of biobutanol in the reactor. These problems have made the commercial scale of biobutanol production uneconomical (Ezeji et al., 2004). Over the last two decades, several studies have been developed to find alternative fermentation processes for biobutanol production and product recovery.

Table 2.3. Biobutanol concentrations (g/L) using different sources of biomass.

\begin{tabular}{|c|c|c|c|}
\hline Bacterial Strain & Substrate used & Butanol production (g/L) & Reference \\
\hline C. beijerinckii & Glucose only & 13 & Qureshi and Ezeji, 2008 \\
\hline C. beijerinckii & Wheat straw & 7.4 & Qureshi et al., 2007 \\
\hline C. beijerinckii & Corn Fiber & 3.4 & Qureshi and Ezeji, 2008 \\
\hline C. beijerinckii & Barely straw & 4.2 & Qureshi et al., 2010 \\
\hline C. beijerinckii & WS and BS (1:1 ratio) & 13.62 & Qureshi et al., 2010 \\
\hline C. beijerinckii & WS and CS (1:1 ratio) & 12.50 & Qureshi et al., 2010 \\
\hline
\end{tabular}

The use of a "cell immobilization" and "cell recycle" continuous bioreactor is a new approach in which the cell concentration can be increased inside the bioreactor by using a filter and the removal of clear liquid; whereas, in a batch reactor, a cell concentration of less than $4 \mathrm{~g} / \mathrm{L}$ is usually obtained. Huang et al. (2004) used a continuous reactor and immobilized cells of $C$. acetobutylicum for ABE production; this study led to a the productivity of $4.6 \mathrm{~g} / \mathrm{L} / \mathrm{h}$. Another study showed that by using a cell recycle bioreactor, a productivity outcome of up to $6.5 \mathrm{~g} / \mathrm{L} / \mathrm{h}$ can be achieved, comparable to a productivity of less than $0.5 \mathrm{~g} / \mathrm{L} / \mathrm{h}$ reached in lab scale batch fermentation (Ezeji et al., 2006).

Product recovery techniques are considered as alternatives for biobutanol production. Adsorption; gas stripping, which is applied for in situ biobutanol recovery and associated with the generation of $\mathrm{CO}_{2}$ and $\mathrm{H}_{2}$, ionic liquids; liquid-liquid extraction, in which butanol or $\mathrm{ABE}$ are removed from fermentation 
broth in the presence of a water-insoluble organic extractant; perstraction, in which the extractant and fermentation broth are separated by a membrane; and pervaporation that allows the volatile compounds be removed selectively from the fermentation broth, are among the best-studied techniques to enhance the amount of biobutanol production. However, there are still some problems associated with each of these new approaches. For example, although the perstraction method is better than liquid-liquid extraction in terms of avoiding toxicity effects on the cells and loss of extraction solvent, some difficulties, such as the limitation on the butanol extraction rate through the membrane as a physical barrier, can be seen while using this technique (Ezeji et al., 2007).

\subsection{Protoplast Fusion and Cell Wall Regeneration}

Protoplast fusion, which was applied in the current study, is a method for cell gene recombination, where the DNA of two kinds of non-divided cells exist together inside a cell during fusion. Protoplast fusion is possible between cells of different genera as a principle; therefore, fusion is a convincing method for cell function improvement. Protoplast fusion is well-known to change the genetic characteristics of microorganisms without the need for complicated engineering techniques (D. V. Gokhale, 1993). Protoplast formation, fusion, and cell wall regeneration are the three steps of protoplast fusion. There are some important conditions to be met in the protoplast fusion process, which include the concentration of lysozyme (used for the formation of protoplasts); polyethylene glycol (PEG; necessary for aggregation of the protoplasts); and the culture conditions for fusant regeneration. Protoplast fusion is well known because of its ability to change the genetic characteristics of microorganisms without any requirement of complex genetic engineering techniques (Peberdy, 1980).

Cell fusion and transformation of gram-positive bacteria are considered capable approaches for genetic studies (Reilly and Rogers, 1987). C. beijerinckii and C. acetobutylicum have industrial potential since 
they have the ability to produce solvents from different carbohydrates via two-stage fermentation. Designing a method for genetic manipulation of $C$. acetobutylicum and C. beijerinckii would permit the improvement of these strains along with the economic feasibility of the industrial process. The primary methods which have been used to produce genetic recombination in gram-positive bacteria are protoplast fusion and transformation (Birrer et al., 1989).

There have been many reports of protoplast formation and cell wall regeneration of certain strains of $C$. acetobutylicum such as P262 and B643, which seemed adaptable for protoplast formation of other Clostridia species (Allcock et al., 1982). The various media that have been described for protoplast formation differed mainly with respect to ionic strength, agar concentration, and osmotic strength. Assessment of the effects of these significant medium ingredients on C. beijerinckii B-592 protoplast regeneration yielded two distinct osmotically reinforced media. One of them allows the growth of large L-colonies referred to as cell-wall deficient bacteria, and the other supports the regeneration of transferred L-colonies and their growth to bacillary form. These media were also capable of supporting the growth of an L-colony and regeneration of $C$. beijerinckii B-593 and C. acetobutylicum ATCC 10132.

Figure 2.6 (a) illustrates a typical L-colony growing close to a C. beijerinckii B-592 bacillary colony on a plate of L-colony medium (BLM). When protoplasts were plated on this plate, they started to grow as large L-colonies (1 $\mathrm{mm}$ in diameter). Figure 2.6 (b) shows the regeneration medium (BRM) onto which L-colonies were transferred. An extreme change in colonial morphology and the large bacillary colonies of B-592 can be seen in this figure.

In order to develop a genetic system for C. acetobutylium strain P262, which is important industrially for the production of acetone and butanol, protoplast fusion and isolation of chromosomal 
recombinants has been studied (Jones et al., 1985). By achieving protoplast fusion of the two mutants of strain P262, the frequency of regenerated C. acetobutylicum was significantly higher compared to that obtained with the only other clostridia strain. Moreover, protoplast fusion may facilitate the transfer of inter-specific genes and plasmids in bacteria.
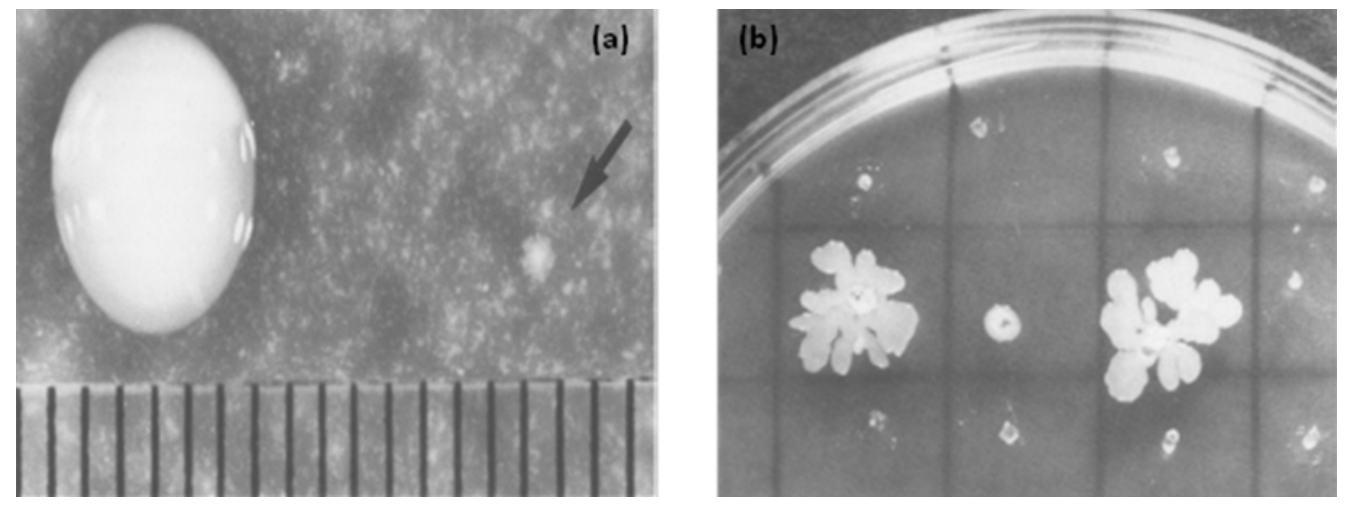

Figure 2.6. (a) C. beijerinckii on BLM medium; (b) reverted L-colonies to the bacillary form (Birrer et al., 1989).

In the current study, it was found that by creating protoplast fusion of $C$. beijerinckii and $C$. thermocellum along with $T$. saccharolyticum, their thermostability was improved in a $45^{\circ} \mathrm{C}$ fermentation medium, which is the optimum temperature of enzymatic hydrolysis. In addition, several studies have been conducted on improving biobutanol-producing cultures to make them more tolerant to elevated levels of acetone, butanol and ethanol concentrations which are toxic to the culture (Ebener et al., 2003). For this reason, genetic engineering techniques to develop strains with higher butanol tolerance, and engineering techniques for simultaneous fermentation and product removal, have been considered as effective solutions. The results of the present study demonstrated that by implementing protoplast fusion, the fused culture of bacteria was able to tolerate the enhanced amounts of the biobutanol concentration. 


\subsection{Bacterial Co-culture}

Co-culture is another approach for the conversion of lignocellulosic residues into biofuels. Because of the high price of enzymatic hydrolysis for producing separate enzymes, adopting a coculture system by using the anaerobe bacteria would simplify the process (Yu et al., 1985). A bacterial co-culture can offer a method to improve cellulose hydrolysis, as well as increase product utilization, thereby enhancing desirable fermentation products.

A sequential co-culture approach was examined for the conversion of lignocellulosic substrates to biofuels and chemicals. Eliminating the high-priced enzymatic hydrolysis step makes the Consolidated Bioprocessing (CBP) more cost-effective. Moreover, the efficiency of butanol production by a single strain of clostridium on cellulosic substrates is low. A co-culture between C. acetobutylicum and $C$. cellulolyticum or $C$. thermocellum is an example that shows the achievement of high rates of cellulose hydrolysis by these bacteria (Nakayama et al., 2011).

Since $C$. thermocellum can only ferment hexose sugars, it has created a great deal of interest in a coculture with microorganisms that are able to ferment pentose sugars to biofuels. Therefore, $C$. thermocellum has been co-cultivated with other anaerobic thermophilic Clostridia, such as $C$. thermosaccharolyticum, which is now classified as Thermoanaerobacterium saccharolyticum; C. thermohydrosulfuricum; and Thermoanaerobacter ethanolicus (Maki et al., 2009). A synthrophic relationship of these organisms with $C$. thermocellum can exploit its cellulases and hemicellulases for hydrolyzing cellulose to cellobiose and cellodextrans, and hemicelluloses to xylobiose, arabinoxylans, and xylooligosaccharides. Then, C. thermocellum will convert cellulose breakdown products to ethanol, and the other strains will utilize products achieved by hemicellulose hydrolysis for ethanol production (Figure 2.7). This would prevent the competition for substrates between strains and will lead to more product formation. The only problem facing this kind of co-culture approach is the 
production of large amounts of by-products, such as acetate and lactate, which decrease the biofuel production by slowing the rate of cell growth (Herrero et al., 1985). Metabolically engineering one microorganism to complete the whole process from beginning to the end itself would be an alternative for a bacterial co-culture; however, molecular engineering of Clostridia may have effects on the production of biofuels.

In our study, the three strains of Clostridia, C. Beijerinckii, C. thermocellum, and T. saccharolyticum were co-cultured. The main aim was to compare the amount of biobutanol production using the two methods of co-culture and protoplast fusion.

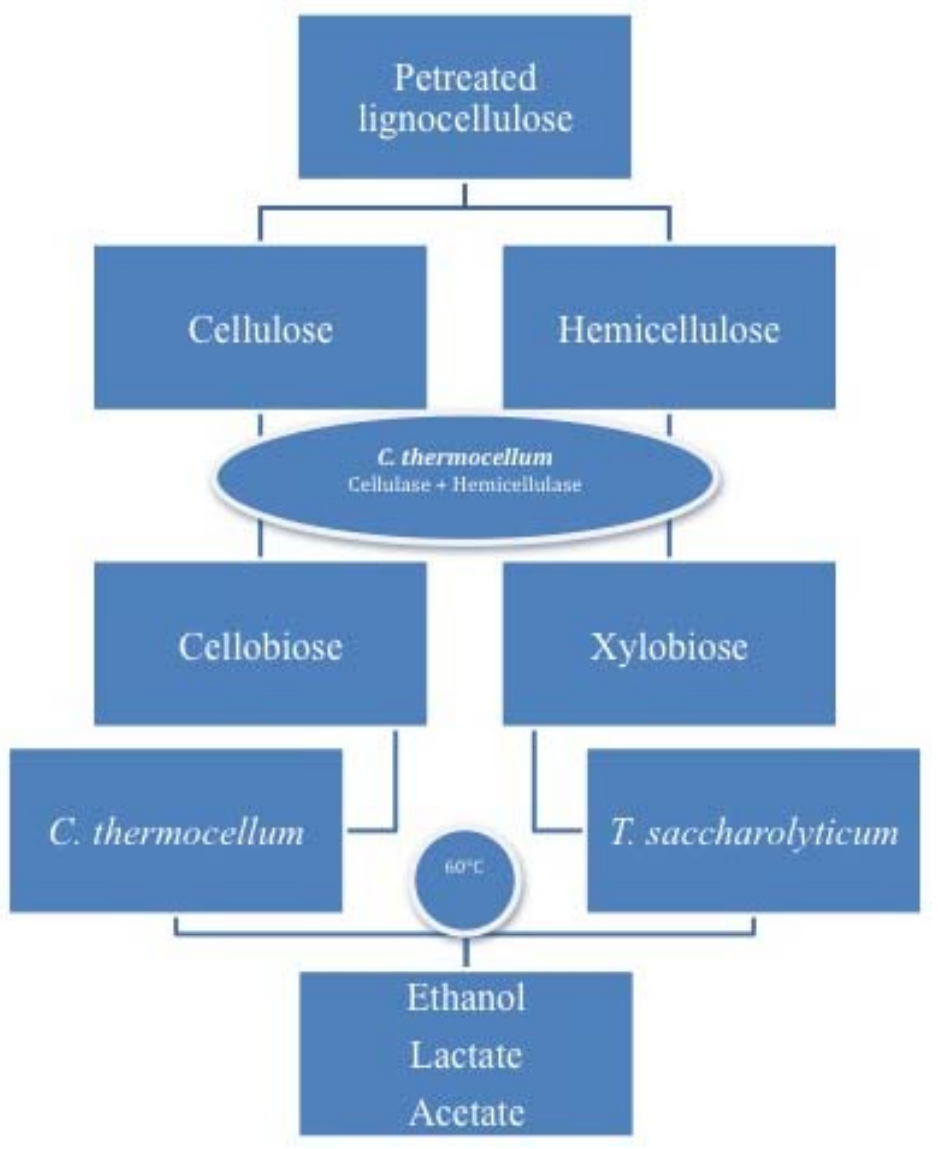

Figure 2.7. The Clostridial co-culture process (Adapted from Maki et al., 2009). 


\section{CHAPTER 3}

\section{MATERIALS AND METHODS}

\subsection{Chemicals and Supplies}

C. beijerinckii (ATCC BA101) was purchased from American Type Culture Collections, whereas C. thermocellum (ATCC 27405) was obtained from Dr. Wolfaardt's lab at Ryerson University and T. saccharolyticum was acquired from Dr. Wenshend Qin from the Department of Biology at Lakehead University. All the chemicals were purchased from Sigma-Aldrich Canada and were used without any further purification. Table A.1 in Appendix A briefly shows all the chemicals used throughout the present study.

\subsection{Experimental work}

Biobutanol produced in SSF using protoplast fusants and co-culture of clostridial species was examined. Two different fusants of $C b C t$ and $C b C t T s$ were prepared and examined for stability. The results of fermentation experiments conducted with $C b C t$ and $C b C t T s$ fusants were compared with corresponding experiments using co-cultures of the same species.

\subsubsection{Media preparation}

Clostridium Basal Medium (CBM) is a medium used for growing wild and fused clostridia strains. It was prepared by adding $2 \mathrm{~g}$ Glucose, $0.04 \mathrm{~g} \mathrm{MgSO}_{4} .7 \mathrm{H}_{2} \mathrm{O}, 0.002 \mathrm{~g} \mathrm{MnSO}_{4} .4 \mathrm{H}_{2} \mathrm{O}, 0.002 \mathrm{~g}$ $\mathrm{FeSO}_{4} .7 \mathrm{H}_{2} \mathrm{O}, 0.0002 \mathrm{~g}$ Para-Amino benzoic acid (PABA), 0.004g Biotin, 0.0002g thiamin $\mathrm{HCl}$ (two vitamins for maintaining active growth of the culture), and $0.8 \mathrm{~g}$ Casein hydrolysate in $200 \mathrm{~mL}$ distilled 
water (Allcock et al., 1982). The solution was autoclaved at $120^{\circ} \mathrm{C}$ for 20 minutes. The PPM or protoplasting medium contained $\mathrm{CBM}$ along with $0.3 \mathrm{M}$ sucrose, $50 \mathrm{mM} \mathrm{CaCl} 2.2 \mathrm{H}_{2} \mathrm{O}$, and $50 \mathrm{mM}$ $\mathrm{MgCl}_{2} \cdot 6 \mathrm{H}_{2} \mathrm{O}$. The $\mathrm{pH}$ was adjusted to 7.5 . Lysozyme $(2.5 \mathrm{mg} / \mathrm{mL})$ was added to the cell suspension in the PPM medium for the formation of protoplasts (Reilly and Rogers, 1987). Clostridial growth medium (CGM) was another alternative medium for C. beijerinckii growth. The medium contained 4\% glucose, $0.75 \mathrm{~g} \mathrm{KH}_{2} \mathrm{PO}_{4}, 0.982 \mathrm{~g} \mathrm{~K}_{2} \mathrm{HPO}_{4}, 1 \mathrm{~g} \mathrm{NaCl}, 0.01 \mathrm{~g}$ of $\mathrm{MnSO}_{4}, 0.004 \mathrm{~g}$ PABA, $0.348 \mathrm{~g}$ $\mathrm{MgSO}_{4}, 0.01 \mathrm{~g} \mathrm{FeSO}_{4}, 2 \mathrm{~g}$ asparagine, $5 \mathrm{~g}$ yeast extract, and $2 \mathrm{~g}\left(\mathrm{NH}_{4}\right)_{2} \mathrm{SO}_{4}$ in 1 liter of distilled water. The $\mathrm{pH}$ was adjusted to 6.5. The NBRC medium 979 (National Biological Research Center), containing 1.3g/L $\left(\mathrm{NH}_{4}\right)_{2} \mathrm{SO}_{4}, 2.6 \mathrm{~g} / \mathrm{L} \mathrm{MgCl}_{2} \cdot 6 \mathrm{H}_{2} \mathrm{O}, 1.43 \mathrm{~g} / \mathrm{L} \mathrm{KH}_{2} \mathrm{PO}_{4}, 7.2 \mathrm{~g} / \mathrm{L} \mathrm{K}_{2} \mathrm{HPO}_{4} \cdot 3 \mathrm{H}_{2} \mathrm{O}, 0.13$ $\mathrm{g} / \mathrm{L} \mathrm{CaCl}_{2} \cdot 2 \mathrm{H}_{2} \mathrm{O}, 6 \mathrm{~g} / \mathrm{L}$ sodium glycerophosphate, $1.1 \mathrm{mg} / \mathrm{L} \mathrm{FeSO} \cdot 7 \mathrm{H}_{2} \mathrm{O}, 0.25 \mathrm{~g} / \mathrm{L}$ glutathione, $4.5 \mathrm{~g} / \mathrm{L}$ yeast extract, $1 \mathrm{mg} / \mathrm{L}$ Resazurin, and $5 \mathrm{~g} / \mathrm{L}$ cellobiose or avicel cellulose, was used in the current study for growing C. thermocellum during the co-culture process (Nakayama et al., 2011).

The medium for Thermophilic Clostridia (MTC) was the medium used for the growth of $T$. saccharolyticum; it contained $5 \mathrm{~g}$ urea, $2 \mathrm{~g}$ citric acid tripotassium salt, $1.0 \mathrm{~g}$ sodium sulphate, $1.0 \mathrm{~g}$ potassium phosphate, $1.25 \mathrm{~g}$ citric acid monohydrate, $1.0 \mathrm{~g}$ magnesium chloride hexahydrate, $2.5 \mathrm{~g}$ sodium bicarbonate, 0.2 calcium chloride dihydrate, $1.0 \mathrm{~g}$ L-cysteine hydrochloride monohydrate, $0.1 \mathrm{~g}$ ferrous chloride, and $0.002 \mathrm{~g}$ resazurin per liter (Joe Shaw et al., 2008).

The regeneration Medium (RM) is a medium for regeneration of the bacterial cell walls; it was prepared by the addition of stock solutions to a basal mixture. Stock solution A contained D-biotin, 0.1 g; PABA, $0.1 \mathrm{~g}$; thiamine- $\mathrm{HCI}, 0.01 \mathrm{~g}$; $\mathrm{FeSO}_{4} .7 \mathrm{H}_{2} \mathrm{O}, 0.1 \mathrm{~g} ; \mathrm{MnSO}_{4} .4 \mathrm{H}_{2} \mathrm{O}, 0.1 \mathrm{~g}$; and $\mathrm{MgSO}_{4} .7 \mathrm{H}_{2} \mathrm{O}$, $2.0 \mathrm{~g}$, all in $100 \mathrm{~mL}$ of distilled water. The solution was filter-sterilized, and kept in a $\mathrm{N}_{2} / \mathrm{CO}_{2}$ atmosphere. Stock solution B consisted of $25 \mathrm{~g}$ glucose in $100 \mathrm{~mL}$ of $\mathrm{H}_{2} \mathrm{O}$ while stock solutions $\mathrm{C}$ and D consisted of 2.5 M solutions of $\mathrm{MgCl}_{2}$ and $\mathrm{CaCI}_{2}$, respectively. Stock solution $\mathrm{E}$ contained $\mathrm{K}_{2} \mathrm{HPO}_{4}$, 
$7.0 \mathrm{~g}$, and $\mathrm{KH}_{2} \mathrm{PO}_{4}, 3.0 \mathrm{~g}$, dissolved in $100 \mathrm{~mL}$ distilled water. Stock solutions $\mathrm{B}$ through E were autoclaved separately. The basal Mixture contained 50g gelatine, $15 \mathrm{~g}$ Agar, $8 \mathrm{~g}$ Yeast extract, $2.5 \mathrm{~g}$ Casamino acids, and $1 \mathrm{~g}$ asparagine. These ingredients were mixed in $930 \mathrm{~mL}$ of distilled water and the mixture was stirred and brought to boiling before autoclaving at $121^{\circ} \mathrm{C}$ for 20 minutes (Birrer et al., 1989). Upon cooling, $10 \mathrm{~mL}$ of stock solution $\mathrm{A}, 40 \mathrm{~mL}$ of solution $\mathrm{B}, 5 \mathrm{~mL}$ of each of solutions $\mathrm{C}$ and $\mathrm{D}$, and $10 \mathrm{~mL}$ of stock solution $\mathrm{E}$ were added to the basal mixture to make the RM medium. Then the liquid medium was poured into petri dishes and left until it solidified to allow the growth of bacteria on its surface.

Cooked meat medium (CMM), which is supplemented with $0.1 \%$ glucose and composed of $100 \mathrm{~g}$ beef heart solids, $20 \mathrm{~g}$ casein/meat peptone, $2 \mathrm{~g}$ dextrose, and $5 \mathrm{~g}$ sodium chloride, was used to maintain the wild strains of bacteria (Murray and American Society for Microbiology, 1995).

\subsubsection{Culture conditions}

All Clostridia strains including wild and fused strains of $C b, C t$, and $T s$ were kept as a cell suspension in $30 \% \mathrm{v} / \mathrm{v}$ sterile glycerol and cooked meat medium $(\mathrm{CMM})$ at $-82^{\circ} \mathrm{C}$ in Eppendorf tubes inside the freezer (Thermo fisher scientific, USA). Prior to inoculation of the strains, their spores were heat shocked at $80^{\circ} \mathrm{C}$ for 5 minutes and then the heat-shocked spore suspensions were grown overnight in CBM and CGM broth under severe anaerobic conditions (Qureshi and Blaschek, 2001). All the manipulations involving cells and protoplasts were carried out in an anaerobic glove box (Terra Universal, Canada) at a mean temperature of $25 \pm 2^{\circ} \mathrm{C}$ (Figure 3.1).

In order to create an anaerobic environment inside the glove box, a vacuum pump was used for 10 min to evacuate the air from the chamber. Then during the inoculation, $\mathrm{N}_{2}$ gas was purged thorough the box 
until all the serum bottles were properly sealed using a crimper. The glove box was cleaned routinely by wiping the work surface with $70 \%$ ethanol before and after the work. In addition, the work surface was exposed to the ultraviolet light to be sterilized for 1-2 hours before inoculation of the bacteria.

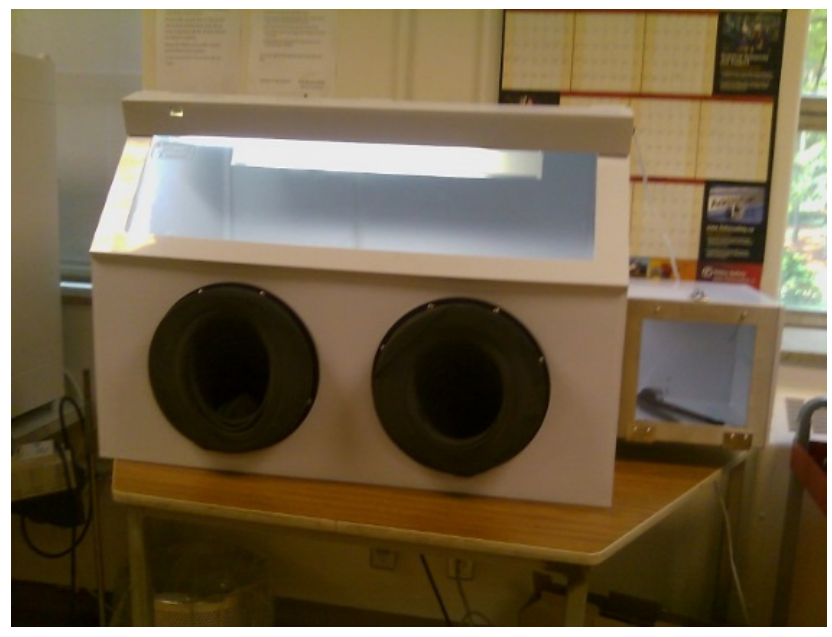

Figure 3.1. Glove box (Terra Universal, Canada) used for the anaerobic environment.

\subsubsection{Protoplast fusion and cell wall regeneration process}

Three wild strains were used in the protoplast fusion formation: $C$. beijerinckii (Cb), $C$. thermocellum (Ct), and T. saccharolyticum (Ts). Fusants of $C b C t$ and $C b C t T s$ formed the final parentfused strains. The stability of the parent strains was then examined in ten growth cycles in terms of genetic stability and biobutanol producing capability.

The process of fusion involves three major steps including protoplast formation, fusion, and cell wall regeneration (Birrer et al., 1989). During the first step or protoplast formation, overnight cultures of the wild strains were diluted 1:4 with fresh, sterile CBM containing $0.4 \%$ or $0.8 \%$ glycine. When the cultures became nearly $100 \%$ motile after $45-60$ minutes, mid-exponentially growing cells were harvested by centrifugation at $10,600 \mathrm{rpm}$ for $10 \mathrm{~min}$. The osmotic strength of each culture was increased by adding the cell pellets to $5 \mathrm{~mL}$ PPM. The $\mathrm{pH}$ was adjusted to 7.5. Lysozyme (Chicken egg 
white grade 1) was then added to the cell suspension at a concentration of $2.5 \mathrm{mg} / \mathrm{mL}$. Protoplasts were formed after $60 \mathrm{~min}$ of incubation at $35^{\circ} \mathrm{C}$ for $\mathrm{Cb}$, and at $45^{\circ} \mathrm{C}$ for $C t$ and $T s$. To extract the protoplasts, the cell suspensions in PPM were centrifuged at 3,300 rpm for $5 \mathrm{~min}$ and the cell pellets were resuspended in fresh PPM without lysozyme. The cell pellets were either used directly for the fusion on the same day or maintained in the fridge in fresh PPM without lysozyme to be used later. In this medium, the protoplasts remained intact for a long time.

During the second step or protoplast fusion, protoplast suspensions of the two and three Clostridia were mixed together and centrifuged at $1,500 \mathrm{rpm}$ for $10 \mathrm{~min}$ at $20^{\circ} \mathrm{C}$. The pelleted mixed protoplasts were gently re-suspended in $1 \mathrm{~mL}$ polyethylene glycol (PEG) $4000(40 \% \mathrm{w} / \mathrm{v})$ in PPM for $2-3 \mathrm{~min}$. Protoplast fusion is a physical phenomenon, during which two or more protoplasts come in contact and adhere to each other in the presence of fusion inducing agents like PEG. Protoplast fusion is classified into two categories: the first is spontaneous fusion during which isolated protoplasts fuse spontaneously. The second form of fusion is called induced fusion, which is categorized as either mechanical fusion, chemofusion, or electrofusion. Chemofusion, which was applied in the current study, is an inexpensive method with a large amount of fusion products (Verma et al., 2004).

In the third step or protoplast regeneration, dilutions of the fused protoplasts were plated onto RM by using a sterile inoculating loop and a spreader. The plates were incubated at $45^{\circ} \mathrm{C}$ in an anaerobic jar (HP011, Thermo Scientific) and a nitrogen atmosphere for 24-48 hours. The regenerated colonies were extracted and suspended in CBM medium with $30 \%(\mathrm{v} / \mathrm{v})$ glycerol, and stored at $-82^{\circ} \mathrm{C}$ in labeled eppendorf tubes to be examined later in terms of biobutanol production (Liu et al., 2010).

The regeneration frequency of the protoplasts was calculated using Equation 3.1, where $a$ is the number of colony forming units (CFU) of cells before protoplasting per $\mathrm{mL}$ (units/mL), which was determined 
by counting viable cells after $24 \mathrm{~h}$ on agar plates; $b$ is the CFU per $\mathrm{mL}$ of regenerated protoplasts after $48 \mathrm{~h}$ on $\mathrm{RM}$ plates in units $/ \mathrm{mL}$; and $c$ is the CFU per $\mathrm{mL}$ of the non-protoplasted units (units/mL), which was calculated by viable counting of the protoplast suspension after dilution in CBM to bring about osmolysis of protoplasts (Jones et al., 1985). The results of the percent of the regenerated protoplasts in the present study are discussed in Chapter 4.

$100(b-c) / a$

\subsubsection{Clostridial co-culture process}

Biobutanol production was also examined in SSF using clostridial co-culture strains. Fermentation experiments applied in this current study were done according to the co-culture technique developed by the Department of Fermentation Science and Technology at Tokyo University, Japan. During fermentation, $8 \%$ of $C t$ was cultured anaerobically at $60^{\circ} \mathrm{C}$ on $100 \mathrm{~mL}$ of National Biological Resource Center (NBRC) medium 979 (Nakayama et al., 2011). Cb was inoculated anaerobically within a CGM medium and the culture was incubated at $35^{\circ} \mathrm{C}$ in a strict nitrogen medium inside the glove box. Ts was also cultured within a MTC medium in a strict anaerobic environment at $60^{\circ} \mathrm{C}(\mathrm{Joe}$ Shaw et al., 2008). The co-culture experiments were conducted in $250 \mathrm{~mL}$ serum bottles. Both $C t$ and Ts cells grown in NBRC and MTC media were collected by centrifugation and after the cell pellets were washed, they were re-suspended in the same media without any added carbon source. $6 \mathrm{~mL}$ of $C t$ and $T s$ cell suspension solutions were then inoculated in $6 \mathrm{~mL}$ of NBRC containing avicel cellulose and MTC medium, respectively. The cultures then were incubated at $60^{\circ} \mathrm{C}$ in serum bottles.

The butanol-producing $C b$ strain that grew exponentially was collected after 24 hours by centrifugation, washed, and re-suspended in CGM containing 4\% glucose. $2 \mathrm{~mL}$ of this cell suspension 
was then added to serum bottles containing both $C t$ and $T s$ after the incubation temperature was decreased to $30-35^{\circ} \mathrm{C}$ (Nakayama et al., 2011). The same procedure was also applied by adding $1 \mathrm{~mL}$ of $C b$ cell suspension to the serum bottles containing $C t$ in order to obtain the $C b-C t$ co-culture. The co-culture samples were then incubated at $30-35^{\circ} \mathrm{C}$ for 3 days. Samples were then collected in eppendorf tubes containing $30 \%(\mathrm{v} / \mathrm{v})$ sterile glycerol and stored at $-82^{\circ} \mathrm{C}$ for further fermentation processes.

\subsubsection{Wheat straw pre-treatment}

WS used in the current study was collected from Springridge Farm located in Milton, ON and stored at room temperature. Before using it as a fermentation substrate, the wheat straw was grounded into fine particles using a $1 \mathrm{~mm}$ sieve screen in a hammer mill (Restsch GmbH Inc., USA) as shown in Figure 3.2. The moisture content of the wheat straw was reduced through heating in a conventional oven at $105^{\circ} \mathrm{C}$ for 10 hours until a constant weight was obtained.

During acidic pre-treatment of the wheat straw, $4.5 \mathrm{~g}$ of dried WS were suspended in $50 \mathrm{~mL}$ of $1 \%$ dilute sulphuric acid $\left(\mathrm{H}_{2} \mathrm{SO}_{4}\right)$ in $250 \mathrm{~mL}$ Wheaton serum bottles (Qureshi et al., 2008b). For preparation of the dilute sulphuric acid (1\%) solution, $1 \mathrm{~mL}$ of $99.99 \%$ sulphuric acid was added to 99

$\mathrm{mL}$ distilled water. The solution of WS-acid was then autoclaved at $121^{\circ} \mathrm{C}$ for 60 minutes. After autoclaving, the lost water was added to maintain a constant volume. 


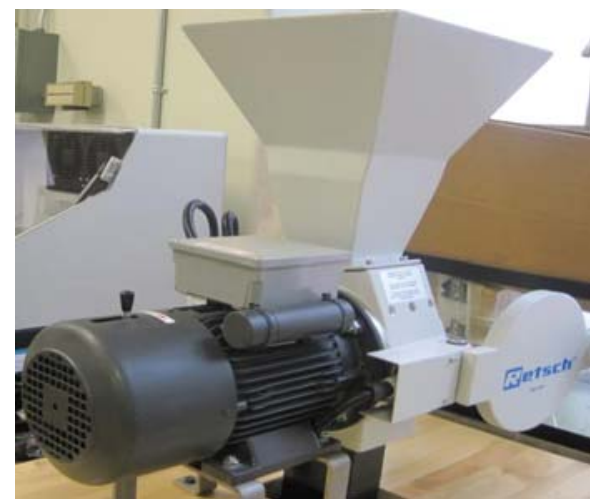

Figure 3.2. Hammer mill used for wheat straw preparation (Retsch GmnH Inc., USA).

After adding water, the serum bottles were allowed to cool down to room temperature to make the WS ready for the SSF process (Qureshi et al., 2008b). In the current study, it was demonstrated that by applying the protoplast fusion technique, the fused strains developed faster at high temperatures and produced the required enzymes, such as endoglucanase, exoglucanase, and $\beta$-glucosidase, for the saccharification of WS. This would eliminate the need to add high-priced enzymes, which are necessary to hydrolyze the substrates in feedstocks, and will decrease the total cost of the procedure.

\subsubsection{SSF experiment using fused and co-culture clostridia}

In the present study, acetone, butanol and ethanol (ABE) were produced from pretreated WS using clostridia-fused and co-cultured bacteria in batch SSF. Experiments were conducted in $250 \mathrm{~mL}$ sealed Wheaton serum bottles. ABE concentrations, sugar consumption, $\mathrm{pH}$ changes and cell growth profiles were examined completely for all SSF experiments. The incubation temperature during fermentation was adjusted to $45^{\circ} \mathrm{C}$ for fused strains and $35^{\circ} \mathrm{C}$ and $45^{\circ} \mathrm{C}$ for co-culture strains. After WS pretreatment, $40 \mathrm{~mL}$ of the growth medium (i.e., $\mathrm{CBM}$ ) were added to the serum bottles to provide nutrients for the strain growth. Before inoculation, the $\mathrm{pH}$ of the solution was adjusted to 6.5 with $10 \mathrm{M}$ sodium hydroxide. The inoculation part was carried out inside the anaerobic chamber and all the manipulations were performed under a constant supply of $\mathrm{N}_{2}$ gas. The serum bottles containing the 
culture medium and pretreated WS were inoculated with 7-8 $\mathrm{mL}$ of actively fused or co-culture strains. After the inoculation, the fermentation bottles were bubbled with $\mathrm{N}_{2}$ gas for around 5-10 minutes. The serum bottles were sealed with blue neoprene rubber stoppers and a metallic cap using a vial crimper (Cole Palmer Canada).

The serum bottles were then transferred to the incubator set at the right fermentation temperature. The bottles containing co-culture strains were maintained at $35^{\circ} \mathrm{C}$ and $45^{\circ} \mathrm{C}$; while those containing the fused strains were kept at $45^{\circ} \mathrm{C}$. The SSF procedure was applied for the first growth cycles of both fused and co-culture strains in order to check the stability of the bacteria and compare ABE production using fused and co-culture strains.

\subsubsection{Sampling}

For the SSF experiments, sampling was done inside the anaerobic glove box, which was cleaned with ethanol and left under UV light for 10 min before sampling. All other equipment, such as syringes, needles, spatulas, and other tools used for culture inoculation were washed with ethanol and kept under UV light for 10 minutes. The serum bottles, which were taken out of the incubator over a period of 5 days, were placed inside the anaerobic glove box and washed with ethanol prior to sampling into eppendorf tubes that were washed with ethanol and autoclaved for 10 minutes before sampling. Sampling was then performed by inserting a sterilized syringe-needle combination through the serum bottle's rubber stopper. It should be mentioned that only the liquid phase of the fermentation medium, containing solvents, acids, sugars and culture cells, was loaded for sampling. Samples were collected every $24 \mathrm{~h}$ and stored in $2 \mathrm{~mL}$ eppendorf tubes at $-82^{\circ} \mathrm{C}$ in the ultra-low temperature freezer (Thermo, Canada) until analyzed. All samples were analyzed for ABE production, acids and sugar concentration 
using HPLC, as well as $\mathrm{pH}$ and cell growth. The results were achieved from a reading of triplicate samples.

\subsection{Analytical Techniques and Methods}

\subsubsection{Enzyme assay}

The enzyme activity in the current study was quantified by the Filter Paper Assay (FPA) method which was adapted from the National Renewable Energy Laboratory in the US department of energy (Adney et al., 2008). This method describes a procedure only for measuring the cellulase activity in terms of filter paper units (FPU) per milliliter of original (i.e., undiluted) enzyme solution. It is important to know that the enzyme preparations should be compared on the basis of equal conversion for quantitative results. During this assay, $2 \mathrm{mg}$ of reducing sugar as glucose was released from $50 \mathrm{mg}$ of filter paper (4\% conversion) in $60 \mathrm{~min}$ and designated as the intercept for calculating Filter Paper Cellulose Units. The DNS assay method was used for measuring the reducing sugars (Wood and Bhat, 1988). It should be mentioned that reducing sugar yield is not a linear function of the quantity of enzymes in the assay mixture. Therefore, the assay procedure involved finding a dilution of the original enzyme stock such that a $0.5 \mathrm{~mL}$ aliquot of the dilution would catalyze $4 \%$ conversion in 60 minutes. The DNS reagent was prepared by mixing $10.6 \mathrm{~g}$ of 3,5 dinitrosalicylic acid and $19.8 \mathrm{~g}$ sodium hydroxide in 1,416 mL distilled water. After dissolving, $306 \mathrm{~g}$ of Rochelle salts (sodium potassium tartrate), along with $7.6 \mathrm{~mL}$ of melted phenol at $50^{\circ} \mathrm{C}$ and $8.3 \mathrm{~g}$ of sodium metabisulfite were added to the above solution. $3 \mathrm{~mL}$ of the sample was titrated with $0.1 \mathrm{~N} \mathrm{HCL}$ (about 5-6 mL of HCL) to the phenolphthalein endpoint. The solution was then stored for filter paper assay experiment.

The procedure for the filter paper assay for saccharifying cellulase involved the parallel and identical treatment of three categories of experimental tubes called assay mixtures, blanks and controls, and glucose standards. A $50 \mathrm{mg}$ Whatman No. 1 filter paper strip at the size of 1.0 x $6.0 \mathrm{~cm}$ was used as the 
substrate. For enzyme assay tubes, a rolled filter paper strip was placed into each 13 x $100 \mathrm{~mm}$ test tubes. $1.0 \mathrm{~mL}$ of $0.05 \mathrm{M} \mathrm{Na}$-citrate was then added to the tubes such that the buffer saturated the filter paper strip. The tubes with buffer and substrate were equilibrated to $50^{\circ} \mathrm{C} .0 .5 \mathrm{~mL}$ enzyme, diluted appropriately in citrate buffer, was added. At least two dilutions had to be made of each enzyme sample such that one dilution released more than $2.0 \mathrm{mg}$ of glucose and one slightly less than $2.0 \mathrm{mg}$ of glucose. In the current study, three dilutions were run to target the $2 \mathrm{mg}$ glucose release target (Appendix B). The solutions were incubated at $50^{\circ} \mathrm{C}$ for 60 minutes. At the end of the incubation time, each assay tube was removed from the bath and the enzyme reaction was stopped by immediately adding $3.0 \mathrm{~mL}$ DNS reagent.

The citrate buffer solution was made by adding $210 \mathrm{~g}$ of citrate acid monohydrate into $750 \mathrm{~mL}$ of deionized buffer. About 50-60 g NaOH was added to the solution until $\mathrm{pH} 4.3$ was achieved. The solution was diluted to $1 \mathrm{~L}$ and the $\mathrm{pH}$ adjusted to 4.5 using $\mathrm{NaOH}$. Moreover, $1.5 \mathrm{~mL}$ of citrate buffer were used as a reagent blank. Enzyme control was prepared separately for each tested dilution by adding $1.0 \mathrm{~mL}$ of citrate buffer to the $0.5 \mathrm{~mL}$ enzyme dilution. Substrate control was achieved by adding $1.5 \mathrm{~mL}$ citrate buffer to a filter-paper strip.

For the glucose standard preparation, a stock solution of $10 \mathrm{mg} / \mathrm{mL}$ of anhydrous glucose was made up. Several dilutions from the stock solution in the ratios of 1:1.5, 1:2, 1:3 and 1:5 were made in the citrate buffer. Glucose standard tubes were prepared by adding $0.5 \mathrm{~mL}$ of each of the above glucose dilutions to $1.0 \mathrm{~mL}$ of citrate buffer in test tubes (Appendix B). Blanks, controls and glucose standards along with the enzyme assay tubes were incubated at $50^{\circ} \mathrm{C}$. After $60 \mathrm{~min}$, they were stopped by adding 3.0 $\mathrm{mL}$ of DNS reagent. All tubes were boiled for exactly $5 \mathrm{~min}$ in boiling water bath containing adequate water for covering the portions of the tubes which were full of the reaction mixture and reagent. Finally, all samples, controls, blanks, and glucose standards were boiled together and then transferred 
to a cold ice-water bath. After settling all the pulp, the tubes were diluted in $0.2 \mathrm{~mL}$ of color-developed reaction mixture plus $2.5 \mathrm{~mL}$ of distilled water. The color formation was determined by measuring absorbance against the reagent blank at $540 \mathrm{~nm}$. A linear glucose standard curve using the absolute amounts of $\mathrm{mg} / 0.5 \mathrm{~mL}$ glucose was plotted against $\mathrm{A}_{540}$. The standard curve was used to determine the amount of glucose released for each sample tube after subtraction of the enzyme blank.

The FPU was calculated using Equation 3.2, where E, the enzyme represents the proportion of original enzyme solution existing in the directly tested enzyme dilution.

$$
F P U=\frac{0.37}{[E]}
$$

where,

$$
\begin{aligned}
& F P U=\text { filter paper activity }(\text { units } / \mathrm{mL}) ; \text { and } \\
& {[E]=\text { concentration of enzymes releasing } 2 \mathrm{mg} \text { glucose }}
\end{aligned}
$$

\subsubsection{Genetic stability of the fused strains}

The polymerase chain reaction (PCR) was used to test the stability of ten generations of both fused strains by amplifying small amounts of DNA. In the PCR method, a specific sequence of DNA of small quantities is taken and amplified for testing. A DNA sequence of the gene of interest, which can be a complete gene or a small sequence within genes, is targeted by the PCR. The process involves three main steps. During the first step, DNA is denatured and DNA strands are separated at $95^{\circ} \mathrm{C}$. In the second step, two sequences of DNA are allowed to form hydrogen bonds where primers bind to the target sequence, through the process of primer annealing at $50-60^{\circ} \mathrm{C}$. Eventually during the third step,

a thermostable taq DNA polymerase makes the DNA become polymerized at $72^{\circ} \mathrm{C}$. Taq is a 
thermophilic bacterium called Thermus aquaticus living in hot springs, and produces DNA polymerase which is an enzyme that amplifies DNA from the primers by the PCR (Sadeghi et al., 2010). Primers that are ranged from 15-30 single nucleotides are used as complementary building blocks of the target sequence. They bind to the target DNA and make double stranded DNA. In this study, the genetic stability of both $C b C t$ and $C b C t T s$ fused strains was determined by extracting the genomic DNA for several growth cycles using the MO BIO UltraClean Microbial DNA Isolation Kit (Medicorp, Canada). For the $\mathrm{CbCt}$ fusant, two biomarkers, $\beta$-glucosidase A gene (bglA) from $\mathrm{Ct}$ and aldehyde dehydrogenase gene (ald) from $C b$, were selected for PCR (Table 3.1). Each of the biomarker genes selected was exclusively specific to each strain. For example, the ald gene chosen for $\mathrm{Cb}$ is a predominant gene involved in the oxidation of aldehydes and finally butanol production. It should be mentioned that there was no similarity in the sequence of this gene to the genome of $C t$ when a nucleotide BLAST was done. On the other hand, the $b g l A$ gene selected for $C t$ is predominantly involved in glucose metabolism. Similarly, when its full sequence was available and the nucleotide sequence was BLASTed, there was no similarity to the whole genome of $C b$. Primers for $b g l A$ and ald were designed using DNAMAN software to reduce primer dimers and ensure $\sim 50 \%$ GC content which is a number of Guanines and Cytosines in the primer as a percentage of total bases. They were designed within the $b g l A$ and ald gene targets to amplify $\sim 538$ bp and $\sim 436$ bp products, respectively. The aldehyde dehydrogenase is a gene that was found in $\mathrm{Cb}$; whereas, a beta-glucoside gene was found in $C t$. On the other hand, bglA and ald are made up of a sequence of four nucleotide bases including adenine (A), cytosine (C), guanine (G), and thymine (T) in the nucleic acid of DNA. Base pairs are the linkage between two bases on complementary DNA. They are connected to each other with hydrogen bonds. For instance, Adenine always pairs with Thymine, while Guanine always pairs with Cytosine. Table 3.1 shows the biomarker genes selected for PCR, as well as the number of base pairs (bp) in the product. 
Table 3.1. Primer sequences and product size for biomarker genes.

\begin{tabular}{|l|l|l|l|}
\hline Gene & Forward (5'-3') & Reverse (5'-3') & Product (bp) \\
\hline bglA & ATCTGGACTCGGAGGTGTT & TTGTGCCATACCAACCAG & 538 \\
\hline ald & ATGTTGCATGCGACCACTTC & TCGGATGCGGGATAATGT & 463 \\
\hline$x y l B$ & ATACAGGTACGCCAAGAGGA & AGTAGTCAGCACCACCGCAT & 620 \\
\hline
\end{tabular}

To determine the genetic stability of $C b C t T s$ fused strains, the same process was applied for genomic DNA extraction for three generations and for controls, including single cultures of $C b, C t$ and $T s$. Three biomarkers $\beta$-glucosidase A gene (bglA), $\beta$-xylosidase $\mathrm{B}(x y l B)$ and aldehyde dehydrogenase gene (ald) from $C t, T s$ and $C b$, respectively, were selected for PCR analysis, and corresponding primer sequences can be found in Table 3.1. As previously mentioned, biomarker genes were selected based on their sole presence in the genome of each corresponding strain. However, the primers were tested on each strain to ensure there would be no amplification of non-specific products in strains for which the biomarker genes were not designed.

The PCR reaction mixtures contained approximately10 ng of genomic DNA individually from each generation, 10 pmol of both forward and reverse primers, 10x Taq thermol buffer with 25 mmol l-1 $\mathrm{MgCl}_{2}, 0.2 \mathrm{mmol}$ deoxynucleoside triphosphate, and $5 \mathrm{U}$ DNA polymerase per $50 \mu \mathrm{l}$ reaction. As previously described, the PCR process was used as follows: primary denaturation for 4 minutes at $95^{\circ} \mathrm{C}$, followed by 35 amplification cycles consisting of denaturing at $95^{\circ} \mathrm{C}$ for 30 seconds, annealing for 1 minute at $54^{\circ} \mathrm{C}$, and extension at $68^{\circ} \mathrm{C}$ for 1 minute; upon completion of 35 amplification cycles a final extension step was done at $72^{\circ} \mathrm{C}$ for 10 minutes. The PCR products were then detected and viewed on a $1 \%$ agarose gel to confirm size, quantity and purity. Figure 3.3 shows the agarose gel electrophoresis apparatus which is a method used for analyzing DNA fragments. Samples from the PCR analysis were loaded into the agarose gel wells within the electrophoresis chamber. The DNA 
samples that are negatively charged due to the phosphate molecule were loaded to the negative end of the chamber.

After applying the electric current though the chamber, the negatively charged samples moved towards the positive end. The DNA fragments with different sizes will travel different lengths based on the pores in the agarose gel. To set up the experiment, the gel chamber is filled with TAE buffer to some millimetres over the gel. TAE is a buffer solution, which consists of a mixture of tri-base, acetic acid and EDTA. Samples that were loaded after mixing with loading dye, sank down to the bottom of the well in the gel. Finally, the chamber lid was closed and electric current at the voltage of $140 \mathrm{~V}$ for 30 minutes was applied.

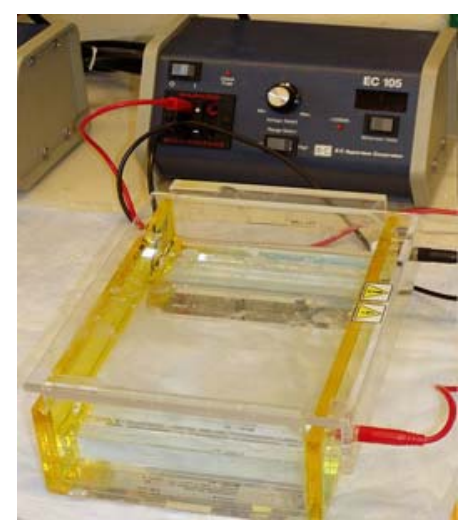

Figure 3.3. Agarose gel electrophoresis apparatus (BioRad Laboratories).

\subsubsection{Hemocytometer}

In the current study, two different methods were applied for counting the bacterial cells. During the first method, cell counting was determined using a hemocytometer (Qiujing XB-K-25) with 1/400 $\mathrm{mm}^{2}$ unit area and $0.1 \mathrm{~mm}$ height (Figure 3.4). Before using, the hemocytometer was cleaned with $75 \%$ ethanol. Cell counting was done under an optical microscope (Zeiss Axio Observer A1). Samples were diluted, and $10 \mu \mathrm{L}$ of the samples were injected on both sides of the hemocytometer to be observed 
under the microscope. Since each side has four quadrants, cells were counted in 8 quadrants and the number of cells in each of the 8 quadrants were recorded. The average cell count in each quadrant was achieved by dividing the number of cells in each quadrant by the total number of quadrants, which is 8 . The achieved number corresponds to the number of cells in $0.1 \mathrm{~mm} \times 1 / 400 \mathrm{~mm}^{2}$ volume of each quadrant. Cell density was also calculated in Cells $/ \mathrm{mL}$ for both fused and co-culture strains of fermentation. The only problem regarding this technique is that without tagging the bacterial cells, the dead cells could not be identified; thus, they were assumed to be insignificant.

The other method used in the present study for cell counting was viable cell counting, which is a traditional approach. In this method samples were diluted in the rate of $10^{7}$ and $0.1 \mathrm{~mL}$ of the final dilution was plated onto the agar plates. Each plate was labeled with the name of the strain and the dilution rate. Plates were incubated overnight at the appropriate temperature for colonies to grow. Each growth colony represents one cell in the original sample. After counting the total number of colonies, it was multiplied by the dilution rate and reported as cells $/ \mathrm{mL}$.

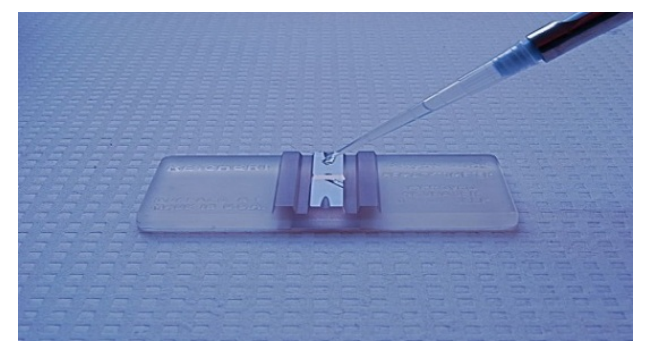

Figure 3.4. Hemocytometer (Qiujing XB-K-25).

\subsubsection{UV/VIS spectrophotometer}

Enzyme activity was measured using a pre-calibrated UV/VIS scanning spectrophotometer as shown in Figure 3.5. The glucose standard curve was plotted by measuring the absorbance of different amounts of glucose standard solution $(\mathrm{mg} / 0.5 \mathrm{~mL})$ at the wavelength of $540 \mathrm{~nm}$ (Figure B.1, Appendix 
B). Enzyme samples were analyzed by measuring absorbance against a reagent blank at the same wavelength. Before analysis, all tubes including the sample assay, blanks, standards and controls were diluted in $0.2 \mathrm{~mL}$ of color developed reaction mixture along with $2.5 \mathrm{~mL}$ of distilled water in the spectrophotometer cuvette, and analyzed.

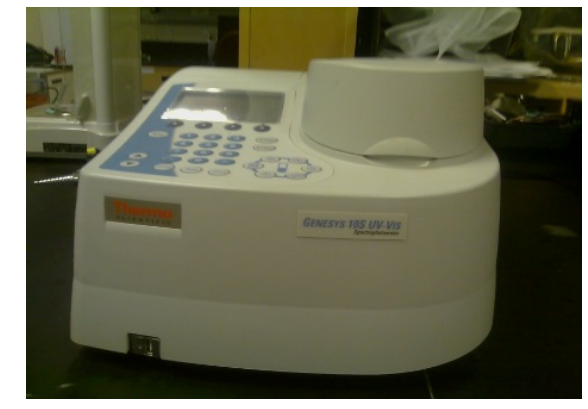

Figure 3.5. GENESYS 10S UV/VIS spectrophotometer (Thermo Fisher Scientific, USA).

\subsubsection{High performance liquid chromatography (HPLC)}

During the SSF process, a sample size of $1 \mathrm{~mL}$ was taken periodically for analyzing (ABE) acetone, butanol, ethanol, acids (acetic acid and butyric acid), sugars and inhibitor concentrations. These samples were stored in eppendorf tubes at $-82^{\circ} \mathrm{C}$ until analyzed. Product concentrations were determined using high performance liquid chromatography (HPLC - Perkin Elmer) as shown in Figure 3.6, which is equipped with an automatic sample injector and a refractive index detector (2414, Waters). The three HPLC columns used were Shodex KC811 for measuring sugars, Shodex SP0810 for measuring inhibitors, and Aminex HPX-87H for measuring ABE solvents and acid concentrations. 


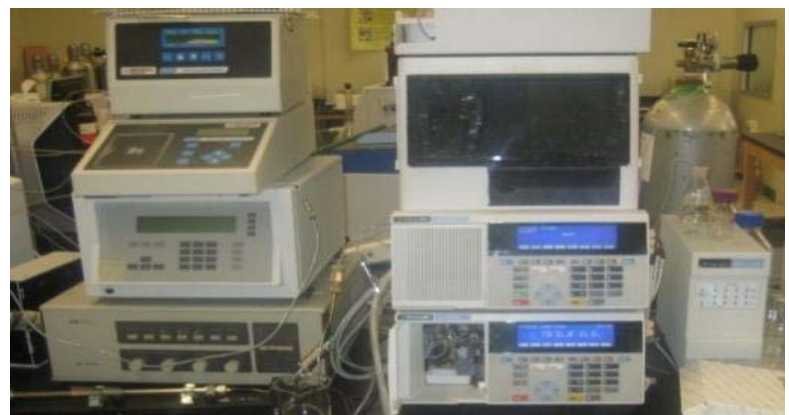

Figure 3.6. HPLC (model \# 600 by Perklin Elmer) equipped with refractive index (model \# HP1047 A, Hewlett Packard).

The samples were centrifuged at $15,000 \mathrm{~g}$ for $15 \mathrm{~min}$ and double filtered through $0.2 \mu \mathrm{m}$ PTFE-filter (Whatman, USA). The solvent (mobile phase, $5 \mathrm{mM} \mathrm{H}_{2} \mathrm{SO}_{4}$ ) was filter-sterilized followed by autoclaving at $121^{\circ} \mathrm{C}$ for $15 \mathrm{~min}$. After that, the solvent was degassed using a vacuum filtration. A blank sample with only double distilled water was applied in the first sample vial tray of HPLC. This blank was used to increase the flow rate of the solvent from $0.0 \mathrm{~mL} / \mathrm{min}$ to $0.6 \mathrm{~mL} / \mathrm{min}$.

The flow rate was maintained at $0.6 \mathrm{~mL} / \mathrm{min}$ for $1 \mathrm{~h}$, whereas, the temperature of the HPLC column increased from $20^{\circ} \mathrm{C}$ to $60^{\circ} \mathrm{C}$. This also fixed the pressure at a constant value and cancelled some noise created during the analysis. Then, $0.1 \mu \mathrm{L}$ of each sample vial set in a sequence was extracted by the automatic injector. Each sample was analyzed through the HPLC for $30 \mathrm{~min}$. Data were processed by the computer software (Tubochrom Navigator). It was significant to fill the HPLC testing vials to a minimum headspace to reduce the loss of solvents in the vapour phase. The reliability of HPLC column and testing parameters were confirmed by running solvents, acids and sugar standards in triplicate.

\subsection{Error Analysis}

In the present study, SSF experiments were conducted in triplicate (i.e., repeated three times) for both fused and co-culture strains. Results reported were the averages of data collected from the 
corresponding experiments. Tables $\mathrm{C} 1$ and $\mathrm{C} 2$ in Appendix $\mathrm{C}$ show results obtained from three SSF repetitions performed for both fused and co-culture strains. Tables in Appendix $\mathrm{C}$ demonstrate ABE and acids production obtained at the end of each SSF experiment.

Tables D1, D2, D3 and D4 in Appendix D show the raw data for total sugar concentrations including average concentration, standard deviation for triplicates and Percent Relative Standard Deviation (\%RSD). Tables F1, F2, F3, and F4 show the results for biobutanol concentration performed for each strain during the three SSF experiments. Tables G1, G2, G3 and G4 represent the results for bacterial cell concentrations for both fused and co-culture strains during the three SSF experiments. Averages and standard deviations were calculated for results obtained from the triplicates. \%RSD was measured by taking a ratio of the standard deviation with the mean and multiplying it by 100 .

The percent error $(\% \mathrm{RSD})$ for total sugar concentration in tables D1, D2, D3, and D4 is in the range of $1 \%$ to $2.5 \%$ for all strains used in the current study. The standard deviation for ABE was in the range of 0.03 to 0.1 and the percent error was in the range of 0.2 to $1 \%$; while for acid concentrations, the standard deviation was in the range of 0.02 to 0.07 with percent error in the range of 0.7 to $2.2 \%$. From tables F1, F2, F3 and F4, the standard deviation range for the biobutanol concentration profiles for $C b C t$ fused and $C b C t$ co-culture were in the range of 0 to 0.1 and 0 to 0.07 with percent RSD in the range of 0 to $17 \%$ and 0 to $14 \%$, respectively. For $C b C t T s$ fused and $C b C t T s$ co-cultured, the standard deviation was in the range of 0 to 0.2 and 0 to 0.07 with the percent RSD in the range of 0 to $12.5 \%$ and 0 to $12 \%$, respectively. To calculate standard deviation and \%RSD, Equations 3.3 and 3.4 were used respectively. 
STDEV $=\sqrt{\sum \frac{(x-\bar{x})^{2}}{(n-1)}}$

where,

STDEV = standard deviation;

$x=$ data point;

$\bar{x}=$ sample mean value; and,

$n=$ sample size.

$R S D(\%)=\frac{S T D E V}{\bar{x}} \times 100$

where,

$R S D(\%)=$ percentage of error. 


\section{CHAPTER 4}

\section{RESULTS AND DISCUSSION}

\subsection{Protoplast Formation and Cell Wall Regeneration of Wild Strains}

In order to compare the regeneration of the cell wall of each bacterial strain, protoplasts were diluted in PPM and plated at various concentrations on regeneration medium (see Section.3.2.3). The percentage of regenerated protoplasts was then quantified (Reilly and Rogers, 1987). Table 4.1 displays the regeneration after $24-48 \mathrm{~h}$ at $35^{\circ} \mathrm{C}$ and $45^{\circ} \mathrm{C}$ for the mesophilic and thermophilic bacteria (i.e., $\mathrm{Cb}$, $C t$ and $T s$ on agar plates).

Table 4.1. Regeneration of $C$. beijerinckii, C. thermocellum and T. saccharolyticum (CFU/mL).

\begin{tabular}{|c|c|c|c|c|}
\hline $\begin{array}{c}\text { Bacterial } \\
\text { strains }\end{array}$ & $\begin{array}{c}\text { Cells }^{\mathrm{a}} \\
(\mathrm{CFU} / \mathrm{mL})\end{array}$ & $\begin{array}{c}\text { Regenerated protoplasts } \\
\text { (CFU/mL) }\end{array}$ & $\begin{array}{c}\text { Non-protoplasted units } \\
\text { (CFU/mL) }\end{array}$ & $\begin{array}{c}\text { Percent } \\
\text { regeneration }^{d}\end{array}$ \\
\hline $\mathrm{Cb}$ & $7.5 \times 10^{6}$ & $2.3 \times 10^{6}$ & $1.2 \times 10^{6}$ & 14.6 \\
\hline$C t$ & $6.4 \times 10^{6}$ & $1 \times 10^{6}$ & $6.5 \times 10^{5}$ & 5.4 \\
\hline$T s$ & $8.1 \times 10^{6}$ & $2 \times 10^{6}$ & $1.1 \times 10^{6}$ & 11.1 \\
\hline
\end{tabular}

${ }^{a}$ cells were grown in CBM prior to protoplast formation. It was determined from a viable cell count on agar plates after $48 \mathrm{~h}$ at $35^{\circ} \mathrm{C}$ and $45^{\circ} \mathrm{C}$.

${ }^{\mathrm{b}}$ protoplasts were formed in PPM by lysozyme treatment $(2.5 \mathrm{mg} / \mathrm{mL})$ for $60 \mathrm{~min}$, centrifuged, suspended in PPM and plated on RM. was determined after $48 \mathrm{~h}$ at $35^{\circ} \mathrm{C}$ and $45^{\circ} \mathrm{C}$.

${ }^{c}$ Non-protoplasted units were determined from a viable cell count of the protoplast suspension after dilution in CBM to bring about osmotic lysis of protoplasts.

${ }^{\mathrm{d}}$ was calculated as described in Section 3.2.3 
From Table 4.1, it can be seen that the highest percentage of regenerated protoplasts after lysozyme treatment was observed with $C b$, while the lowest was observed with $C t$. Previous studies showed that the regular regeneration frequencies were at the range of $8-25 \%$, which is in agreement with the results of regeneration frequencies obtained in the current study. Reilly and Rogers (1987) demonstrated that $\mathrm{Ca}^{2+}$ and $\mathrm{Mg}^{2+}$ in the PPM could affect subsequent protoplast regeneration during protoplast formation. The required amount of both $\mathrm{Ca}^{2+}$ and $\mathrm{Mg}^{2+}$ for maximum regeneration seems to be at concentrations over $25 \mathrm{mM}$. They concluded that concentrations of $\mathrm{Ca}^{2+}$ at the range of $10 \mathrm{mM}$ or below in the PPM would have resulted in little or no regeneration of the protoplasts. Therefore, $\mathrm{CaCl}_{2}$ and $\mathrm{MgCl}_{2}$ were added to PPM medium in the present study at the concentrations of $50 \mathrm{mM}$ to get the highest regeneration frequencies.

\subsection{Results of the Genetic Stability Test of $C b C t$ and $C b C t T s$ Fused Strains}

As previously described, the stability of the fused strains was examined by PCR reactions and the agarose gel electrophoresis method on ten consecutive growth cycles. The electrophoresis results for all growth cycles of $C b C t$ fused strains are shown in Figure 4.1. In this figure, G1 represents the first growth cycle or parent fusion, G2, G3, G4 and G5 represent the second, third, fourth, and fifth growth cycles, respectively. In order to ensure long-term stability of the fused strain, the tenth growth cycle was analyzed as G10. As shown in Table 3.1, the biomarker control genes that were chosen for all growth cycles of $C b C t$ fused strains were: $\beta$-glucosidase A gene (bglA) and aldehyde dehydrogenase gene $(a l d)$, from the wild strains of $C t$ and $C b$, respectively. As shown in Figure 4.1, for all growth cycles of $C b C t$ fused strains, the DNA fragments from the PCR are transferred to the negative end of the electrophoresis chamber to obtain the DNA profile. Since they have different molecular weights, they move down the gel at different speeds. Usually the shortest DNA molecule moves the farthest. For instance, in the current study the ald gene travelled farther than $b g l A$ gene (Figure 4.1). It should be noted that the presence of the biomarker control genes in all growth cycles 
confirms the existence of genes from both wild strains in the fused strains. It also tells us the quantity of genetic information transferred to the fused strains through the protoplast fusion technique. For instance, as it can be found in Figure 4.1, in the second growth cycle (G2) the ald gene is less visible, which can led to lower ABE productivity. It should be also mentioned that the strong expression of both biomarker genes in G10 confirms that the protoplast fusion was both successful and stable over the long-term. Therefore, in the present study, the tenth generation of the $C b C t$ fused strain was picked to examine the production of solvents through the SSF process.

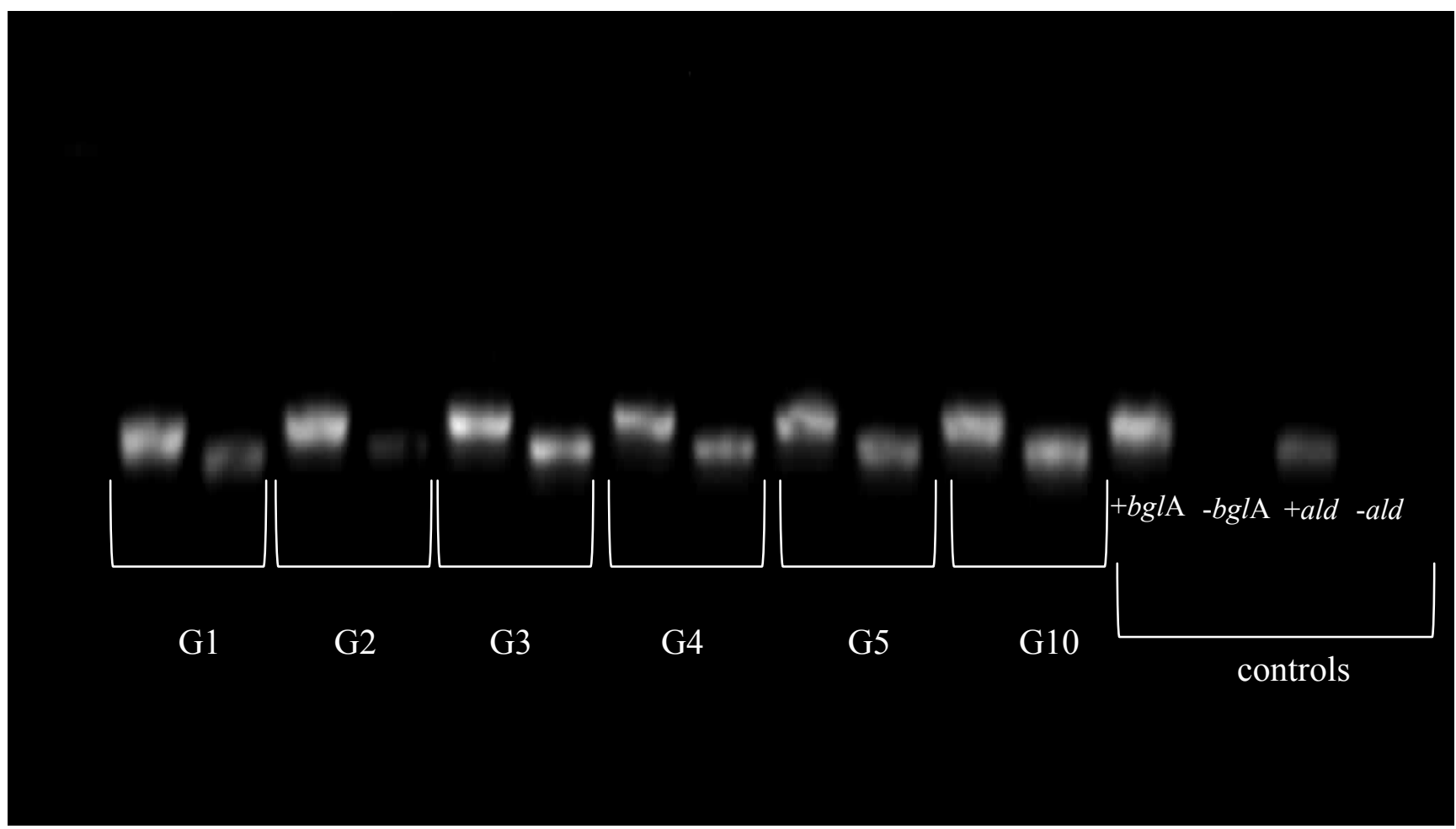

Figure 4.1. Agarose gel electrophorosis of PCR products for biomarkers. From left: generations 1 to 5 and 10 (G1-G5 and G10); first band (solid line) and second band (dotted line) are bglA and ald gene, respectively, representing $C t$ and $C b$, positive and negative controls as designated.

A similar analysis was performed for $C b C t T s$ fusant strains. Figure 4.2 A shows both biomarker gene products for $b g l A$ and $x y l B$ of $C t$ and $T s$, respectively. Results show that the fusant $C b C t T s$ did not appear to be genetically stable. The ald gene biomarker product was the only product detected within 
the first two generations of growth, indicating the detectable presence of $\mathrm{Cb}$. Controls showing the presence and absence of biomarkers in corresponding bacterial species can be seen in Figure 4.2 B. This instability in $C b C t T s$ fused strains can be attributed to several factors. First, the fusion represents a homologous crossover between the genome of each species involved as long as each protoplast was successfully established. It does not ensure that large or whole portions of the genome will crossover because the process is random in the sense that it depends on what portions of the genome are homologous and where. One should also consider the variability in the species and the species metabolism; these differences can cause less homology in areas perhaps where the biomarkers were chosen. The biomarker genes are designed specifically for each strain; thus they were chosen regarding genes involved in the specific metabolism for each strain, resulting in lower genetic detection if there is not enough homology.

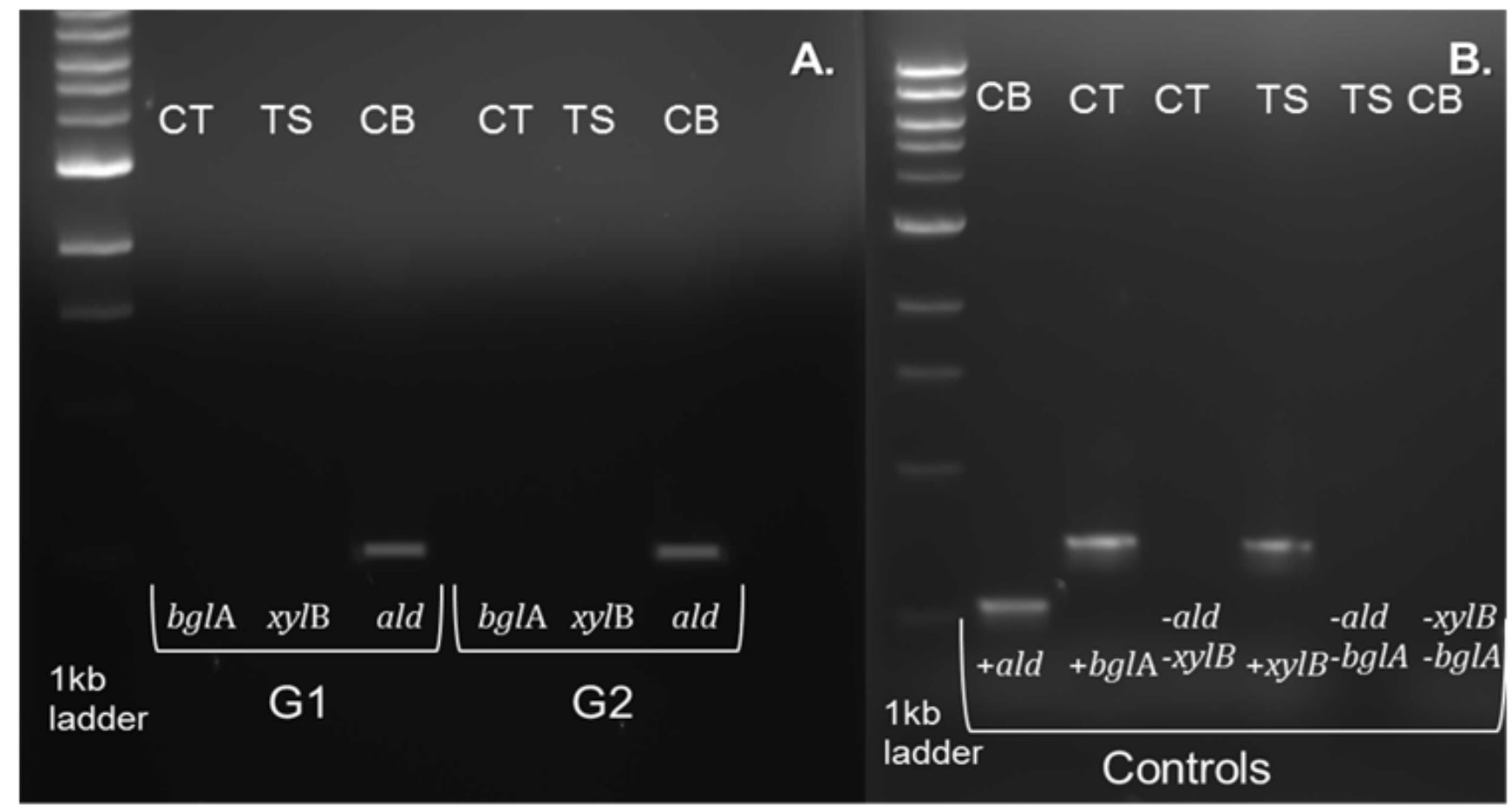

Figure 4.2. A) Agarose gel electrophoresis of PCR products for biomarkers. From left: Generations 1 and 2 (G1, G2); third band in each generation: ald, respectively, representing $C$. beijerinckii. B) Positive (band present) and negative controls (no bands) for the presence/absence of biomarkers in each corresponding strain as labeled. 
Since the HPLC results report enhanced biobutanol production, it may be of interest in the future to identify the specific genetic changes to this strain. It could be the result of just one or two genes crossing over from one or both strains $(C t$ and $T s)$. The downside is to determine the changes which requires a much larger effort. One would have to sequence specific areas of the genome including cofactors, regulators, and genes involved in the metabolism, which are related to butanol production. However, these factors are not the only ones that can result in increased butanol production; perhaps physiological changes in the growth conditions or tolerance to environmental stresses of C. beijerinckii were improved. Ideally, one would have to sequence the whole genome if it is a truly good strain, and then compare the genome sequence fraction-by-fraction to that of the wild-type to identify changes (new genes, mutations), which is a very daunting task.

\subsection{Production of ABE Solvents}

\subsubsection{CbCt fused versus CbCt co-culture strains}

In the first part of the experiments, SSF was performed using $C b C t$ fused strains. Table 4.2 shows the final concentration of $\mathrm{ABE}$, as well as the acid production obtained for both fused and coculture strains. As shown in Table 4.2, $C b C t$ fused were able to produce $23 \mathrm{~g} / \mathrm{L}$ of total ABE and 13.82

$\mathrm{g} / \mathrm{L}$ of biobutanol at $45^{\circ} \mathrm{C}$. However, their corresponding co-culture strains produced only $9.52 \mathrm{~g} / \mathrm{L}$ of total $\mathrm{ABE}$ and $5.79 \mathrm{~g} / \mathrm{L}$. According to the previous study done by Parekh et al. (1999), using the same $C b$ strain (BA101) has produced equivalent amounts of ABE solvents (i.e., $24 \mathrm{~g} / \mathrm{L}$ ) at a pilot plant scale using a corn steep water medium. In the current study, a total solvent concentration of $23 \mathrm{~g} / \mathrm{L}$ was obtained from the $C b C t$ fusant at a laboratory scale. This demonstrates a high potential to enhance production of biofuel by utilizing the fused strains at industrial scale. 
Table 4.2. ABE and acid concentrations for all fused and co-cultured strains during SSF.

\begin{tabular}{|c|c|c|c|c|c|}
\hline \multirow{2}{*}{ Fused and Co-culture strains } & \multicolumn{3}{|c|}{ ABE (g/L) } & \multicolumn{2}{|c|}{ Acids (g/L) } \\
\hline & Acetone & Butanol & Ethanol & Acetic acid & Butyric acid \\
\hline$C b C t$ (fused) at $45^{\circ} \mathrm{C}$ & 6.89 & 13.82 & 2.29 & 1.75 & 0.87 \\
\hline CbCt (Co-culture) at $35^{\circ} \mathrm{C}$ & 2.77 & 5.79 & 0.96 & 2.21 & 1.17 \\
\hline CbCtTs (fused) at $45^{\circ} \mathrm{C}$ & 6.44 & 12.80 & 4.69 & 1.82 & 0.95 \\
\hline CbCtTs (Co-culture) at $35^{\circ} \mathrm{C}$ & 3.84 & 6.25 & 1.95 & 2.46 & 1.30 \\
\hline
\end{tabular}

Previous studies reported equivalent butanol production of $13 \mathrm{~g} / \mathrm{L}$ and $15.8 \mathrm{~g} / \mathrm{L}$ that were obtained with glucose and corn as the main substrates (Qureshi et al., 2008a and Ezeji et al., 2004). WS that was used in the present study as the substrate is an agricultural waste rather than a food source, which highlights the importance of the proposed work. Figure 4.3 shows the ABE concentration profile during fermentation using $\mathrm{CbCt}$ fused strains.

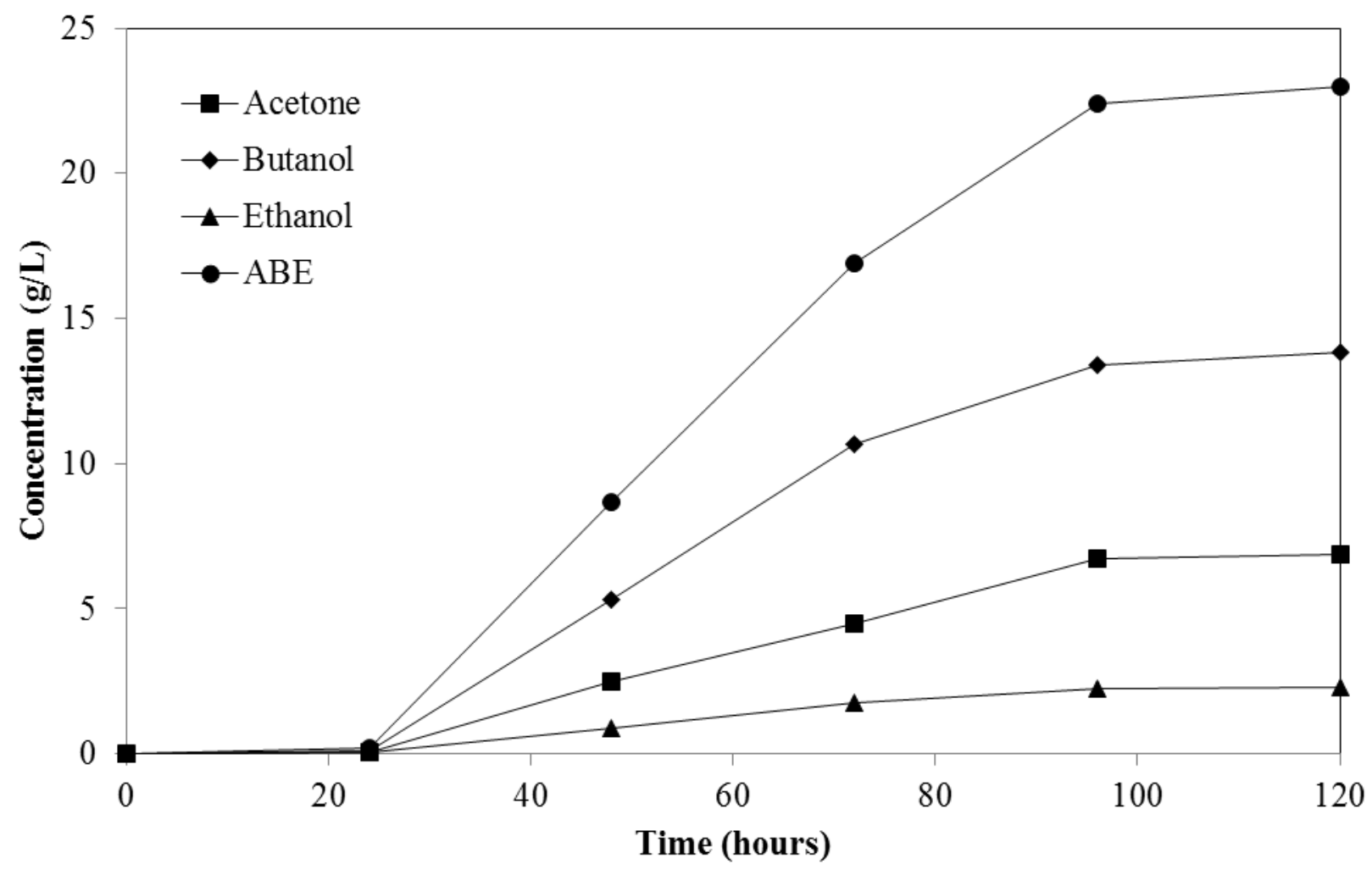

Figure 4.3. ABE concentration profile during SSF using $C b C t$ fused strains at $45^{\circ} \mathrm{C}$ (Average RSD: $0.6 \%$ ). 
Figure 4.3 shows that after 120 hours of SSF, the $C b C t$ fused strain produced $23 \mathrm{~g} / \mathrm{L}$ of total ABE by consuming $36.01 \mathrm{~g} / \mathrm{L}$ of sugars. From Figure 4.3 it can be also concluded that between $24 \mathrm{~h}$ and $96 \mathrm{~h}$ the production of solvents was most predominant with the production of $6.75 \mathrm{~g} / \mathrm{L}, 13.42 \mathrm{~g} / \mathrm{L}$, and 2.2 $\mathrm{g} / \mathrm{L}$ of acetone, butanol, and ethanol, respectively. During the next $24 \mathrm{~h}$ of fermentation, the total increase in solvent concentration was about $4 \%$ from $22.02 \mathrm{~g} / \mathrm{L}$ to $23.00 \mathrm{~g} / \mathrm{L}$ at the end of fermentation.

As shown in Table 4.2, the concentrations of acetone, butanol and ethanol at the end of fermentation were $6.89 \mathrm{~g} / \mathrm{L}, 13.82 \mathrm{~g} / \mathrm{L}$ and $2.2 \mathrm{~g} / \mathrm{L}$, respectively. Considering the concentration of butanol from Figure 4.3, it can be observed that between $24 \mathrm{~h}$ and $96 \mathrm{~h}$, it almost reached its maximum concentration of about $13.42 \mathrm{~g} / \mathrm{L}$. After this time, the total increase in butanol concentration was about $2.75 \%$ from $13.42 \mathrm{~g} / \mathrm{L}$ to $13.82 \mathrm{~g} / \mathrm{L}$ at the end of fermentation.

Apparently, the fused strain showed a strong tolerance level to butanol toxicity. This confirms that the protoplast fusion technique has created strains with a higher level of tolerance to butanol toxicity that has led to enhanced butanol production of around $14 \mathrm{~g} / \mathrm{L}$. It should be also mentioned that this novel strain experienced butanol toxicity after $96 \mathrm{~h}$ as could be seen in Figure 4.3. However, acetone and ethanol were not considered as toxic solvents to bacterial cells in the current study since their concentrations were not more than $10 \mathrm{~g} / \mathrm{L}$ (i.e., a level toxic to bacterial cells). Table 4.3 displays the total sugars consumed by both co-culture and fused strains during SSF. It also shows the average bacterial cell proliferation rate for all strains. 
Table 4.3. Concentration of sugar consumption and average cell proliferation rate for all strains.

\begin{tabular}{|c|c|c|}
\hline Fused and Co-culture strains & Total sugars consumed (g/L) & $\begin{array}{c}\text { Average cell Proliferation rate } \\
\mathbf{( 1 0} \mathbf{5} \text { cells/mLh) }\end{array}$ \\
\hline $\boldsymbol{C b C t}$ (fused) & 36.01 & 3.85 \\
\hline $\boldsymbol{C b C t}$ (Co-culture) & 25.26 & 3.66 \\
\hline $\boldsymbol{C b C t T s}$ (fused) & 38.3 & 4.02 \\
\hline $\boldsymbol{C b C t} \boldsymbol{T}$ (Co-culture) & 27.24 & 3.36 \\
\hline
\end{tabular}

The co-culture strains corresponding to the fused ones were examined for $\mathrm{ABE}$ production at $35^{\circ} \mathrm{C}$ and $45^{\circ} \mathrm{C}$. Figure 4.4 shows the ABE concentration profile during SSF using $C b C t$ co-culture strains at $35^{\circ} \mathrm{C}$. As can be observed from this figure, $C b C t$ co-culture strains produced $2.77 \mathrm{~g} / \mathrm{L}$ of acetone, 5.8 $\mathrm{g} / \mathrm{L}$ of butanol, and $0.96 \mathrm{~g} / \mathrm{L}$ of ethanol at the end of fermentation. Previous studies done on this method reported about $2 \mathrm{~g} / \mathrm{L}$ of butanol using crystalline cellulose as the main substrate (Nakayama et al., 2011). However, in the current study, a concentration of $5.8 \mathrm{~g} / \mathrm{L}$ was obtained from WS substrate using the $C b C t$ co-culture strain. It should be also noted that none of the solvents produced in the coculture experiment had toxic effects on bacterial cells since they were far below the toxic range of the cell cultures. 


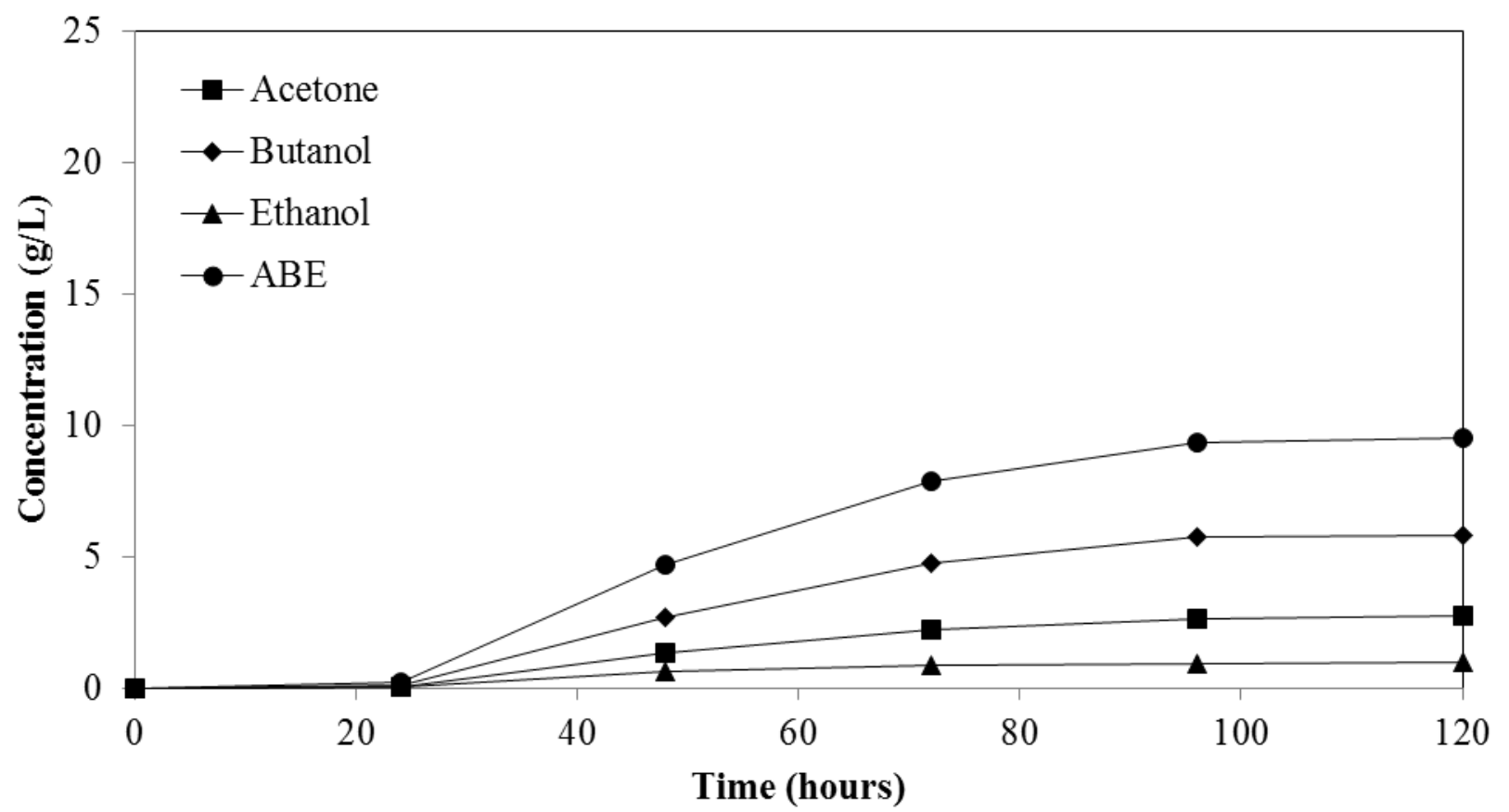

Figure 4.4. ABE concentration profile during SSF using $\mathrm{CbCt}$ co-culture strains at $35^{\circ} \mathrm{C}$ (Average RSD: $0.9 \%)$.

Comparing the results of solvents produced using co-culture strains to that of the fused strain, one might conclude that $C b C t$ fused strains were able to produce around $139 \%$ more butanol than the butanol produced by $C b C t$ co-culture strains at the end of fermentation. It should be also considered that the co-culture strains were not able to produce butanol at $45^{\circ} \mathrm{C}$. However, insignificant amounts of ethanol were produced from $C t$ as an ethanogenic bacterium. The reason is that $C b$, which is a butanol producing bacterium, is not a thermophilic strain and thus, is not effective at a high temperature of about $45^{\circ} \mathrm{C}$.

\subsubsection{CbCtTs fused versus CbCtTs co-culture strains}

In the second part of the experiments, the $\mathrm{ABE}$ concentration profile during SSF was determined for both $C b C t T s$ fused and $C b C t T s$ co-culture strains. As previously described, $T$. saccharolyticum is a thermophilic anaerobic bacterium which is able to directly metabolise 
hemicellulose and xylan polymers, as well as cellobiose and other primary sugars (Joe Shaw et al., 2008). Therefore, in the current study the two thermophilic strains were fused with one mesophilic butanol producing strain to increase the thermal stability of the entire system during SSF, and to breakdown longer sugar chains.

From Table 4.2, it can be concluded that the final butanol concentration achieved from $C b C t T s$ fused strain is comparable to previous studies done on butanol production using $C b$ as the butanol producing strain. One study by Qureshi et al. (2008) reached a butanol production level at the range of $13.00 \mathrm{~g} / \mathrm{L}$ from glucose during SSF using C. beijerinckii whereas, in the current study $12.80 \mathrm{~g} / \mathrm{L}$ of butanol were obtained from wheat straw as the substrate. Another study that applied SSF and gas stripping for butanol removal from the system showed butanol production of up to $12.70 \mathrm{~g} / \mathrm{L}$ (Qureshi et al., 2007). However, the fused strains in the present study produced almost the same butanol concentrations without employing gas stripping or other butanol removal methods. The total ABE produced in the current study was about $23.94 \mathrm{~g} / \mathrm{L}$ for $C b C t T s$ fused strains, which is relatively high, compared to previous studies.

The concentration of furfural as an inhibitor during the SSF was also measured in this study. It was at the range of 0.01 to $0.03 \mathrm{~g} / \mathrm{L}$ for all strains, which is considerably less than the inhibitory amount of 1 $\mathrm{g} / \mathrm{L}$ (Modig et al., 2002). Therefore, in this study the negative effects of furfural on the fermentation process were neglected. From Table 4.2, it can be also seen that CbCtTs co-culture strains produced about $12.04 \mathrm{~g} / \mathrm{L}$ of total $\mathrm{ABE}$ and $6.25 \mathrm{~g} / \mathrm{L}$ of butanol at $35^{\circ} \mathrm{C}$, which is lower than the butanol produced by fused strains at $45^{\circ} \mathrm{C}$. This demonstrates that the optimum temperature for enzyme activity necessary for saccharification and fermentation is $45^{\circ} \mathrm{C}$ as indicated earlier. Figure 4.5 displays the concentration of ABE during SSF using CbCtTs fused strains. 


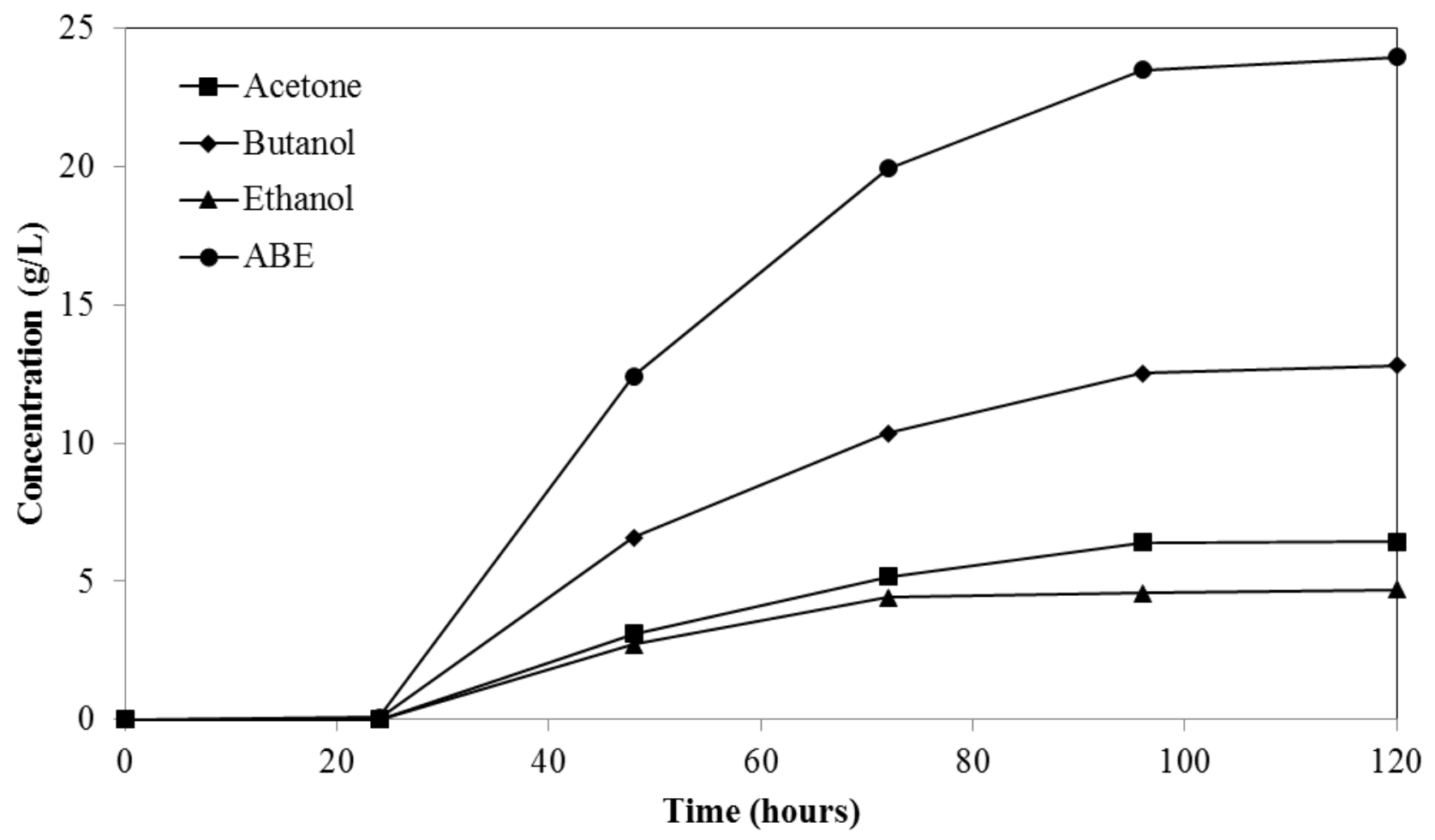

Figure 4.5. ABE concentration profile during SSF using $C b C t T s$ fused strains at $45^{\circ} \mathrm{C}$ (Average RSD: $0.29 \%)$.

Figure 4.5 shows that the $C b C t T s$ fused strains produced $23.94 \mathrm{~g} / \mathrm{L}$ of total ABE after 120 hours of SSF. It can be also observed that the production of solvents was most predominant between $24 \mathrm{~h}$ and $96 \mathrm{~h}$ with the production of $6.39 \mathrm{~g} / \mathrm{L}$ acetone, $12.52 \mathrm{~g} / \mathrm{L}$ butanol, and $4.57 \mathrm{~g} / \mathrm{L}$ ethanol during that time period.

The concentrations of individual solvents were also shown in Table 4.2. It shows the final concentrations of acetone, butanol, and ethanol at the end of fermentation, which were $6.44 \mathrm{~g} / \mathrm{L}, 12.80$ $\mathrm{g} / \mathrm{L}$ and $4.69 \mathrm{~g} / \mathrm{L}$, respectively. It should be also mentioned that solvent toxicity, which is a cause of concern, could be seen during the SSF. It can be observed that during the $96 \mathrm{~h}$ period the solvent reached a concentration of $23.48 \mathrm{~g} / \mathrm{L}$. However, during the next $24 \mathrm{~h}$, there was a small increase of 
about $2 \%$ in total ABE concentration from $23.48 \mathrm{~g} / \mathrm{L}$ to $23.94 \mathrm{~g} / \mathrm{L}$ due to solvent toxic effects on cell activity and metabolism.

As described above, butanol concentration at the range of $7-13 \mathrm{~g} / \mathrm{L}$ is extremely toxic to bacterial cells (Jones and Woods, 1986). According to this assumption, butanol toxicity could be the main factor behind the decrease in ABE production after $96 \mathrm{~h}$. This relative decrease was demonstrated by the increase of just $2.2 \%$ in butanol concentration from $12.52 \mathrm{~g} / \mathrm{L}$ at $96 \mathrm{~h}$ to $12.80 \mathrm{~g} / \mathrm{L}$ at the end of fermentation. However, it can be concluded that the genetic improvement of bacterial strains through protoplast fusion has resulted in novel strains with a higher butanol tolerance level followed by high butanol production at the range of $12.80 \mathrm{~g} / \mathrm{L}$, in the case of $C b C t T s$ fused strains. It should be also mentioned that acetone and ethanol concentrations in the current study did not contribute to solvent toxicity based on previous studies by Costa, J. M (1983) and Leung, J.C.Y (1981), in which the toxic level of acetone and ethanol on cell growth was $70 \mathrm{~g} / \mathrm{L}$ and 50 to $60 \mathrm{~g} / \mathrm{L}$, respectively. As shown in Table 4.3, the CbCtTs fused strains produced $23.94 \mathrm{~g} / \mathrm{L}$ of total ABE after 120 hours of SSF by consuming $38.3 \mathrm{~g} / \mathrm{L}$ of total sug

To understand the effectiveness of protoplast fusion, the co-culture method was also performed as a benchmark for $C b C t T s$ strains. In this method, solvent production from wheat straw during SSF was measured. As previously indicated, the main objective of co-culture is to compare the concentration of solvents produced by co-culture strains to that of fused strains. In the case of the co-culture strain, SSF was performed at two different temperatures, of $35^{\circ} \mathrm{C}$ and $45^{\circ} \mathrm{C}$. However, co-culture strains were not able to produce solvents at $45^{\circ} \mathrm{C}$, compared to certain production with the fusants.

Figure 4.6 displays the ABE concentration profile during SSF using $C b C t T s$ co-culture strains. Since $\mathrm{Cb}$ is a mesophilic strain that cannot tolerate temperatures higher than $35-37^{\circ} \mathrm{C}$, the $\mathrm{SSF}$ that was 
performed at the higher temperature did not produce any solvents. This method was performed to understand the effectiveness of genetically modified bacteria to produce solvents at a higher temperature.

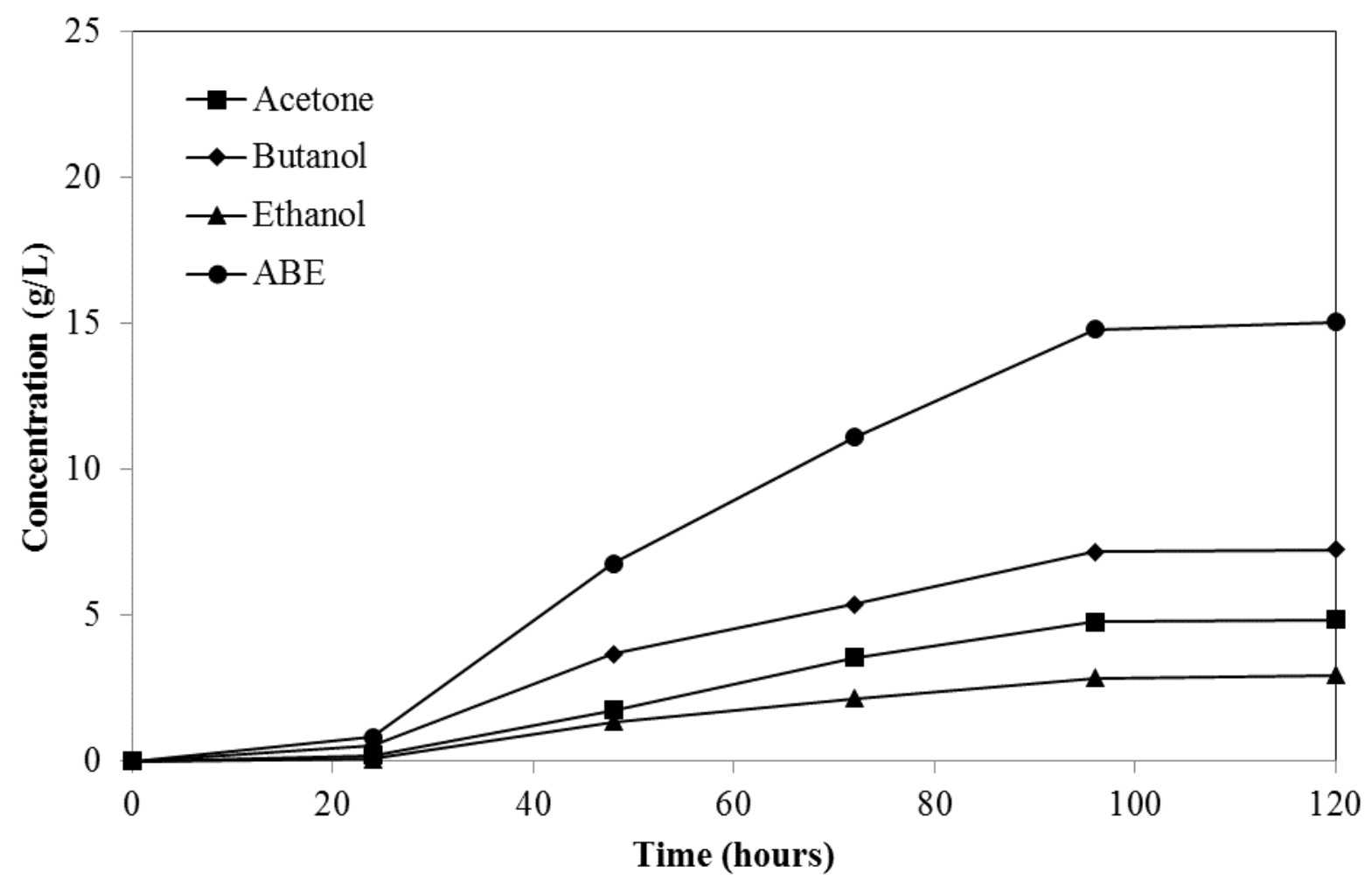

Figure 4.6. ABE concentration profile during SSF using $C b C t T s$ co-culture strains at $35^{\circ} \mathrm{C}$ (Average RSD: 0.24\%).

As seen in Figure 4.6, during the first $24 \mathrm{~h}$ of fermentation, there was not significant increase in the solvent concentration due to bacterial growth and enzymes produced for saccharification of polysaccharides into monomeric sugars. It was followed by a considerable increase in solvent production until the end of fermentation when the concentration of acetone, butanol and ethanol reached to $3.84,6.25$, and $1.95 \mathrm{~g} / \mathrm{L}$, respectively. It should be mentioned that since the butanol concentration was less than $7 \mathrm{~g} / \mathrm{L}$ after $120 \mathrm{~h}$, butanol toxicity does not seem to be a major concern 
regarding bacterial cells in this case. Acetone and ethanol concentrations were also not considered as toxic to the co-culture strains since their levels were far below the toxic range.

From Figure 4.6 it can be concluded that the $C b C t T s$ co-culture strains were able to produce lower amounts of solvents compared to their corresponding fused strains. Comparing the biobutanol concentrations, it can be observed that the CbCtTs fused strains were able to produce $104 \%$ more butanol than the $C b C t T s$ co-culture strains. As previously described, the SSF using co-culture strains was also performed at $45^{\circ} \mathrm{C}$. Results showed that $C b$ which is the butanol producing bacteria was not able to produce any biobutanol at that temperature. However, $C t$ and $T s$, which are the two thermophilic strains, were able to produce some amounts of ethanol at a high temperature.

\subsection{Production of Acids and $\mathrm{pH}$ Change}

Butyric acid and acetic acid were the two acids generated during SSF using the fused and coculture strains in the present study (Jin et al., 2011). As previously described these acids are produced during the acidogenic phase of the ABE metabolic pathway. From Table 4.2, it can be concluded that

the highest concentrations of acids were produced by using CbCtTs co-culture strain. This strain produced about $2.46 \mathrm{~g} / \mathrm{L}$ of acetic acid and $1.30 \mathrm{~g} / \mathrm{L}$ of butyric acid. It was followed by $C b C t$ co-culture strain that produced $2.21 \mathrm{~g} / \mathrm{L}$ of acetic acid and $1.17 \mathrm{~g} / \mathrm{L}$ of butyric acid. Therefore, co-culture strains produced more acids compared to fused strains.

Changes in $\mathrm{pH}$ were also measured during the experiments. Figure 4.7 shows the change in $\mathrm{pH}$ during SSF for all bacterial strains. As shown in this figure, the lowest level of $\mathrm{pH}$ of about 4.32 was obtained for $C b C t T s$ co-culture strains after $24 \mathrm{~h}$ of fermentation. The $\mathrm{pH}$ for $C b C t T s$ fused strains, which produced around $1.82 \mathrm{~g} / \mathrm{L}$ of acetic acid and $0.95 \mathrm{~g} / \mathrm{L}$ of butyric acid, dropped from 6.49 to around 4.50 for the first $24 \mathrm{~h}$ before increasing to 5.23 at $48 \mathrm{~h}$. In the case of $C b C t$ fused strains that produced about 
$1.75 \mathrm{~g} / \mathrm{L}$ of acetic acid and $0.87 \mathrm{~g} / \mathrm{L}$ of butyric acid, the $\mathrm{pH}$ dropped to 4.89 after $24 \mathrm{~h}$. However, for $C b C t$ co-culture strains the $\mathrm{pH}$ dropped to around 4.9 after 48 of fermentation. From Figure 4.7, it can be concluded that the reduction in $\mathrm{pH}$ at the beginning of fermentation is due to the production of acetic acid and butyric acid; while the following increase in $\mathrm{pH}$ can be attributed to the production of acetone, butanol and ethanol as solvents during the solventogenesis stage (Maddox et al., 1995).

It should be noticed that the $\mathrm{pH}$ of the system is considered a significant indicator of the biological synthetic process and major changes can inhibit the production of solvents (Maddox et al., 2000). Therefore, by monitoring the changes from the optimum $\mathrm{pH}$ during the fermentation and using the fused strains developed in the present study, there will be a chance to enhance biobutanol production.

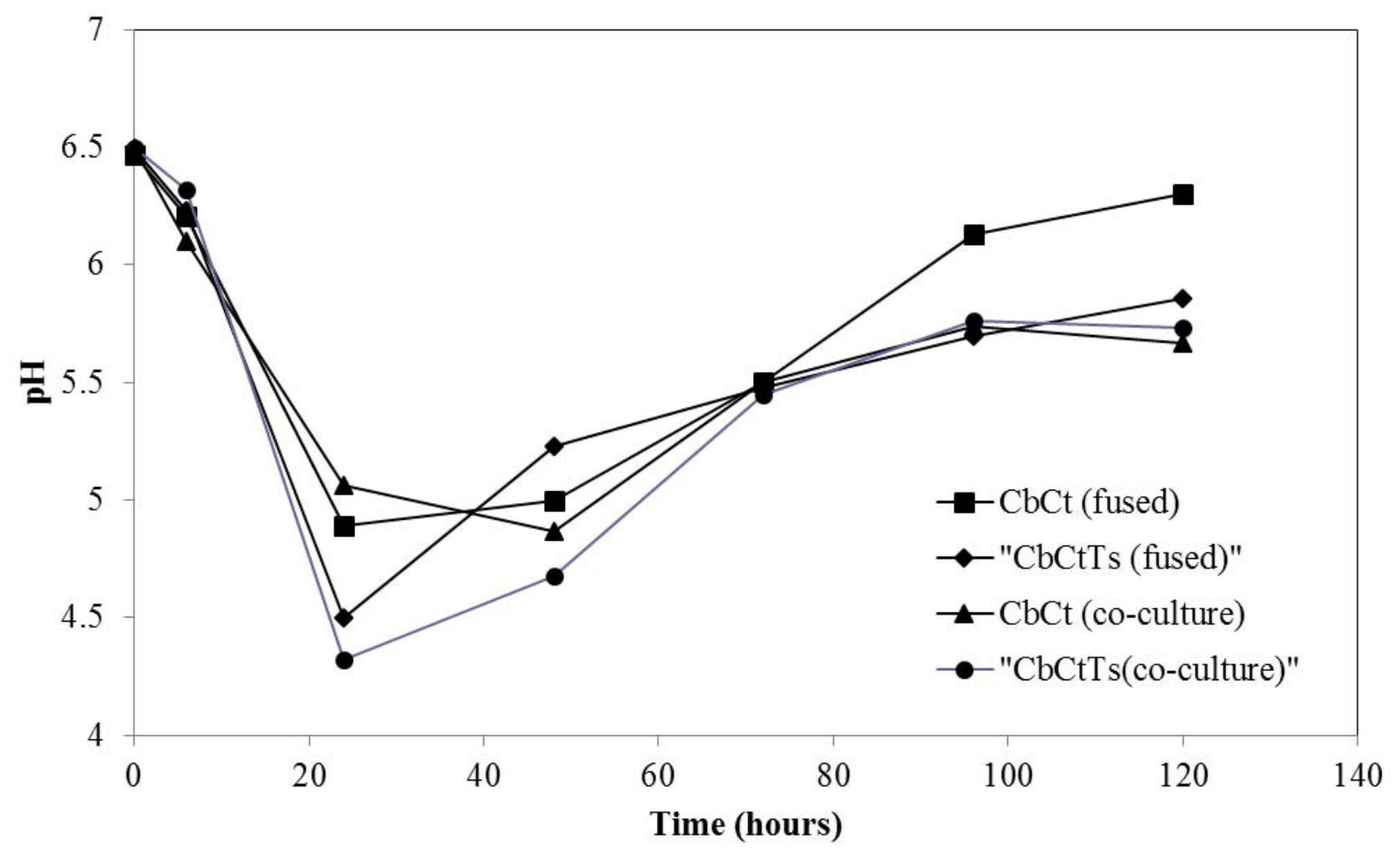

Figure 4.7. pH Changes during SSF for all fused and co-culture bacterial strains (Average RSD: $3.4 \%)$. 


\subsection{Sugars’ Concentrations Profiles during SSF}

\subsubsection{CbCt fused versus CbCt co-culture strains}

Table 4.4 shows the final concentrations of individual and total sugars during SSF of $C b C t$ fused strains.

Table 4.4. Individual and total sugars concentrations during SSF for $C b C t$ fused strains.

\begin{tabular}{|c|c|c|c|c|c|c|}
\hline Time (h) & Glucose (g/L) & Xylose (g/L) & Arabinose (g/L) & Mannose (g/L) & Galactose (g/L) & Total sugar (g/L) \\
\hline 0 & 16 & 10 & 1.5 & 0.1 & 2.2 & 29.8 \\
\hline 24 & 23.5 & 13.76 & 2.85 & 1.4 & 1.65 & 43.16 \\
\hline 48 & 9.31 & 8.31 & 2.42 & 1.24 & 1.54 & 22.82 \\
\hline 72 & 2.41 & 6.73 & 0.76 & 0.54 & 1.46 & 11.9 \\
\hline 96 & 0.85 & 6.18 & 0.036 & 0.032 & 1.41 & 8.508 \\
\hline 120 & 0.52 & 5.76 & 0 & 0 & 0.87 & 7.15 \\
\hline
\end{tabular}

The results in Table 4.4 show that the total sugars consumed with $C b C t$ fused was $36.01 \mathrm{~g} / \mathrm{L}$, while it was $25.26 \mathrm{~g} / \mathrm{L}$ for $C b C t$ co-culture strains. A similar result can be seen for $C b C t T s$ fused and co-culture strains. According to these results, the two fused strains ( $C b C t$ and $C b C t T s)$ consumed more sugars compared to the sugar consumed by their corresponding co-culture strains. This eventually led to higher solvent production from fused strains compared to that of co-culture strains. Figure 4.8 displays the amount of remaining sugars including glucose, xylose, galactose, arabinose, and mannose at the end of the fermentation process in the system using $\mathrm{CbCt}$ fused strains. 


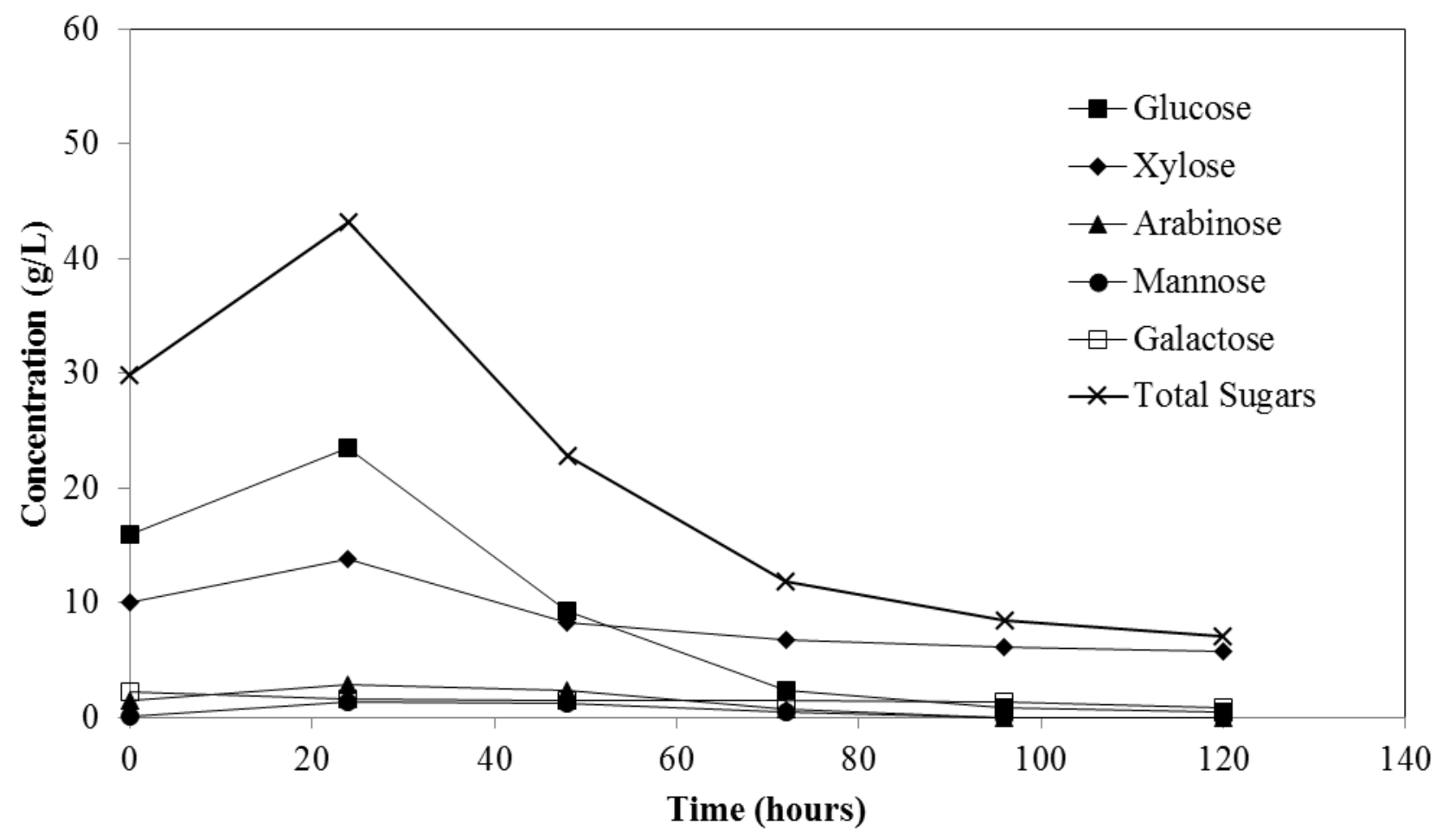

Figure 4.8. Individual sugar's concentrations with respect to total sugars during SSF for $\mathrm{CbCt}$ fused strains (Average RSD: 1.65\%).

Examining this Figure shows that the sugar concentrations increased in the first $24 \mathrm{~h}$ of fermentation. The increase in the total sugar is the result of saccharification of polysaccharides into monomers like glucose, xylose, mannose, galactose and arabinose by action of the enzymes released from the fused strains. This can obviously be observed for glucose, xylose, and arabinose, while the increase in the concentration of galactose and mannose was relatively minor. Concentrations of individual and total sugars during SSF are also shown in table 4.4 for the same strains.

As indicated in Table 4.4, the total sugar consumption for $C b C t$ fused strains was $36.01 \mathrm{~g} / \mathrm{L}$, which is higher than the amount of sugars consumed in previous studies done using only $C b$ as the fermentative bacteria (Liu et al., 2010). This shows that the fused strains have the potential to consume more sugars 
compared to their wild strains. From Figure 4.8, it can be concluded that $C b C t$ fused strains were able to consume more sugars compared to their corresponding co-culture strains. Therefore fewer sugars remained in the system at the end of fermentation for $C b C t$ fused strains.

As shown in Figure 4.8, arabinose and mannose were completely consumed at the end of fermentation. It should be also mentioned that during the first 24 hours of fermentation, the concentration of sugars increased by around $44 \%$ in the system. This is attributable to the hydrolysis enzymes released from the bacteria, which leads to breaking the polysaccharides into monomeric sugars in the system. Compared to $C t, C b$ is a bacterium that is more capable of breaking down pentose sugars such as xylose. Therefore, as shown in Table 4.4, there was a steady decline in the xylose concentration from $13.76 \mathrm{~g} / \mathrm{L}$ to $5.76 \mathrm{~g} / \mathrm{L}$ at the end of fermentation; however, the glucose concentration declined more rapidly (from $23.5 \mathrm{~g} / \mathrm{L}$ at $24 \mathrm{~h}$ to $0.52 \mathrm{~g} / \mathrm{L}$ at $120 \mathrm{~h})$ due to its consumption by the two bacteria $(C b$ and $C t)$, which are able to consume both pentose and hexose sugars. Table 4.4 displays the amount of individual and total sugars remained during the fermentation process. From this table, it can be concluded that pentose sugars such as xylose were not completely consumed at the end of fermentation. However, six carbon sugars like glucose were mostly consumed, and very small amounts $(0.52 \mathrm{~g} / \mathrm{L})$ remained in the system. This suggests that the $C b C t$ fused strains preferred to consume glucose compared to other monomeric sugars. Other hemicellulose derived sugars such as arabinose and mannose were totally consumed.

As indicated before, the same process was applied for $C b C t$ co-culture strains. Figure 4.9 shows the amounts of individual and total sugars remaining in the system using $C b C t$ co-culture strains. Compared to $C b C t$ fused strains, the amount of total sugar that remained in the system at the end of fermentation using $C b C t$ co-culture strains doubled that of the fused strains. As can be seen in Table 4.5, during the saccharification, the total sugar concentration released into the system was $40.71 \mathrm{~g} / \mathrm{L}$. However, at the end of fermentation, the amount of total sugars that remained in the system was 15.45 
$\mathrm{g} / \mathrm{L}$ (glucose $5.1 \mathrm{~g} / \mathrm{L}$, xylose $8.35 \mathrm{~g} / \mathrm{L}$ ), which can indicate the amount of sugar consumed by the coculture strains. It should be also mentioned that arabinose and mannose were completely consumed at the end of SSF.

Table 4.5. Individual and total sugars concentrations during SSF for $C b C t$ co-culture strains. Time (h) $\mid$ Glucose (g/L) Xylose (g/L)|Arabinose (g/L)|Mannose (g/L) $\mid$ Galactose (g/L) Total sugars (g/L)

\begin{tabular}{|c|c|c|c|c|c|c|}
\hline 0 & 16 & 10 & 1.5 & 0.1 & 2.2 & 29.8 \\
\hline 24 & 18.65 & 12.2 & 5.2 & 2.1 & 2.56 & 40.71 \\
\hline 48 & 13.75 & 9.53 & 2.58 & 1.03 & 2.287 & 29.177 \\
\hline 72 & 7.39 & 8.84 & 0.65 & 0.32 & 2.15 & 19.35 \\
\hline 96 & 5.18 & 8.48 & 0 & 0 & 2.1 & 15.76 \\
\hline 120 & 5.1 & 8.35 & 0 & 0 & 2 & 15.45 \\
\hline
\end{tabular}

It can be also concluded from Table 4.5 that $C b C t$ co-culture strains preferred to consume glucose than hemicellulose derived sugars, such as xylose. Therefore, a considerable decrease in the glucose concentration can be seen at the end of the fermentation process (from $18.65 \mathrm{~g} / \mathrm{L}$ at $24 \mathrm{~h}$ to $5.1 \mathrm{~g} / \mathrm{L}$ at 120h). However, lesser amounts of pentose sugars such as xylose were consumed during the fermentation process. 


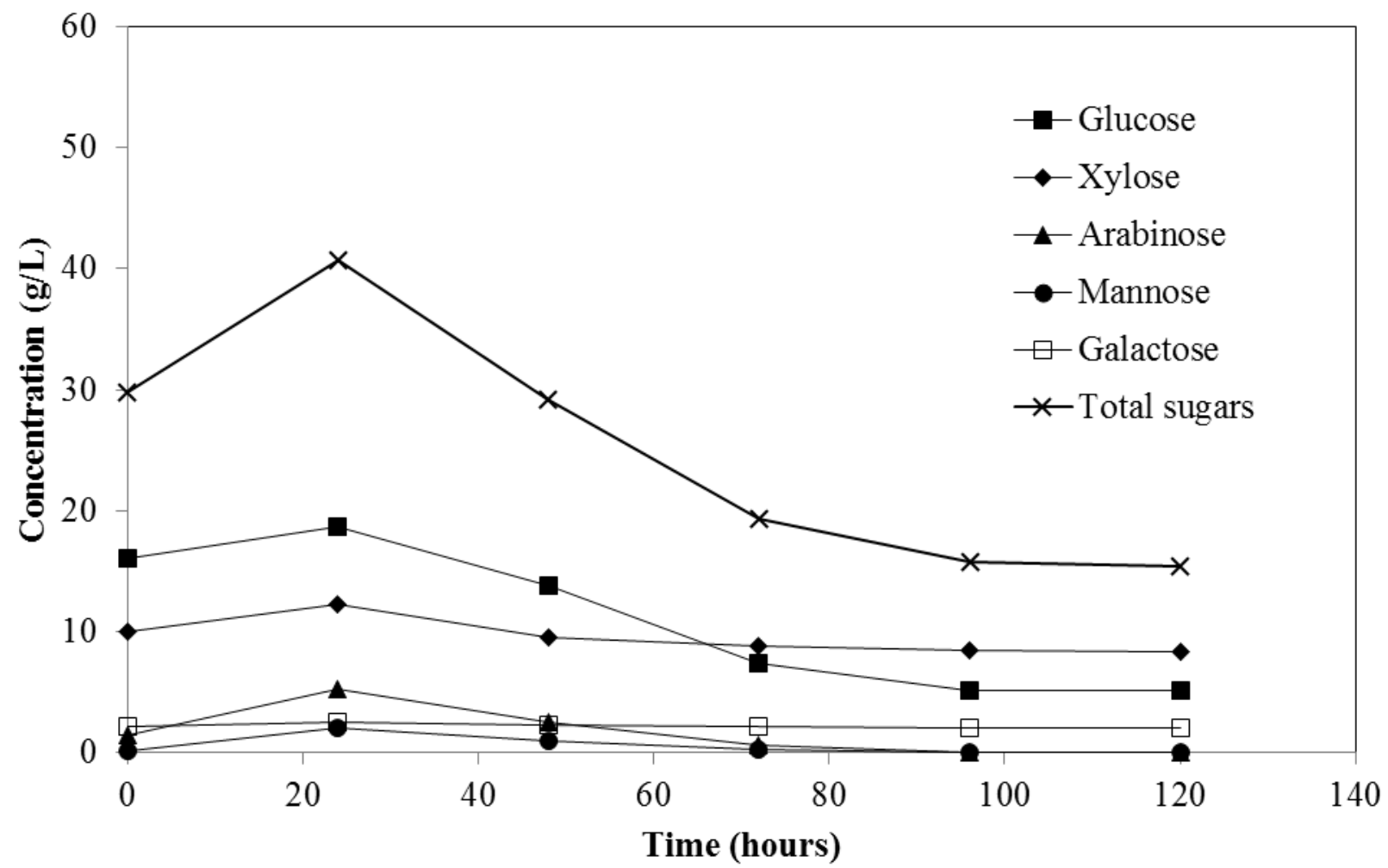

Figure 4.9. Individual sugar's concentrations with respect to total sugars during SSF for CbCt coculture strains (Average RSD: 1.3\%).

\subsubsection{CbCtTs fused versus CbCtTs co-culture strains}

As described above, the SSF process was also applied to the three fused bacteria (CbCtTs). Sugar consumption was measured for the mentioned fused strains as well. Figure 4.10 shows the changes in the amounts of individual sugar concentrations, such as glucose, xylose, arabinose, mannose, and galactose, during SSF. It also displays the total sugar concentration with respect to the initial concentration of sugars at the beginning of fermentation. Table 4.6 shows the individual and total sugar concentrations during $120 \mathrm{~h}$ of fermentation for $C b C t T s$ fused strains. 
Table 4.6. Individual and total sugars concentrations during SSF for CbCtTs fused strains.

\begin{tabular}{|c|c|c|c|c|c|c|}
\hline Time (h) & Glucose (g/L) & Xylose (g/L) & Arabinose (g/L) & Mannose (g/L) & Galactose (g/L) & Total sugars (g/L) \\
\hline 0 & 15.42 & 9.75 & 1.45 & 0.093 & 2.12 & 28.84 \\
\hline 24 & 21.1 & 17.00 & 3.30 & 1.41 & 2.26 & 45.08 \\
\hline 48 & 12.38 & 5.52 & 2.28 & 1.38 & 1.64 & 23.21 \\
\hline 72 & 6.5 & 2.59 & 1.13 & 0.80 & 1.77 & 12.81 \\
\hline 96 & 3.43 & 2.14 & 0 & 0 & 1.43 & 7.00 \\
\hline 120 & 3.24 & 2.11 & 0 & 0 & 1.42 & 6.78 \\
\hline
\end{tabular}

Similar to the previous cases, Figure 4.10 also shows that sugar concentrations increased during the first 24 hours of fermentation. This is simply due to the saccharification of cellulose and hemicellulose into monomers, such as glucose, xylose, mannose, arabinose, and galactose, by the action of the enzymes released from the fused strains. A higher increase in sugar concentration was mainly obtained by glucose and xylose compared to all other individual sugars. However the increases in arabinose and mannose concentrations were considerably lower as indicated in Table 4.6.

As shown in Figure 4.10, this increase in sugar concentrations was followed by a sharp decrease during the next days of fermentation due to the consumption of sugars and production of solvents. Table 4.6 indicates the concentration of total sugars reached $28.84 \mathrm{~g} / \mathrm{L}$ after pretreatment. However, after $24 \mathrm{~h}$, this concentration increased to around $45.00 \mathrm{~g} / \mathrm{L}$ as the result of hydrolysis enzymes produced by the three fused strains. As shown in Figure 4.10, within 24 hours of saccharification a $57 \%$ increase in sugar concentration was accounted for the $C b C t T s$ fused strains. It should be also noted that no external enzymes were added to the samples during SSF and that all enzymes were generated after inoculation with the fused strains, for both cases mentioned in the current study. As previously mentioned, $C t$ is a cellulolytic bacterium, capable of converting cellulose and cellobiose to glucose (Tsai et al., 2009). 


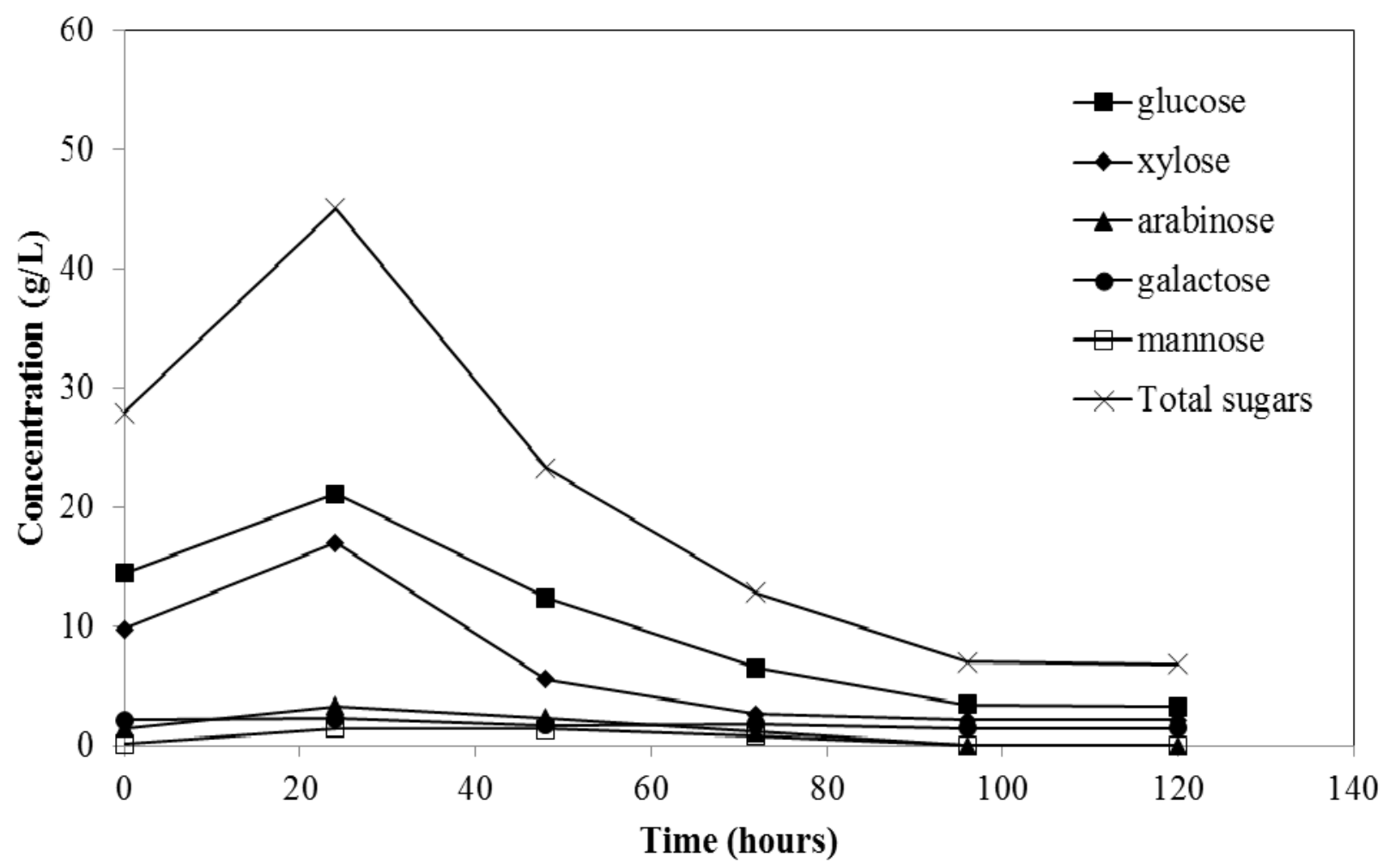

Figure 4.10. Individual sugar's concentrations with respect to total sugars during SSF for CbCtTs fused strains (Average RSD: 0.8\%).

Moreover, $T s$ that was used in the second part of the experiments, is also considered an anaerobic bacterium, able to directly ferment hemicellulose and xylan polymers, as well as primary sugars in cellulosic biomass (Joe Shaw et al., 2008). As previously shown in Table 4.2, CbCtTs fused strains produced $12.80 \mathrm{~g} / \mathrm{L}$ of butanol at the end of fermentation. Again, the resistance of the bacteria to butanol toxicity can be attributed to the ability of fused strains with higher levels of tolerance. From Figure 4.10, at the beginning of fermentation and after pretreatment, glucose formed $60 \%$ of the total sugars. The major consumption of both glucose and xylose can be seen between $24 \mathrm{~h}$ to $48 \mathrm{~h}$, where the glucose and xylose remaining in the system dropped from $21.1 \mathrm{~g} / \mathrm{L}$ to $12.38 \mathrm{~g} / \mathrm{L}$ and from $17 \mathrm{~g} / \mathrm{L}$ to $5.52 \mathrm{~g} / \mathrm{L}$, respectively. At the end of fermentation, only $3.24 \mathrm{~g} / \mathrm{L}$ of glucose and $2.11 \mathrm{~g} / \mathrm{L}$ of xylose remained. It can be also seen that compared to xylose, greater amounts of glucose were consumed 
during the $120 \mathrm{~h}$ using $C b C t T s$ strains. Thus, higher percentages of glucose during the first hours of fermentation inhibited consumption of xylose during the next hours.

However, $T s$ is a bacterium that is able to utilize five carbon sugars such as xylose. Therefore, compared to the previous case described in this study ( $C b C t$ fused), $C b C t T s$ fused strains were capable of using greater amounts of xylose during the $120 \mathrm{~h}$ of fermentation. It should be noted, however, that xylose was not consumed completely and about $2.11 \mathrm{~g} / \mathrm{L}$ remained in the system at the end of fermentation. Considering other sugars, it can clearly be seen that no traces of arabinose and mannose remained at the end of SSF and they were completely consumed; however, only asmall amount of galactose remained at the end of fermentation.

Figure 4.11 displays the changes in the concentrations of individual sugars, such as glucose, xylose, arabinose, mannose, and galactose, with respect to the initial concentration of total sugars at the beginning of SSF using $C b C t T s$ co-culture strains. From Figure 4.11, it can be concluded that after 120 $\mathrm{h}$ of fermentation, around $13.94 \mathrm{~g} / \mathrm{L}$ of total sugars remained in the system. As stated for $C b C t T s$ fused strains, in the case of $C b C t T s$ co-culture strains, glucose was consumed more rapidly compared to xylose, which shows the preferential consumption of glucose over xylose by the three co-culture strains. As a result, at the end of fermentation, the glucose remaining dropped from $15.52 \mathrm{~g} / \mathrm{L}$ to 7.1 $\mathrm{g} / \mathrm{L}$, where the xylose concentration decreased from $9.75 \mathrm{~g} / \mathrm{L}$ to $4.15 \mathrm{~g} / \mathrm{L}$. This shows that compared to glucose, lower percent of xylose was consumed by $C b C t T s$ co-culture strains. 


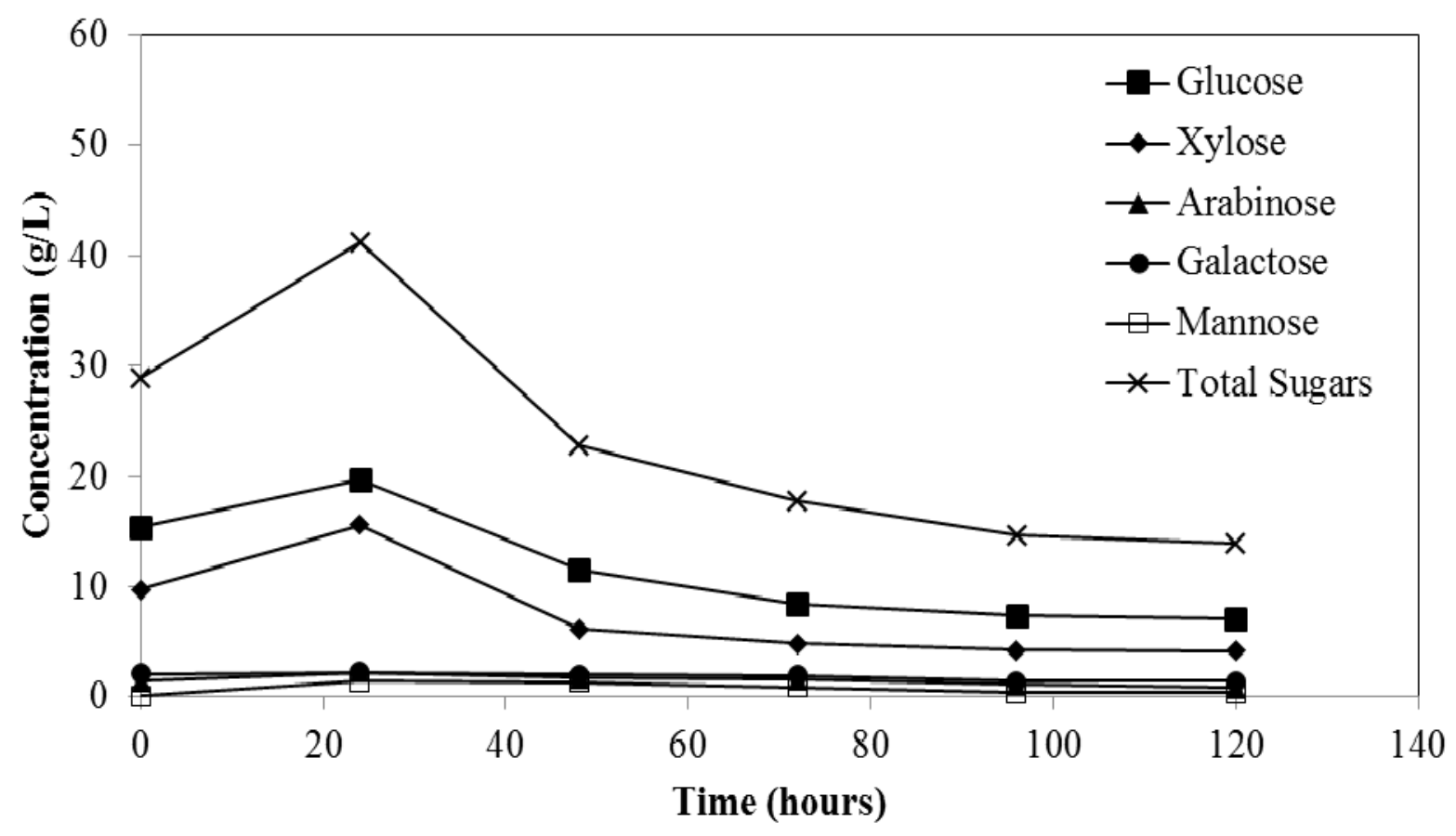

Figure 4.11. Individual sugar's concentrations with respect to total sugars during SSF for CbCtTs co-culture strains (Average RSD: 0.36\%).

Table 4.7 shows the corresponding concentrations of individual sugars with respect to total sugars using $C b C t T s$ co-culture strains during SSF. From Table 4.7, it can be seen that arabinose and mannose were almost consumed at the end of fermentation. However, about $7.1 \mathrm{~g} / \mathrm{L}$ glucose, $4.1 \mathrm{~g} / \mathrm{L}$ xylose, $1.43 \mathrm{~g} / \mathrm{L}$ galactose, and $13.94 \mathrm{~g} / \mathrm{L}$ of total sugars remained in the system. The amount of total sugars consumed for $C b C t T s$ co-culture strains was $27.24 \mathrm{~g} / \mathrm{L}$, which shows a decline of about $40 \%$ in sugar consumption compared to their corresponding fused strains. 
Table 4.7. Individual and total sugars concentrations during SSF for CbCtTs co-culture strains.

\begin{tabular}{|c|c|c|c|c|c|c|}
\hline Time (h) & Glucose (g/L) & Xylose (g/L) & Arabinose (g/L) & Mannose (g/L) & Galactose (g/L) & Total sugars (g/L) \\
\hline 0 & 15.42 & 9.75 & 1.45 & 0.093 & 2.12 & 28.84 \\
\hline 24 & 19.7 & 15.56 & 2.24 & 1.41 & 2.26 & 41.18 \\
\hline 48 & 11.55 & 6.16 & 1.72 & 1.39 & 2.04 & 22.88 \\
\hline 72 & 8.48 & 4.86 & 1.58 & 0.92 & 1.96 & 17.81 \\
\hline 96 & 7.35 & 4.25 & 1.17 & 0.42 & 1.43 & 14.63 \\
\hline 120 & 7.1 & 4.15 & 0.86 & 0.39 & 1.43 & 13.94 \\
\hline
\end{tabular}

\subsection{Bacterial Cell Growth during SSF}

Cell growth for both $C b C t$ and $C b C t T s$ fused and co-culture strains was measured during SSF. Several parameters contributed to bacterial cell growth, and Table 4.3 shows the average cell proliferation rate for all bacterial strains with respect to sugar consumption. From this table, it can be concluded that more bacterial cells tend to metabolise a greater amount of total sugars and produce more solvents. Figures 4.12 and 4.13 display the changes in cell concentration for both fused and coculture strains. During the first 6 hours all bacteria experienced a lag phase. In this phase the cell concentration remained almost constant because the strains were adjusting themselves to the medium, temperature, and $\mathrm{pH}$ levels. After this phase, a sharp increase in cell concentration can be seen, where the cells grew exponentially by feeding on the nutrients present in the culture medium and entering to the exponential phase. The exponential phase ended after $72-84 \mathrm{~h}$ when the cell concentration decreased slowly by entering the decay phase. This phase corresponds to the solventogenic phase in the SSF process, where butanol toxicity inhibits the cell growth.

As shown in Figure 4.12, an increase in cell concentration can be seen for $C b C t$ fused strains between $12 \mathrm{~h}$ and $60 \mathrm{~h}$, when the strains grew exponentially. It was followed by the stationary phase during the 
next $36 \mathrm{~h}$, when the cell concentration remained almost constant. As described before, $C b C t$ fused strains are capable of tolerating higher butanol concentrations of around $12.5 \mathrm{~g} / \mathrm{L}$. This can clearly be seen until $84 \mathrm{~h}$ when there was no decline in cell concentration. Moreover, this strain exhibited a wider stationary phase until $96 \mathrm{~h}$, in which the butanol concentration was less than $13.42 \mathrm{~g} / \mathrm{L}$. This was followed by a decay phase at $96 \mathrm{~h}$, when the cell concentration decreased slowly due to butanol toxicity at the range of $13.42 \mathrm{~g} / \mathrm{L}$. The corresponding $C b C t$ co-culture strains showed a growth phase between $12 \mathrm{~h}$ and $72 \mathrm{~h}$, when the butanol concentration reached around $4.76 \mathrm{~g} / \mathrm{L}$. Since the co-culture strains produced lower butanol levels compared to their fused strains, the stationary phase was longer for the co-culture strains and they did not experience a considerable decay phase.

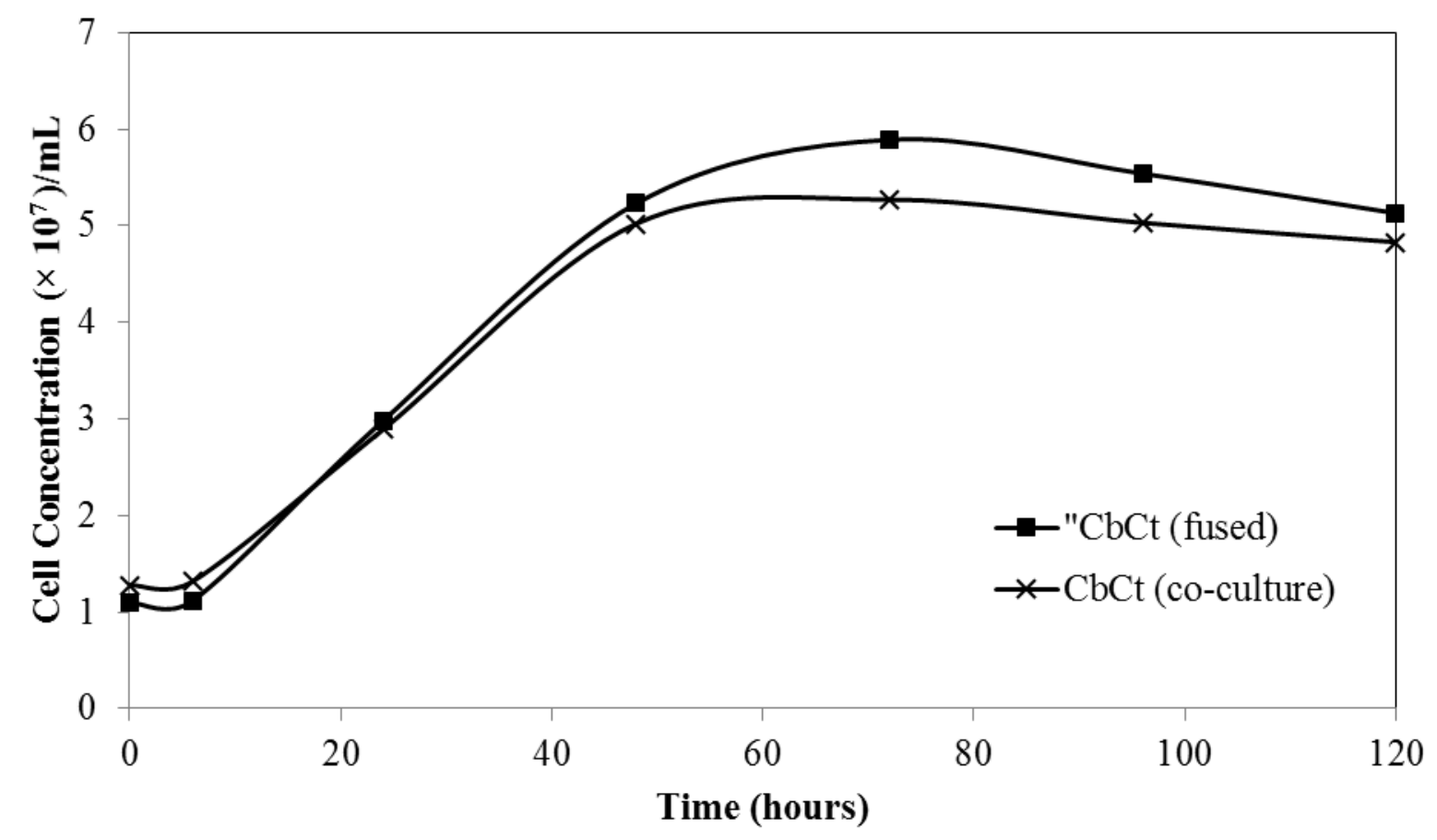

Figure 4.12. Changes in cell concentration for $\boldsymbol{C b C t}$ fused and $\boldsymbol{C b C t}$ co-culture strains during SSF (Average RSD: $3.4 \%$ ).

Figure 4.13 shows the changes in cell growth for $C b C t T s$ fused and co-culture strains during SSF. A similar analysis of $C b C t T s$ fused and co-culture strains showed that these strains also exhibited a lag 
phase between $0 \mathrm{~h}$ and $6 \mathrm{~h}$. This was followed by an exponential phase, when the cells grew rapidly between $12 \mathrm{~h}$ and $72 \mathrm{~h}$. During the next $24 \mathrm{~h}$, both fused and co-culture strains experienced a stationary phase until $96 \mathrm{~h}$ when the fused cells entered the decay phase due to butanol toxicity at the range of more than $12.5 \mathrm{~g} / \mathrm{L}$. However, the cell concentration for the corresponding co-culture strains remained almost constant without any significant changes for the rest of SSF.

\subsection{Yield Calculations}

Total ABE yield was calculated for total production with respect to total sugar consumption; it was determined by dividing final $\mathrm{ABE}$ as well as acetone, butanol and ethanol concentrations with total sugars consumed in $120 \mathrm{~h}$ of fermentation; the results are listed in Table 4.8, and show that yields obtained for the fused strain were generally higher than the corresponding co-culture. In the current study, it was found that the total sugar produced in the hydrolysis of wheat straw was around $55 \mathrm{~g} / \mathrm{L}$. It was almost equivalent to the total sugar concentration reported in the previous studies, which was at the range of 55-65 g/L in hydrolysate (Qureshi et al., 2007). According to Table 4.2, the production of $\mathrm{ABE}$ was the highest, where the total $\mathrm{ABE}$ yield for $C b C t$ fused strains was around 0.48 , with an acetone yield of 0.14 , a butanol yield of 0.28 , and an ethanol yield of about 0.04 . Furthermore, the total $\mathrm{ABE}$ yield obtained from $\mathrm{CbCt}$ fused strains was almost the same as the one previously reported which was 0.40 of the total $\mathrm{ABE}$ and 0.26 of biobutanol (Ezeji, 2004). It was also comparable to the results obtained from the study by Qureshi et al. (2007), in which the total ABE yield of 0.41 was reported. However, it should be mentioned that in those studies gas stripping method and bioreactor were used to increase the solvent production. On the other hand, the $C b C t T s$ fused strains total ABE yield was 0.49 , which was almost the same as that obtained from $C b C t$ fused strains. In this case, the acetone yield reduced from 0.14 to 0.13 and the butanol yield dropped from 0.28 to 0.26 . 


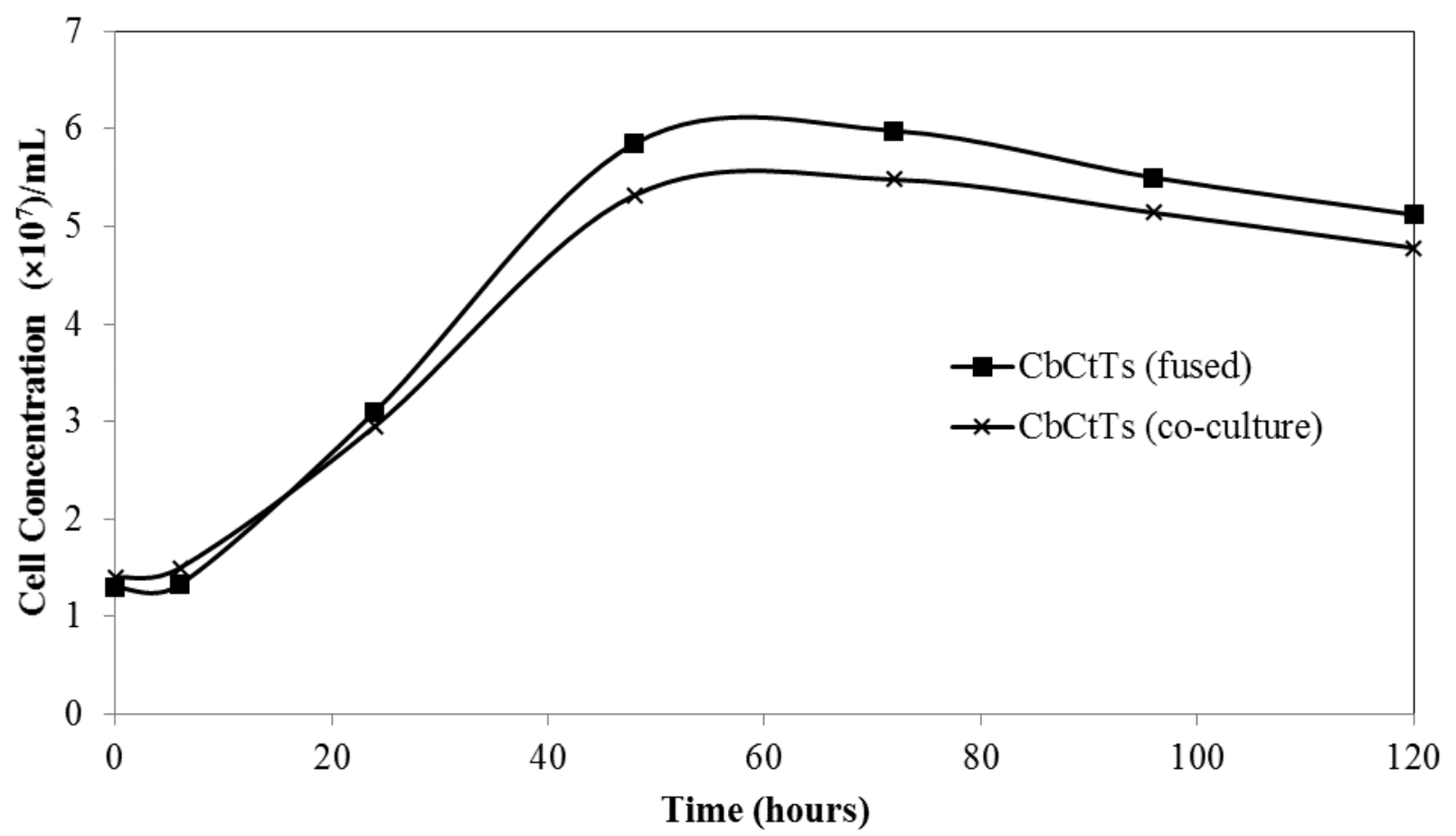

Figure 4.13. Changes in cell concentration for $C b C t T s$ fused and $C b C t T s$ co-culture strains during SSF (Average RSD: $4.1 \%)$.

However, the ethanol yield increased from 0.04 , in the case of $C b C t$ fused strains, to 0.09 , in the case of $C b C t T s$ fused strains, which shows the capability of the three fusants for ethanol production compared to the two fusants process. It should be mentioned that in this case, total ABE yield is still a little higher than that reported in the study by Qureshi et al. (2007), in which $C b$ was the only bacterium to produce biobutanol. Besides, the total $\mathrm{ABE}$ yield obtained from $\mathrm{CbCt}$ co-culture strains was 0.24 which was the smallest yield; however, $C b C t T s$ co-culture strains reported an ABE yield of 0.29 , which is higher than the previous case. Overall, it can be concluded that the two and three fused strains were able to produce higher yields of total $\mathrm{ABE}$ and biobutanol compared to their corresponding co-culture strains. 
Table 4.8. Total ABE and individual yields for all fused and co-culture strains

\begin{tabular}{|c|c|c|c|c|}
\hline Strains & $\begin{array}{c}\text { ABE Yield } \\
\left(\mathbf{Y}_{\mathbf{A B E} / \mathbf{S})^{\mathbf{a}}}\right.\end{array}$ & $\begin{array}{c}\text { Acetone Yield } \\
\left(\mathbf{Y}_{\mathbf{A} / \mathbf{S}}\right)^{\mathbf{b}}\end{array}$ & $\begin{array}{c}\text { Butanol Yield } \\
\left(\mathbf{Y}_{\mathbf{B} / \mathbf{S}}\right)^{\mathbf{c}}\end{array}$ & $\begin{array}{c}\text { Ethanol Yield } \\
\left(\mathbf{Y}_{\mathbf{E} / \mathbf{S}}\right)^{\mathbf{d}}\end{array}$ \\
\hline$C b C t$ Fused & 0.48 & 0.14 & 0.28 & 0.04 \\
\hline$C b C t T s$ Fused & 0.49 & 0.13 & 0.26 & 0.09 \\
\hline$C b C t$ Co-culture & 0.24 & 0.07 & 0.14 & 0.02 \\
\hline$C b C t T s$ Co-culture & 0.29 & 0.09 & 0.15 & 0.04 \\
\hline
\end{tabular}

${ }^{\mathrm{a}} \mathrm{Y}_{\mathrm{ABE} / \mathrm{S}}$ was calculated by dividing final ABE concentration with total sugars consumed in $120 \mathrm{~h}$

${ }^{\mathrm{b}} \mathrm{Y}_{\mathrm{A} / \mathrm{S}}$ was calculated by dividing final Acetone concentration with total sugars consumed in $120 \mathrm{~h}$

${ }^{\mathrm{c}} \mathrm{Y}_{\mathrm{B} / \mathrm{S}}$ was calculated by dividing final Butanol concentration with total sugars consumed in $120 \mathrm{~h}$

${ }^{\mathrm{d}} \mathrm{Y}_{\mathrm{E} / \mathrm{S}}$ was calculated by dividing final Ethanol concentration with total sugars consumed in $120 \mathrm{~h}$

\subsection{Enzyme Assay Evaluation}

The production of three enzymes including cellulase (endoglucanase and exoglucanase), and $\beta$ glucosidase was measured in terms of a filter paper assay (FPA) which was described in section 3.3.1. Table 4.9 displays the glucose concentrations released from the filter paper for each sample and the corresponding enzyme activity in filter paper units per $\mathrm{mL}(\mathrm{FPU} / \mathrm{mL})$. It should be noted that in the current study enzymes were produced by both thermophilic and mesophilic bacterial strains. However, according to Maki et al., (2009) cellulosome producing $C t$ and its potential to ferment hydrolysis products makes it an excellent candidate for the future of biofuels. Moreover, cellulase generated by $C t$ has a very high enzyme activity on cellulose.

According to the literature, both thermophilic and mesophilic bacteria are able to produce enzymes that hydrolyze cellulose and hemicellulose into monomers. Then the strain metabolises them to acids and ABE solvents (Jin et al., 2011). Ct, which is an anaerobic thermophilic bacterium, is able to produce both cellulose degrading enzymes and cellulosomes cellulases; hence, it has been considered as a 
significant strain for decades (Dashtban et al., 2010). In the current study, the fused strains were able to produce enzymes required for cellulose hydrolysis such as endoglucanase, exoglucanase and $\beta$ glucosidase during the SSF process.

Table 4.9. Concentrations of released glucose from samples and enzyme activity for $C b C t$ and CbCtTs fused strains.

\begin{tabular}{|c|c|c|c|c|}
\hline \multirow{2}{*}{ Dilution \# } & \multicolumn{2}{|c|}{ CbCt (fused) } & \multicolumn{2}{c|}{ CbCtTs (fused) } \\
\cline { 2 - 5 } & Abs 540 nm & Glucose (mg/0.5mL) & Abs 540 nm & Glucose (mg/0.5mL) \\
\hline 1 & 0.587 & 2.561 & 0.635 & 2.764 \\
\hline 2 & 0.434 & 1.889 & 0.485 & 2.111 \\
\hline 3 & 0.282 & 1.228 & 0.327 & 1.424 \\
\hline $\begin{array}{c}\text { Enzyme activity } \\
(\text { FPU/mL) }\end{array}$ & \multicolumn{2}{|c}{68.51} & & 75.51 \\
\hline
\end{tabular}

As shown in Table 4.9, $C b C t$ fused strains produced $68.51 \mathrm{FPU} / \mathrm{mL}$ cellulolytic enzymes and $C b C t T s$ fused generated 75.51 FPU/mL enzymes. Compared with the activity of commercial enzymes, such as accellerase 1,500 with an activity of $43.21 \mathrm{FPU} / \mathrm{mL}$ (Pessani, 2011), the enzyme activity of the fused strains applied in the current study revealed a new idea for enzymatic hydrolysis associated with the conversion of lignocellulosic feedstock to biofuels during SSF.

Finally, in terms of energy return on investment, it should be noted that the pretreatment process used in this study does not consume more energy than the energy of biobutanol produced. The energy consumed during the pretreatment of wheat straw was around $21.5 \mathrm{KJ}$, calculated by using Equation 4.1. However, the energy content of biobutanol produced using $C b C t$ and $C b C t T s$ fused strains was about $24.3 \mathrm{KJ}$ and $22.7 \mathrm{KJ}$, respectively. This energy content of biobutanol was calculated using the heat capacity of butanol $(2679 \mathrm{KJ} / \mathrm{mole})$ multiply by the number of moles of butanol. Therefore, 
considering the energy input into the pretreatment process as the only significant source of energy input, it can be concluded that the return of energy from the products was relatively good in the present study, as can be seen from the values shown above. Even at the industrial scale, fermentation is not very energy input driven since there is no need to put high-pressure steam (energy) into the system.

$Q=m \times c_{h} \times \Delta T$

where,

$$
\begin{aligned}
& Q=\text { heat of a measured substance }(\mathrm{J}) ; \\
& m=\text { the mass of the substance }(\mathrm{g}) ; \\
& c_{h}=\text { the specific heat }\left(\mathrm{J} / \mathrm{g} .{ }^{\circ} \mathrm{C}\right) ; \text { and } \\
& \Delta T=\text { the change in temperature }\left({ }^{\circ} \mathrm{C}\right)
\end{aligned}
$$

Nowadays, a number of companies are investigating novel techniques to produce biobutanol on an industrial scale using microorganisms. The two leading technology developers in this area, Gevo and Butamax, are currently involved in a patent dispute. Gevo aims to be producing $1 \mathrm{M}$ gallons of isobutanol per month at the commercial-scale. 


\section{CHAPTER 5}

\section{CONCLUSIONS AND RECOMMENDATIONS}

\subsection{Conclusions}

In the current study, a protoplast fusion technique was applied to produce novel clostridial strains with capabilities of biobutanol production higher than wild strains. Fermentation production experiments were conducted in SSF using renewable green resources (i.e., WS in the present study). The fused strains that were produced, tested, and used in the current study have shown a higher capability to produce biobutanol with strong tolerance to butanol toxicity. Apparently, genetic improvements through the protoplast fusions have led to higher levels of tolerance to butanol and higher biobutanol production of around $13.82 \mathrm{~g} / \mathrm{L}$ and $12.80 \mathrm{~g} / \mathrm{L}$, using $C b C t$ and $C b C t T s$ fusants, respectively. This characteristic will be of prime interest for commercialization of this technology, which leads to more profitability.

The combination of the thermophilic strains with the capability of enzyme production required for degradation of cellulose and cellobiose into sugars, along with the mesophilic butanol producing strain demonstrated significant ability to eliminate the addition of high-priced enzymes required for saccharification, and to revolutionize butanol production. Furthermore, the present study showed success in performing SSF at a higher temperature of $45^{\circ} \mathrm{C}$, which represents a better temperature to maximize internal enzyme activity, thus leading to higher butanol production. 
Comparing $C b C t$ fused with $C b C t T s$ fused strains, it can be concluded that although $T s$ is a bacterium that is able to directly ferment hemicellulose to alcohols, it does not have a significant effect on higher butanol production. However, in the case of $C b C t T s$ fused strains, the ethanol concentration was higher than that reported using $C b C t$ fused strains.

Moreover, fused strains in general showed superiority in terms of butanol production compared to coculture strains. As described in the text, $C b C t$ fused strains produced $13.81 \mathrm{~g} / \mathrm{L}$ of butanol, a concentration significantly higher than the butanol produced by their corresponding co-culture which was only about $5.79 \mathrm{~g} / \mathrm{L}$. Similar to this, the $C b C t T s$ fused strains produced $12.80 \mathrm{~g} / \mathrm{L}$ of butanol, which was considerably higher compared to $6.25 \mathrm{~g} / \mathrm{L}$ of butanol obtained from their co-culture counterparts. Also, the total ABE yield achieved by using fused strains was higher than that obtained from their corresponding co-culture strains.

In terms of enzyme activity, both fused strains showed the potential to produce enzymes required for saccharification and fermentation. While $C t$ was able to produce enzymes for degradation of cellulose and cellobiose to monomeric sugars, $T s$ and $C b$ had the potential to hydrolyze hemicellulose to pentose sugars and ferment them to biobutanol. They also contributed to cellobiose reduction to produce alcohol. As mentioned before, this characteristic makes the fused strains significant for biobutanol production at an industrial scale.

Finally, a genetic stability test was performed for both fused strains using PCR followed by Agarose Gel Electrophoresis. The results showed that $C b C t$ fused strains displayed genetic stability during ten growth cycles. $C b C t T s$ fused strains did not demonstrate genetic stability; however, they were able to produce considerable amounts of biobutanol and total ABE. 


\subsection{Recommendations}

Future work could be done on applying fused strains at a large scale using a bioreactor to improve the production of biobutanol. Using a well-designed bioreactor would be helpful to limit some of the obstacles associated with a high biobutanol concentration, as well as to control the $\mathrm{pH}$ of the system which is an important indicator of the biological synthetic processes. In addition, a cell recycling method to recycle the bacterial cells to the system, and gas stripping technique to remove butanol and further reduce the effect of butanol toxicity on the strains, are of prime interest. Thus, a combination of gas stripping and genetically improved fused bacterial strains may have the potential to produce commercial levels of biobutanol.

Moreover, studying the effect of UV-mutations on the fused strains could be considered a potential method to produce stronger species that might have the capability to alter or avoid some unwanted paths in the biobutanol production process.

Finally, in terms of genetic stability of the tri-fusant, this strain obtained only a few genes which led to enhancement of biobutanol. Therefore, a sequencing project could address this issue by detecting the changes occurring during the protoplast fusion of the tri-fusant. 


\section{APPENDICES}

\section{Appendix A. Chemicals Used in the Present study}

Table A.1. List of chemicals used in the present study

\begin{tabular}{|c|c|c|}
\hline Product & Company & Catalogue No. \\
\hline Glycerole & Sigma-Aldrich (St. Louis, MO) & 56815 \\
\hline Cooked Meat Medium (CMM) & Oxoid Ltd. (Basingstoke, Hampshire, UK) & MT0350 \\
\hline Glucose & Sigma-Aldrich (St. Louis, MO) & G8769 \\
\hline D-biotin & Sigma-Aldrich (St. Louis, MO) & B4501 \\
\hline PABA & Sigma-Aldrich (St. Louis, MO) & 6930 \\
\hline Thiamine- $\mathrm{HCl}$ & Sigma-Aldrich (St. Louis, MO) & T4625 \\
\hline $\mathrm{FeSO}_{4} \cdot 7 \mathrm{H}_{2} \mathrm{O}$ & Sigma-Aldrich (St. Louis, MO) & F8048 \\
\hline $\mathrm{MnSO}_{4} \cdot 4 \mathrm{H}_{2} 0$ & Sigma-Aldrich (St. Louis, MO) & M7634 \\
\hline $\mathrm{MgSO}_{4.7} \mathrm{H}_{2} \mathrm{O}$ & Sigma-Aldrich (St. Louis, MO) & 63138 \\
\hline $\mathrm{H}_{2} \mathrm{SO}_{4}$ & Sigma-Aldrich (St. Louis, MO) & 339741 \\
\hline $\mathrm{KH}_{2} \mathrm{PO}_{4}$ & Sigma-Aldrich (St. Louis, MO) & 322431 \\
\hline $\mathrm{K}_{2} \mathrm{HPO}_{4}$ & Sigma-Aldrich (St. Louis, MO) & GO139 \\
\hline $\mathrm{NaOH}$ & Sigma-Aldrich (St. Louis, MO) & S5881 \\
\hline DNS acid & Sigma-Aldrich (St. Louis, MO) & D0550 \\
\hline Sodium potassium tartrate tetrahydrate & Sigma-Aldrich (St. Louis, MO) & 217255 \\
\hline Fluka-Yeast extract & Sigma-Aldrich (St. Louis, MO) & 70161 \\
\hline Sucrose & Sigma-Aldrich (St. Louis, MO) & S0389 \\
\hline Poly ethylene glycol (PEG) & Sigma-Aldrich (St. Louis, MO) & $\mathrm{X} 2753$ \\
\hline Casein hydrolysate & Sigma-Aldrich (St. Louis, MO) & 22090 \\
\hline Resazurine & Sigma-Aldrich (St. Louis, MO) & 62758138 \\
\hline Urea & Sigma-Aldrich (St. Louis, MO) & 57136 \\
\hline $\mathrm{MgCl}_{2}$ & Sigma-Aldrich (St. Louis, MO) & 7791186 \\
\hline Sodium bisulphite & Sigma-Aldrich (St. Louis, MO) & 243973 \\
\hline
\end{tabular}




\begin{tabular}{|l|l|l|}
\hline Product & Company & Catalogue No. \\
\hline$\left(\mathrm{NH}_{4}\right)_{2} \mathrm{SO}_{4}$ & Sigma-Aldrich (St. Louis, MO) & 7783202 \\
\hline Asparagine & Sigma-Aldrich (St. Louis, MO) & A0884 \\
\hline Agar & Sigma-Aldrich (St. Louis, MO) & 5038 \\
\hline Citric acid & Sigma-Aldrich (St. Louis, MO) & 5949291 \\
\hline Casamino acid & Cole palmer & S79955 \\
\hline Sodium bicarbonate & Sigma-Aldrich (St. Louis, MO) & S5761 \\
\hline Iron (II) chloride & Sigma-Aldrich (St. Louis, MO) & 372870 \\
\hline Glutathione & Sigma-Aldrich (St. Louis, MO) & G4251 \\
\hline Sodium glycerophosphate & Sigma-Aldrich (St. Louis, MO) & S579297 \\
\hline NaCl & Sigma-Aldrich (St. Louis, MO) & S7653 \\
\hline CaCl ${ }_{2}$ & Sigma-Aldrich (St. Louis, MO) & 10043524 \\
\hline Lysozyme & Fluca & 12650883 \\
\hline Gelatine & Fluca & 9000708 \\
\hline Cellobiose & Fluca & 528507 \\
\hline
\end{tabular}


Appendix B. Glucose Standard Curve and Filter Paper Assay Analysis

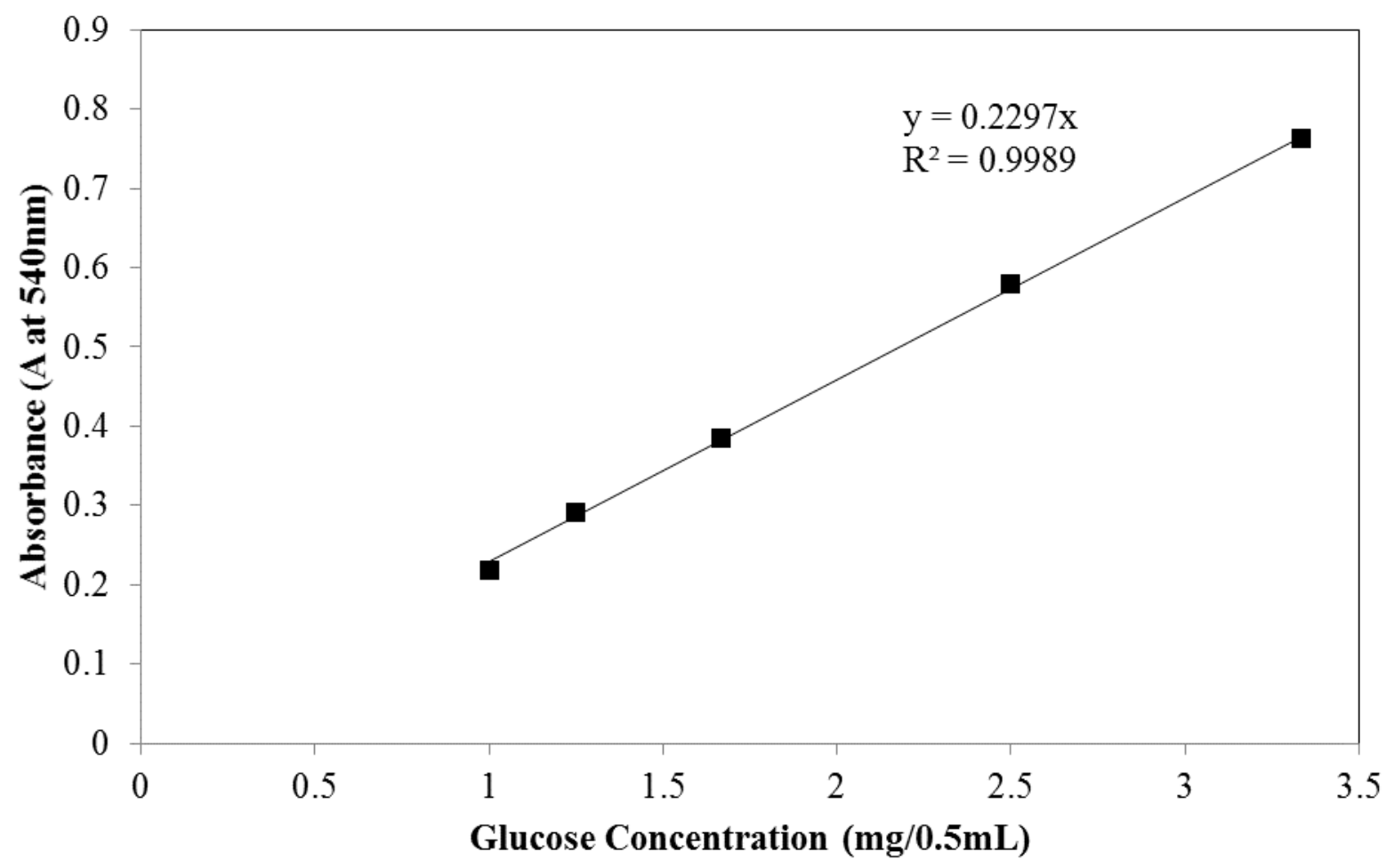

Figure B.1. Glucose calibration curve for filter paper assay analysis at $540 \mathrm{~nm}$ using UV-VIS.

Table B.1. Glucose standards dilutions and UV absorbance at $540 \mathrm{~nm}$.

\begin{tabular}{|c|c|c|c|c|}
\hline Glucose stock (mL) & Citrate buffer $\mathbf{( m L )}$ & Dilution & Concentration & Abs. 540 nm \\
\hline 1.0 & 0.5 & $1: 1.5$ & $3.35 \mathrm{mg} / 0.5 \mathrm{~mL}$ & 0.765 \\
\hline 1.0 & 1.0 & $1: 02$ & $2.50 \mathrm{mg} / 0.5 \mathrm{~mL}$ & 0.579 \\
\hline 1.0 & 2.0 & $1: 03$ & $1.65 \mathrm{mg} / 0.5 \mathrm{~mL}$ & 0.384 \\
\hline 1.0 & 3.0 & $1: 04$ & $1.25 \mathrm{mg} / 0.5 \mathrm{~mL}$ & 0.292 \\
\hline 1.0 & 4.0 & $1: 05$ & $1.00 \mathrm{mg} / 0.5 \mathrm{~mL}$ & 0.220 \\
\hline
\end{tabular}


Table B.2. Enzyme dilutions in sodium citrate buffer $0.05 \mathrm{M}$ and $\mathrm{pH} 4.8$.

\begin{tabular}{|c|c|c|c|}
\hline Dilution No. & Citrate buffer $(\mathbf{m L})$ & $\mathbf{1 : 2 0}$ Enzyme $(\mathbf{m L})$ & *Concentration \\
\hline 1 & 17.0 & 3.0 & 0.00750 \\
\hline 2 & 18.0 & 2.0 & 0.00500 \\
\hline 3 & 18.5 & 1.5 & 0.00375 \\
\hline
\end{tabular}

*The term "concentration" is used to represent the proportion of the original enzyme solution present in the dilution added to the assay mixture.

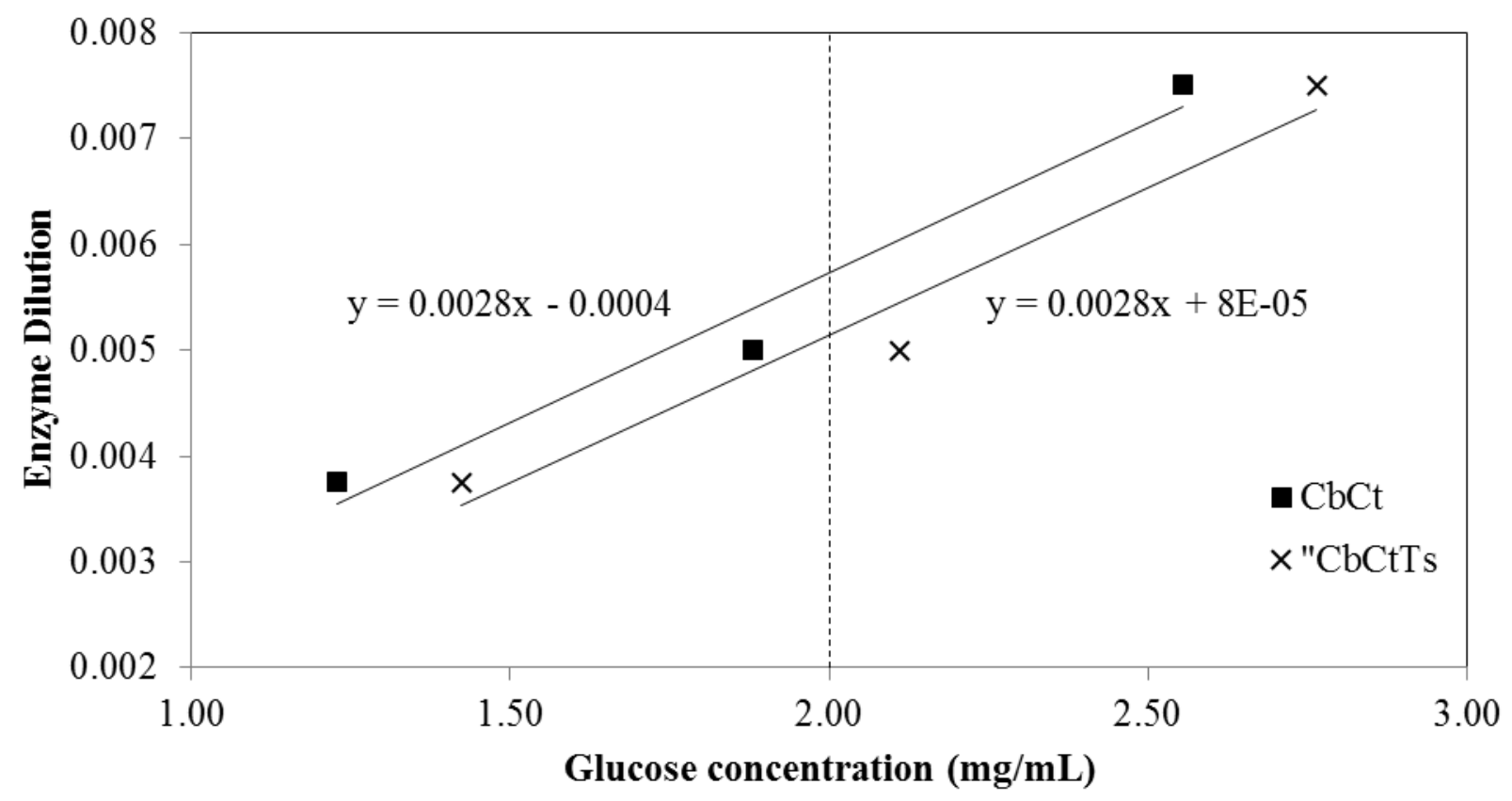

Figure B.2. Determining enzyme concentration that release $2 \mathrm{mg}$ of glucose by plotting liberated glucose against enzyme dilution

Calculation of FPU from Figure B.2 by using Equation 3.2:

$F P U=\frac{0.37}{[E]}$

For $C b C t$ fused $=0.37 / 0.0054=68.51 \mathrm{FPU} / \mathrm{mL}$

For $C b C t T s$ fused $=0.37 / 0.0049=75.51 \mathrm{FPU} / \mathrm{mL}$ 
Appendix C. Raw Data for ABE and Acids from three SSF Experiments

Table C.1. ABE concentration from three SSF experiments for all fusants.

\begin{tabular}{|l|l|l|l|l|l|l|}
\hline Strains & SSF 1 (g/L) & SSF 2 (g/L) & SSF 3 (g/L) & Mean (g/L) & STDEV & \% RSD \\
\hline$C b C t$ (fused) & 22.83 & 23.05 & 23.12 & 23 & 0.15 & 0.65 \\
\hline$C b C t$ (co-culture) & 9.62 & 9.44 & 9.5 & 9.52 & 0.09 & 0.94 \\
\hline$C b C t T s$ (fused) & 23.91 & 23.89 & 24.02 & 23.94 & 0.07 & 0.29 \\
\hline$C b C t T s$ (co-culture) & 12.01 & 12.05 & 12.07 & 12.04 & 0.03 & 0.24 \\
\hline
\end{tabular}

Table C.2. Final acid concentration from three SSF experiments for all fusants.

\begin{tabular}{|l|l|l|l|l|l|l|}
\hline Strains & SSF 1 (g/L) & SSF 2 (g/L) & SSF 3 (g/L) & Mean (g/L) & STDEV & \% RSD \\
\hline$C b C t$ (fused) & 2.6 & 2.61 & 2.65 & 2.62 & 0.03 & 1.01 \\
\hline$C b C t$ (co-culture) & 3.3 & 3.4 & 3.44 & 3.38 & 0.07 & 2.13 \\
\hline$C b C t T s$ (fused) & 2.8 & 2.75 & 2.76 & 2.77 & 0.02 & 0.72 \\
\hline$C b C t T s$ (co-culture) & 3.7 & 3.8 & 3.78 & 3.76 & 0.05 & 1.32 \\
\hline
\end{tabular}


Appendix D. Raw Data for Total Sugar Consumption during SSF

Table D.1. Raw data for total sugars during SSF for $\boldsymbol{C b C t}$ fused strains.

\begin{tabular}{|c|c|c|c|c|c|c|}
\hline Time (h) & SSF1 (g/L) & SSF2 (g/L) & SSF3 (g/L) & Mean (g/L) & STDEV & \%RSD \\
\hline 0 & 30.00 & 29.70 & 29.70 & 29.80 & 0.17 & 0.58 \\
\hline 24 & 42.86 & 43.02 & 43.60 & 43.16 & 0.39 & 0.90 \\
\hline 48 & 22.60 & 22.80 & 23.06 & 22.82 & 0.23 & 1.01 \\
\hline 72 & 11.52 & 12.38 & 11.80 & 11.90 & 0.44 & 3.69 \\
\hline 96 & 8.73 & 8.30 & 8.49 & 8.50 & 0.22 & 2.53 \\
\hline 120 & 7.10 & 7.25 & 7.10 & 7.15 & 0.09 & 1.21 \\
\hline
\end{tabular}

Table D.2. Raw data for total sugars during SSF for $\mathrm{CbCt}$ co-culture strains.

\begin{tabular}{|c|c|c|c|c|c|c|}
\hline Time (h) & SSF1 (g/L) & SSF2 (g/L) & SSF3 (g/L) & Mean (g/L) & STDEV & \%RSD \\
\hline 0 & 30.00 & 29.70 & 29.70 & 29.8 & 0.17 & 0.58 \\
\hline 24 & 40.42 & 41.25 & 40.46 & 40.71 & 0.47 & 1.15 \\
\hline 48 & 29.74 & 29.56 & 28.21 & 29.17 & 0.84 & 2.87 \\
\hline 72 & 19.46 & 19.37 & 19.21 & 19.35 & 0.13 & 0.65 \\
\hline 96 & 15.45 & 16.18 & 15.65 & 15.76 & 0.38 & 2.39 \\
\hline 120 & 15.52 & 15.43 & 15.40 & 15.45 & 0.06 & 0.40 \\
\hline
\end{tabular}


Table D.3. Raw data for total sugars during SSF for CbCtTs fused strains

\begin{tabular}{|c|c|c|c|c|c|c|}
\hline Time (h) & SSF1 (g/L) & SSF2 (g/L) & SSF3 (g/L) & Mean (g/L) & STDEV & \%RSD \\
\hline 0 & 28.83 & 28.85 & 28.86 & 28.84 & 0.015 & 0.05 \\
\hline 24 & 45.45 & 45.04 & 44.76 & 45.08 & 0.34 & 0.75 \\
\hline 48 & 23.33 & 22.85 & 23.47 & 23.21 & 0.32 & 1.37 \\
\hline 72 & 12.59 & 12.85 & 12.99 & 12.81 & 0.20 & 1.56 \\
\hline 96 & 6.97 & 6.98 & 7.06 & 7.00 & 0.04 & 0.57 \\
\hline 120 & 6.74 & 6.81 & 6.79 & 6.78 & 0.03 & 0.44 \\
\hline
\end{tabular}

Table D.4. Raw data for total sugars during SSF for CbCtTs co-culture strains

\begin{tabular}{|c|c|c|c|c|c|c|}
\hline Time (h) & SSF1 (g/L) & SSF2 (g/L) & SSF3 (g/L) & Mean (g/L) & STDEV & \%RSD \\
\hline 0 & 28.83 & 28.85 & 28.86 & 28.84 & 0.015 & 0.05 \\
\hline 24 & 41.10 & 41.18 & 41.28 & 41.18 & 0.090 & 0.21 \\
\hline 48 & 22.73 & 23.09 & 22.83 & 22.88 & 0.180 & 0.78 \\
\hline 72 & 17.82 & 17.75 & 17.87 & 17.81 & 0.060 & 0.33 \\
\hline 96 & 14.62 & 14.60 & 14.68 & 14.63 & 0.040 & 0.27 \\
\hline 120 & 13.99 & 13.99 & 13.85 & 13.94 & 0.080 & 0.57 \\
\hline
\end{tabular}


Appendix E. Standard Curves for ABE, Acids and Sugars (HPLC)

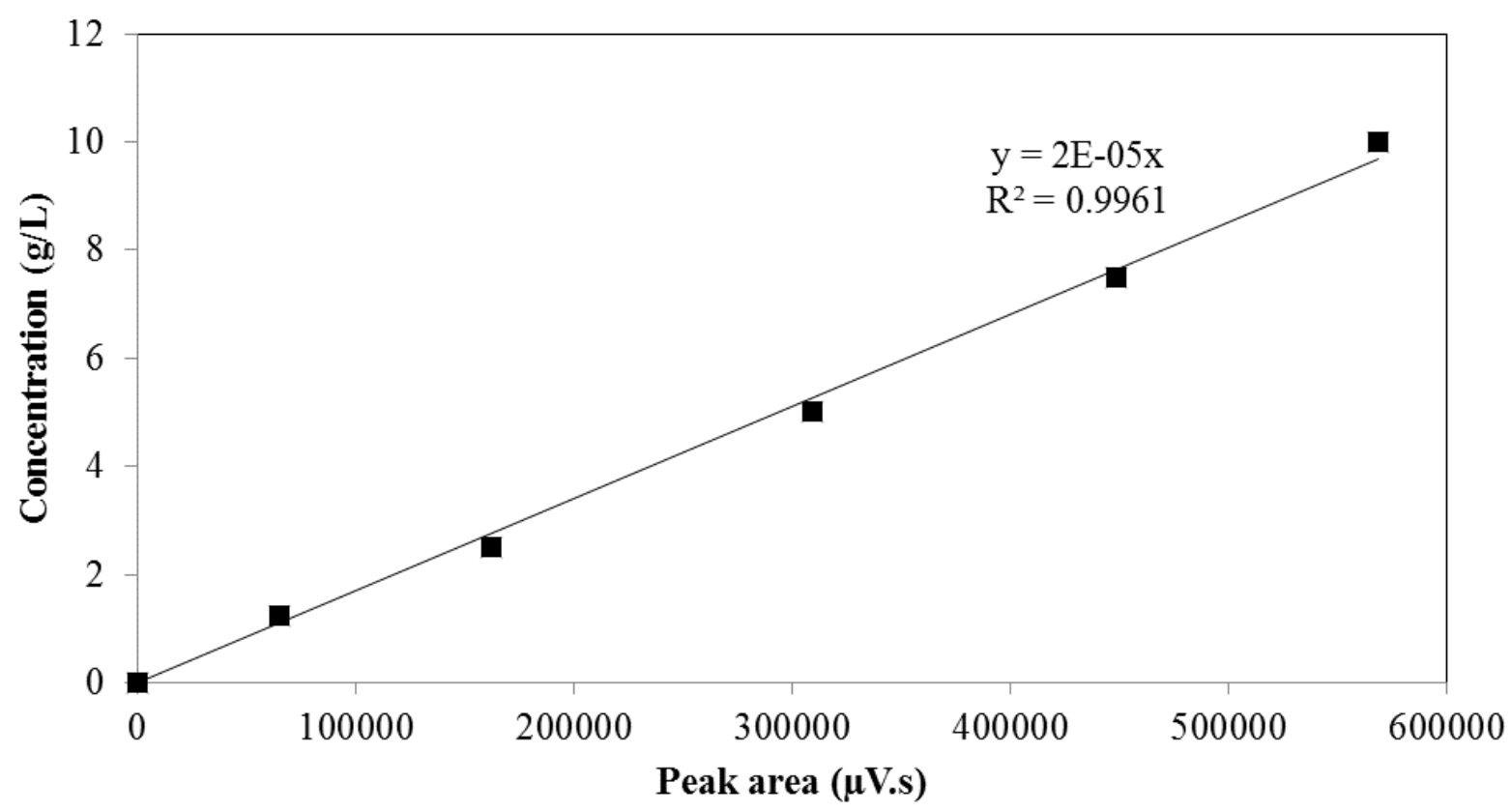

Figure E.1. HPLC standard curve for acetone with retention time of $t=\mathbf{1 5 . 0 3} \mathbf{m i n}$.

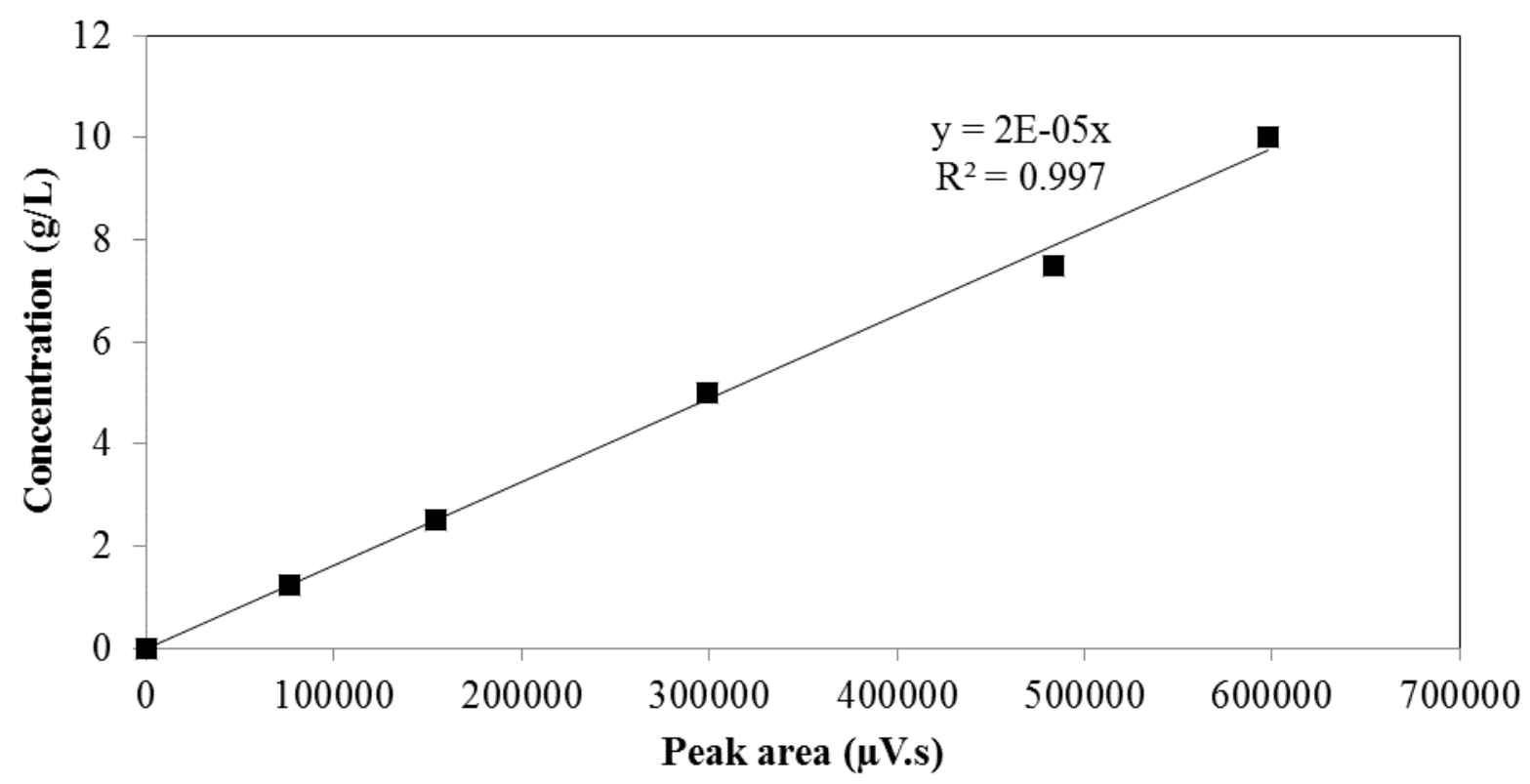

Figure E.2. HPLC standard curve for butanol with retention time of $t=15.54 \mathrm{~min}$. 


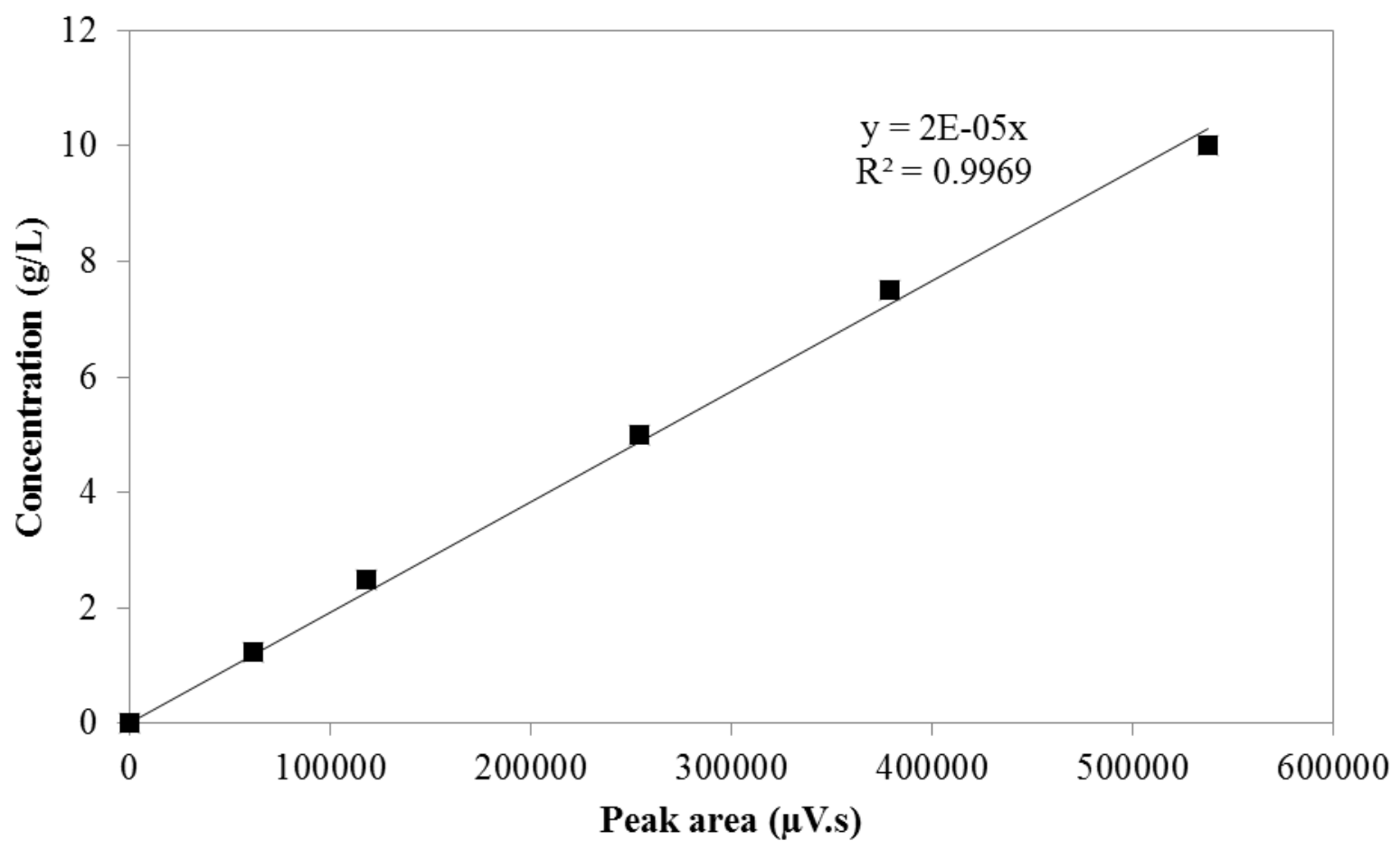

Figure E.3. HPLC standard curve for ethanol with retention time of $t=13.69 \mathrm{~min}$.

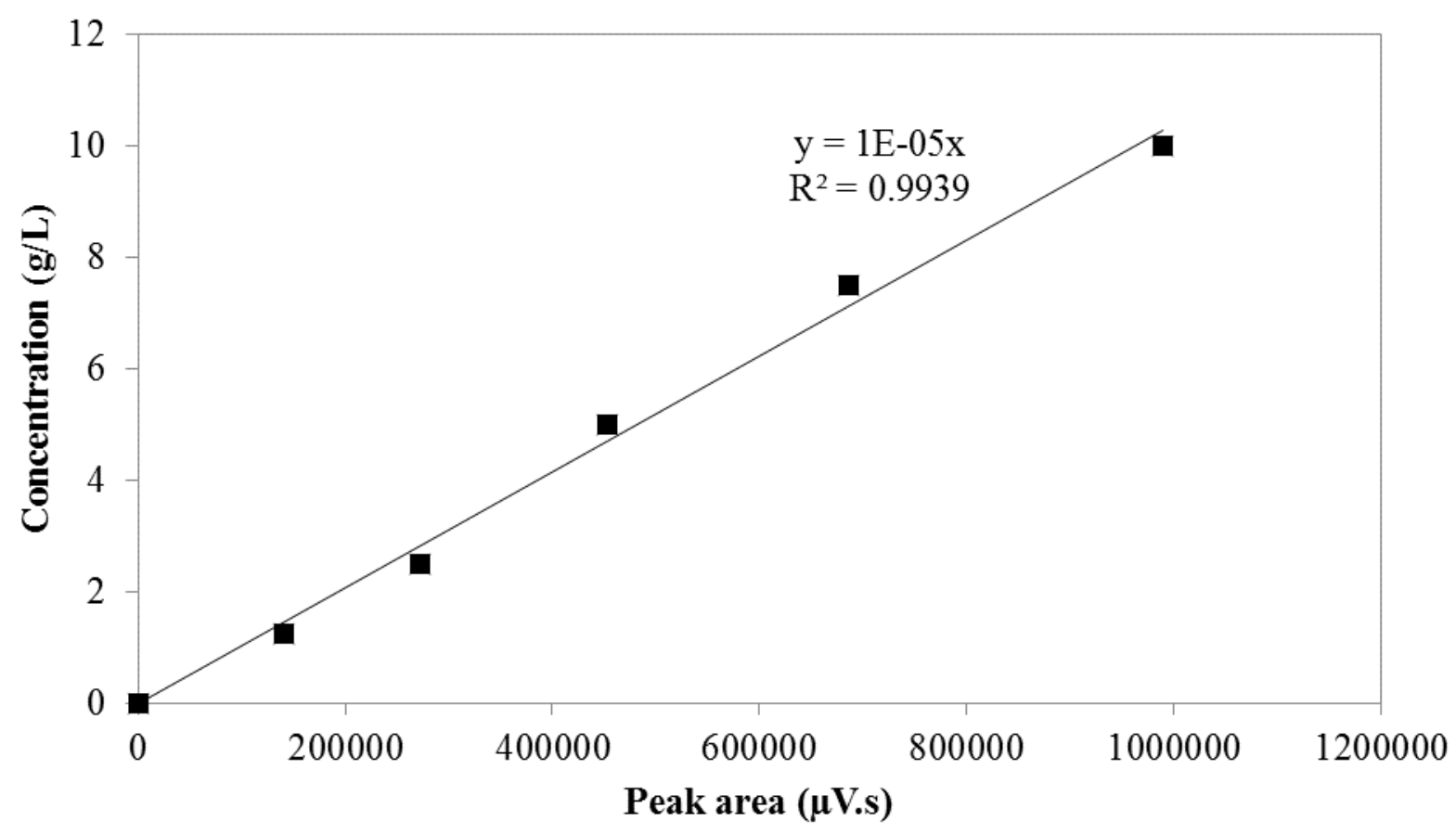

Figure E.4. HPLC standard curve for Acetic acid with retention time of $t=11.71 \mathrm{~min}$. 


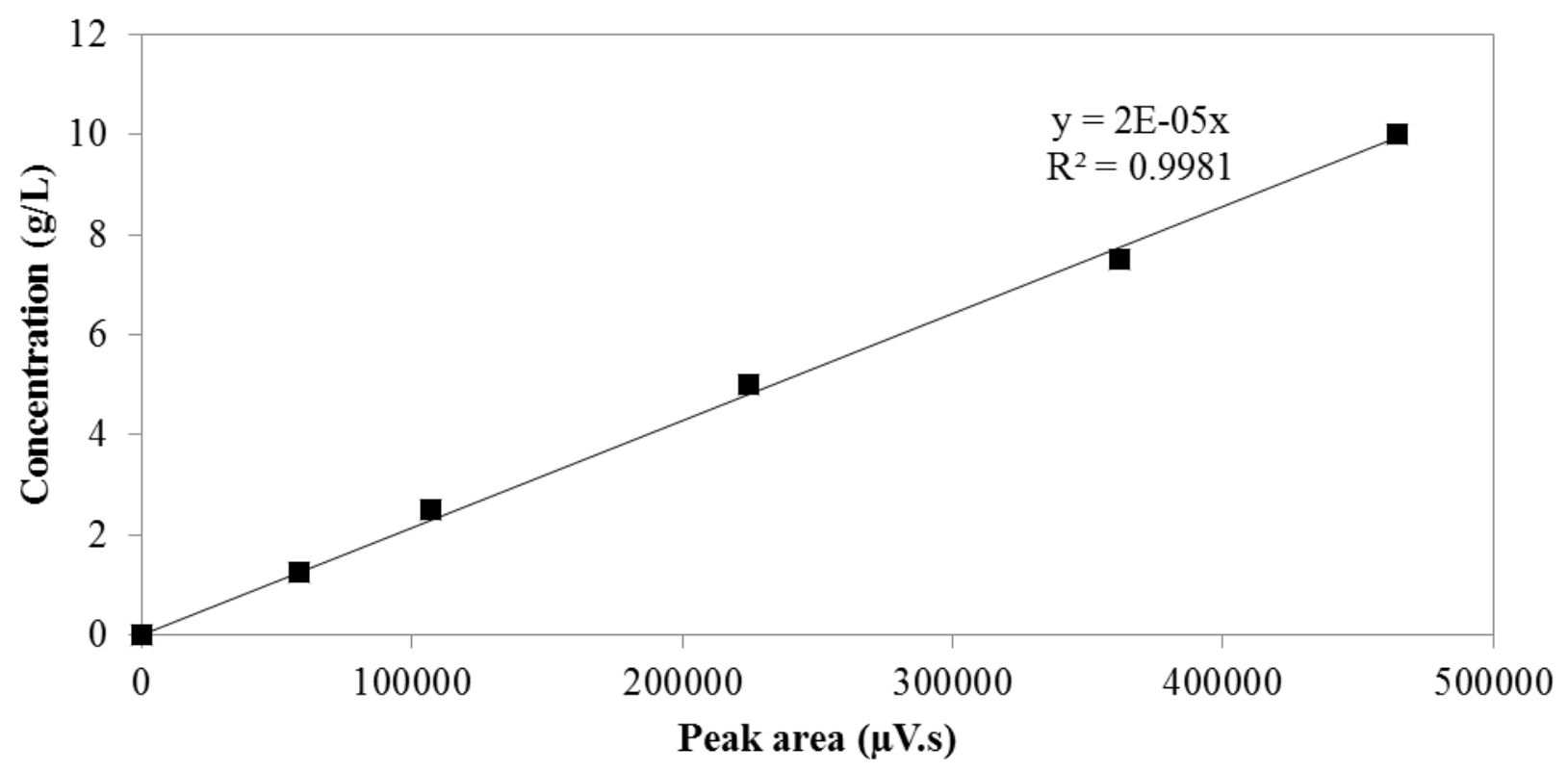

Figure E.5. HPLC standard curve for butyric acid with retention time of $t=12.38 \mathrm{~min}$.

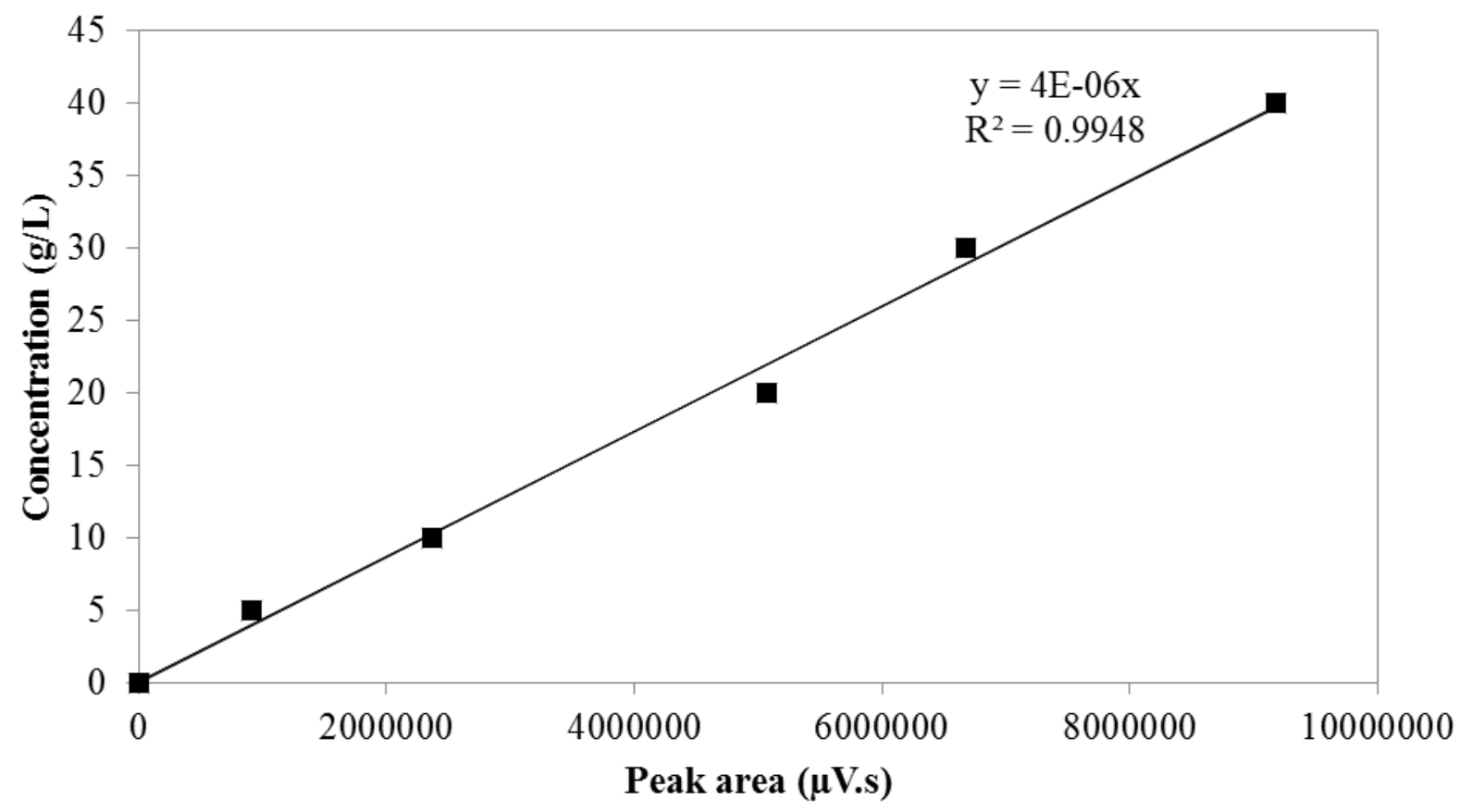

Figure E.6. HPLC standard curve for glucose with retention time of $t=12.92 \mathrm{~min}$. 


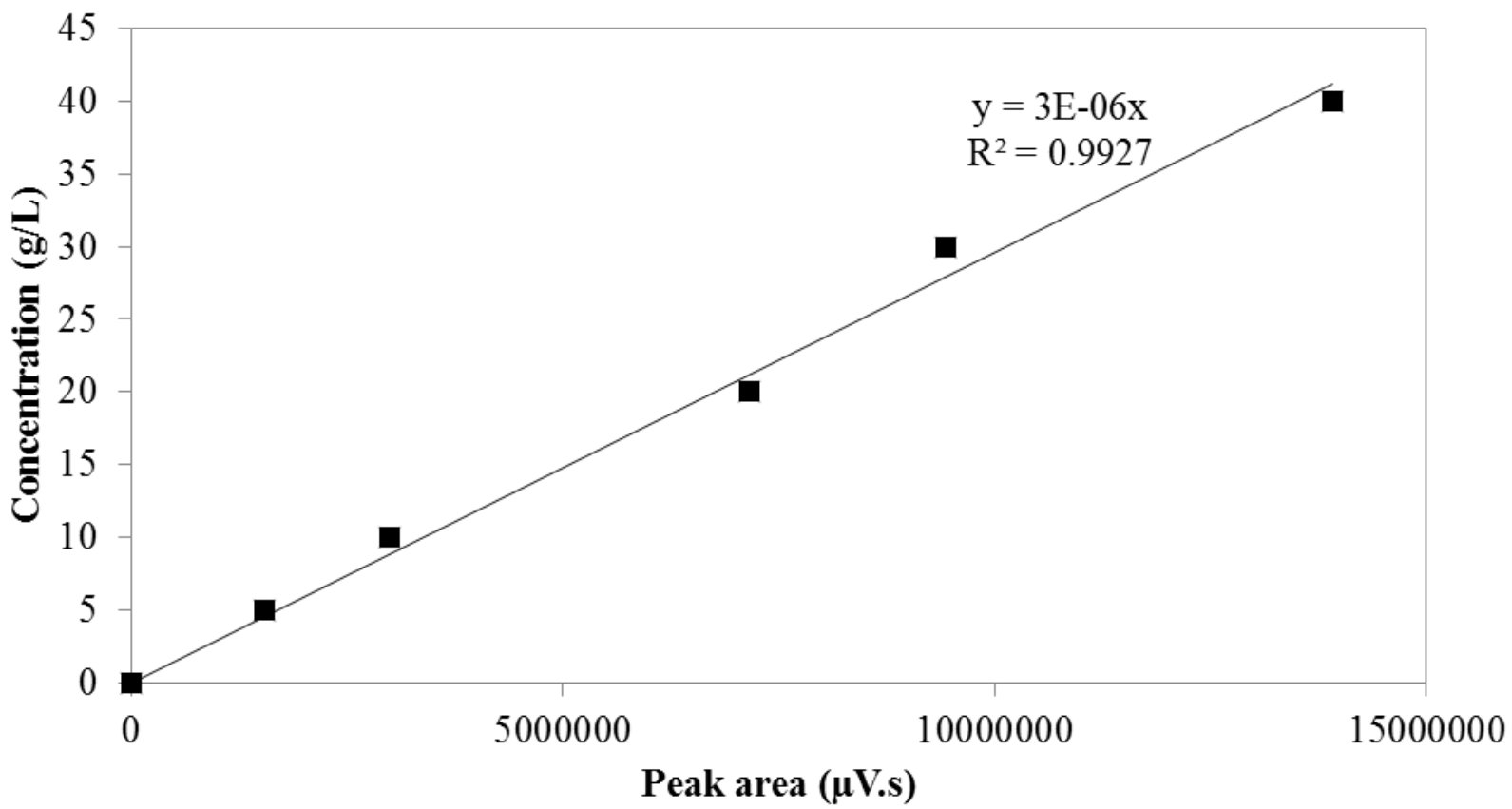

Figure E.7. HPLC standard curve for xylose with retention time of $t=14.02 \mathrm{~min}$.

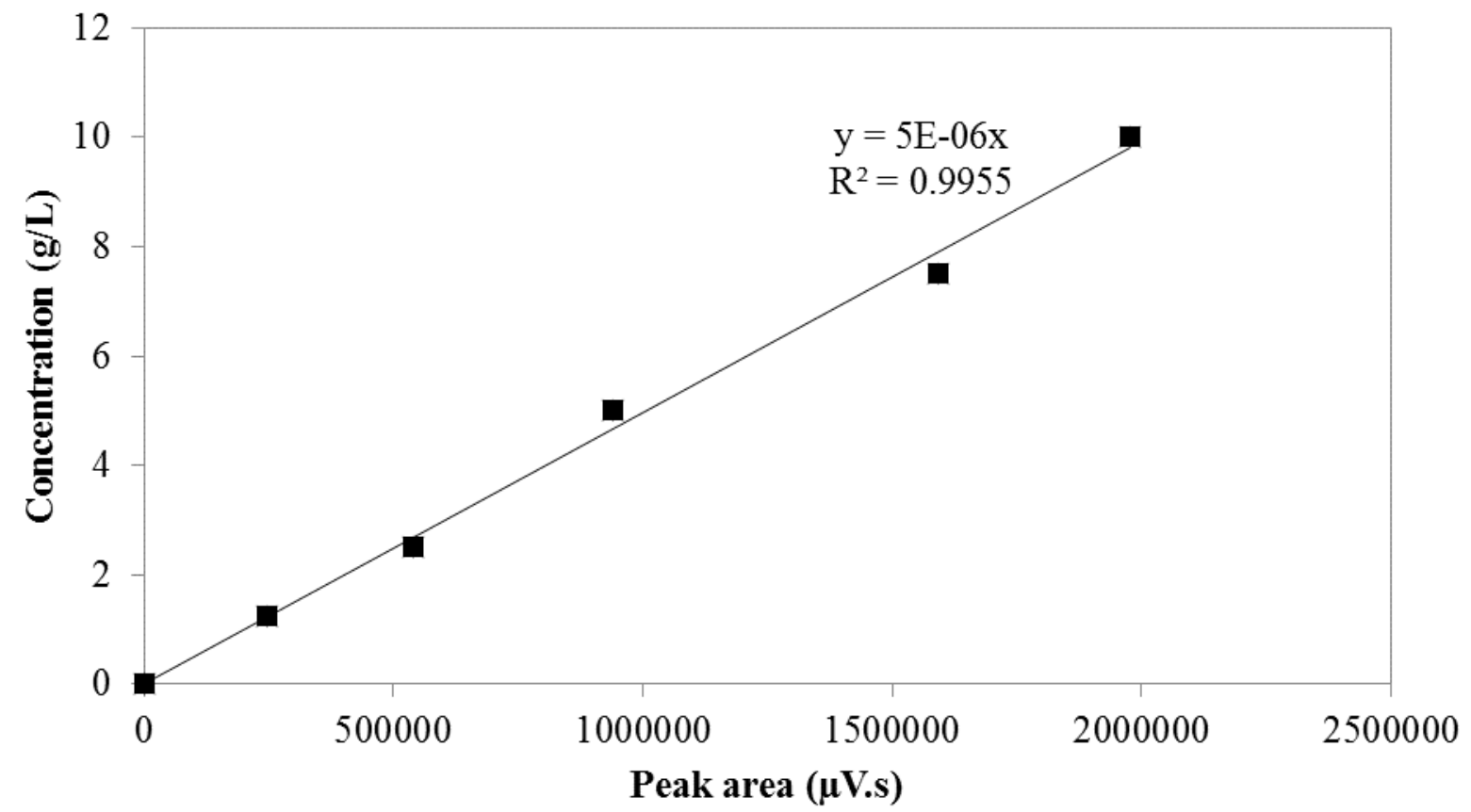

Figure E.8. HPLC standard curve for Mannose with retention time of $t=9.38 \mathrm{~min}$. 


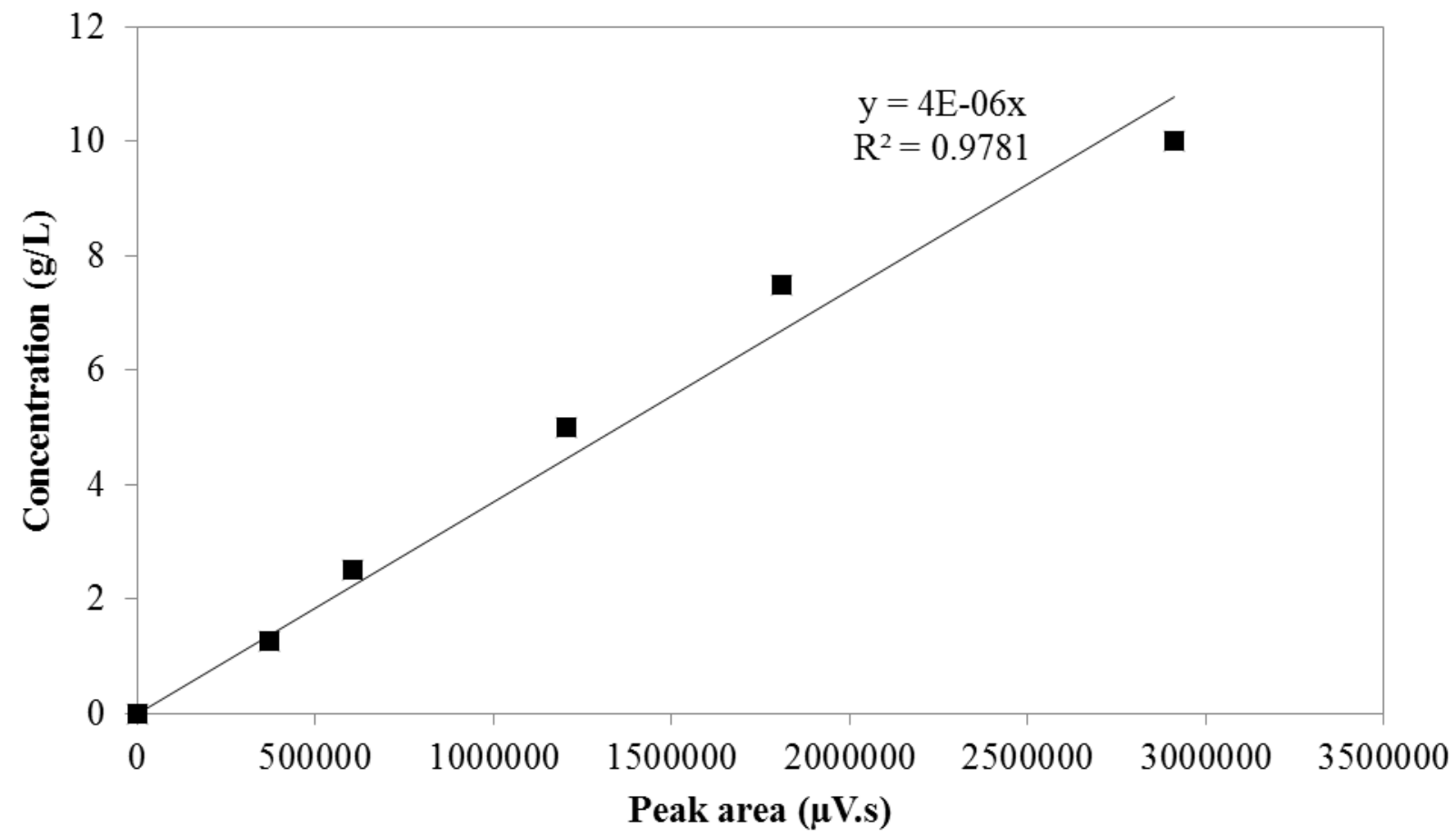

Figure E.9. HPLC standard curve for arabinose with retention time of $t=21.61 \mathrm{~min}$. 
Appendix F. Raw Data for Biobutanol Concentration Profile during SSF Experiments

Table F.1. Biobutanol concentration profile for $\mathrm{CbCt}$ fused strains during SSF experiments.

\begin{tabular}{|c|c|c|c|c|c|c|}
\hline Time (h) & SSF 1 (g/L) & SSF 2 (g/L) & SSF 3 (g/L) & Mean (g/L) & STDEV & \% RSD \\
\hline 0 & 0.00 & 0.00 & 0.00 & 0.00 & 0.00 & 0.00 \\
\hline 24 & 0.12 & 0.09 & 0.09 & 0.10 & 0.02 & 17.58 \\
\hline 48 & 5.24 & 5.30 & 5.42 & 5.32 & 0.09 & 1.72 \\
\hline 72 & 10.58 & 10.74 & 10.69 & 10.67 & 0.08 & 0.77 \\
\hline 96 & 13.35 & 13.41 & 13.50 & 13.42 & 0.08 & 0.56 \\
\hline 120 & 13.76 & 13.84 & 13.83 & 13.81 & 0.04 & 0.32 \\
\hline
\end{tabular}

Table F.2. Biobutanol concentration profile for $\mathrm{CbCt}$ co-culture strains during SSF experiments.

\begin{tabular}{|c|c|c|c|c|c|c|}
\hline Time (h) & SSF 1 (g/L) & SSF 2 (g/L) & SSF 3 (g/L) & Mean (g/L) & STDEV & \% RSD \\
\hline 0 & 0.00 & 0.00 & 0.00 & 0.00 & 0.00 & 0.00 \\
\hline 24 & 0.12 & 0.09 & 0.11 & 0.11 & 0.02 & 14.32 \\
\hline 48 & 2.65 & 2.74 & 2.65 & 2.68 & 0.05 & 1.94 \\
\hline 72 & 4.74 & 4.74 & 4.80 & 4.76 & 0.03 & 0.73 \\
\hline 96 & 5.77 & 5.77 & 5.65 & 5.73 & 0.07 & 1.21 \\
\hline 120 & 5.83 & 5.71 & 5.80 & 5.78 & 0.06 & 1.08 \\
\hline
\end{tabular}


Table F.3. Biobutanol concentration profile for CbCtTs fused strains during SSF experiments.

\begin{tabular}{|c|c|c|c|c|c|c|}
\hline Time (h) & SSF 1 (g/L) & SSF 2 (g/L) & SSF 3 (g/L) & Mean (g/L) & STDEV & \% RSD \\
\hline 0 & 0.00 & 0.00 & 0.00 & 0.00 & 0.00 & 0.00 \\
\hline 24 & 0.04 & 0.05 & 0.04 & 0.04 & 0.005 & 12.5 \\
\hline 48 & 6.70 & 6.50 & 6.56 & 6.58 & 0.10 & 1.51 \\
\hline 72 & 10.43 & 10.12 & 10.50 & 10.35 & 0.20 & 1.93 \\
\hline 96 & 12.64 & 12.43 & 12.50 & 12.52 & 0.10 & 0.79 \\
\hline 120 & 12.76 & 12.84 & 12.81 & 12.80 & 0.04 & 0.31 \\
\hline
\end{tabular}

Table F.4. Biobutanol concentration profile for CbCtTs co-culture strains during SSF experiments.

\begin{tabular}{|c|c|c|c|c|c|c|}
\hline Time (h) & SSF 1 (g/L) & SSF 2 (g/L) & SSF 3 (g/L) & Mean (g/L) & STDEV & \% RSD \\
\hline 0 & 0.00 & 0.00 & 0.00 & 0.00 & 0.00 & 0.00 \\
\hline 24 & 0.04 & 0.05 & 0.04 & 0.04 & 0.005 & 12.5 \\
\hline 48 & 2.66 & 2.70 & 2.65 & 2.67 & 0.02 & 0.74 \\
\hline 72 & 4.47 & 4.38 & 4.32 & 4.39 & 0.07 & 1.59 \\
\hline 96 & 6.12 & 6.21 & 6.16 & 6.16 & 0.04 & 0.64 \\
\hline 120 & 6.23 & 6.25 & 6.27 & 6.25 & 0.02 & 0.32 \\
\hline
\end{tabular}


Appendix G. Cell Growth Profile for all Fused and Co-culture Strains

Table G.1. Cell growth profile for $C b C t$ fused strains.

\begin{tabular}{|c|c|c|c|c|c|c|}
\hline Time (h) & Plate \# 1 & Plate \# 2 & Plate \# 3 & Mean & STDEV & \% RSD \\
\hline 0 & $1.10 \mathrm{E}+07$ & $1.20 \mathrm{E}+07$ & $1.00 \mathrm{E}+07$ & $1.10 \mathrm{E}+07$ & $1.00 \mathrm{E}+06$ & $9.09 \mathrm{E}+00$ \\
\hline 6 & $1.10 \mathrm{E}+07$ & $1.20 \mathrm{E}+07$ & $1.08 \mathrm{E}+07$ & $1.12 \mathrm{E}+07$ & $6.42 \mathrm{E}+05$ & $5.57 \mathrm{E}+00$ \\
\hline 24 & $2.10 \mathrm{E}+07$ & $2.45 \mathrm{E}+07$ & $4.40 \mathrm{E}+07$ & $2.98 \mathrm{E}+07$ & $1.23 \mathrm{E}+07$ & $4.12 \mathrm{E}+01$ \\
\hline 48 & $5.20 \mathrm{E}+07$ & $5.40 \mathrm{E}+07$ & $5.10 \mathrm{E}+07$ & $5.23 \mathrm{E}+07$ & $1.52 \mathrm{E}+06$ & $2.90 \mathrm{E}+00$ \\
\hline 72 & $5.80 \mathrm{E}+07$ & $5.90 \mathrm{E}+07$ & $6.00 \mathrm{E}+07$ & $5.90 \mathrm{E}+07$ & $1.00 \mathrm{E}+06$ & $1.69 \mathrm{E}+00$ \\
\hline 96 & $5.50 \mathrm{E}+07$ & $5.70 \mathrm{E}+07$ & $5.40 \mathrm{E}+07$ & $5.53 \mathrm{E}+07$ & $1.52 \mathrm{E}+06$ & $2.74 \mathrm{E}+00$ \\
\hline 120 & $5.10 \mathrm{E}+07$ & $5.00 \mathrm{E}+07$ & $5.30 \mathrm{E}+07$ & $5.13 \mathrm{E}+07$ & $1.52 \mathrm{E}+06$ & $2.96 \mathrm{E}+00$ \\
\hline
\end{tabular}

Table G.2. Cell growth profile for $\mathrm{CbCt}$ co-culture strains.

\begin{tabular}{|c|c|c|c|c|c|c|}
\hline Time (h) & Plate \# 1 & Plate \# 2 & Plate \# 3 & Mean & STDEV & \% RSD \\
\hline 0 & $1.30 \mathrm{E}+07$ & $1.20 \mathrm{E}+07$ & $1.30 \mathrm{E}+07$ & $1.27 \mathrm{E}+07$ & $5.77 \mathrm{E}+05$ & $4.54 \mathrm{E}+00$ \\
\hline 6 & $1.30 \mathrm{E}+07$ & $1.30 \mathrm{E}+07$ & $1.40 \mathrm{E}+07$ & $1.33 \mathrm{E}+07$ & $5.77 \mathrm{E}+05$ & $4.33 \mathrm{E}+00$ \\
\hline 24 & $2.90 \mathrm{E}+07$ & $2.80 \mathrm{E}+07$ & $3.00 \mathrm{E}+07$ & $2.90 \mathrm{E}+07$ & $1.00 \mathrm{E}+06$ & $3.44 \mathrm{E}+00$ \\
\hline 48 & $5.00 \mathrm{E}+07$ & $5.00 \mathrm{E}+07$ & $5.10 \mathrm{E}+07$ & $5.03 \mathrm{E}+07$ & $5.77 \mathrm{E}+05$ & $1.14 \mathrm{E}+00$ \\
\hline 72 & $5.20 \mathrm{E}+07$ & $5.20 \mathrm{E}+07$ & $5.40 \mathrm{E}+07$ & $5.27 \mathrm{E}+07$ & $1.15 \mathrm{E}+06$ & $2.19 \mathrm{E}+00$ \\
\hline 96 & $4.90 \mathrm{E}+07$ & $5.00 \mathrm{E}+07$ & $5.10 \mathrm{E}+07$ & $5.00 \mathrm{E}+07$ & $1.00 \mathrm{E}+06$ & $2.00 \mathrm{E}+00$ \\
\hline 120 & $4.80 \mathrm{E}+07$ & $4.90 \mathrm{E}+07$ & $4.80 \mathrm{E}+07$ & $4.83 \mathrm{E}+07$ & $5.77 \mathrm{E}+05$ & $1.19 \mathrm{E}+00$ \\
\hline
\end{tabular}


Table G.3. Cell growth profile for CbCtTs fused strains.

\begin{tabular}{|c|c|c|c|c|c|c|}
\hline Time (h) & Plate \# 1 & Plate \# 2 & Plate \# 3 & Mean & STDEV & \% RSD \\
\hline 0 & $1.30 \mathrm{E}+07$ & $1.20 \mathrm{E}+07$ & $1.40 \mathrm{E}+07$ & $1.30 \mathrm{E}+07$ & $1.00 \mathrm{E}+06$ & $7.69 \mathrm{E}+00$ \\
\hline 6 & $1.30 \mathrm{E}+07$ & $1.30 \mathrm{E}+07$ & $1.40 \mathrm{E}+07$ & $1.33 \mathrm{E}+07$ & $5.77 \mathrm{E}+05$ & $4.33 \mathrm{E}+00$ \\
\hline 24 & $3.10 \mathrm{E}+07$ & $3.20 \mathrm{E}+07$ & $3.00 \mathrm{E}+07$ & $3.10 \mathrm{E}+07$ & $1.00 \mathrm{E}+06$ & $3.22 \mathrm{E}+00$ \\
\hline 48 & $5.80 \mathrm{E}+07$ & $5.90 \mathrm{E}+07$ & $5.85 \mathrm{E}+07$ & $5.85 \mathrm{E}+07$ & $5.00 \mathrm{E}+05$ & $8.54 \mathrm{E}-01$ \\
\hline 72 & $6.00 \mathrm{E}+07$ & $5.85 \mathrm{E}+07$ & $6.10 \mathrm{E}+07$ & $5.98 \mathrm{E}+07$ & $1.25 \mathrm{E}+06$ & $2.09 \mathrm{E}+00$ \\
\hline 96 & $5.40 \mathrm{E}+07$ & $5.70 \mathrm{E}+07$ & $5.40 \mathrm{E}+07$ & $5.50 \mathrm{E}+07$ & $1.73 \mathrm{E}+06$ & $3.14 \mathrm{E}+00$ \\
\hline 120 & $5.10 \mathrm{E}+07$ & $5.10 \mathrm{E}+07$ & $5.20 \mathrm{E}+07$ & $5.13 \mathrm{E}+07$ & $5.77 \mathrm{E}+05$ & $1.12 \mathrm{E}+00$ \\
\hline
\end{tabular}

Table G.4. Cell growth profile for CbCtTs co-culture strains.

\begin{tabular}{|c|c|c|c|c|c|c|}
\hline Time (h) & Plate \# 1 & Plate \# 2 & Plate \# 3 & Mean & STDEV & \% RSD \\
\hline 0 & $1.40 \mathrm{E}+07$ & $1.30 \mathrm{E}+07$ & $1.50 \mathrm{E}+07$ & $1.40 \mathrm{E}+07$ & $1.00 \mathrm{E}+06$ & $7.14 \mathrm{E}+00$ \\
\hline 6 & $1.60 \mathrm{E}+07$ & $1.40 \mathrm{E}+07$ & $1.50 \mathrm{E}+07$ & $1.50 \mathrm{E}+07$ & $1.00 \mathrm{E}+06$ & $6.66 \mathrm{E}+00$ \\
\hline 24 & $2.10 \mathrm{E}+07$ & $2.30 \mathrm{E}+07$ & $4.50 \mathrm{E}+07$ & $2.96 \mathrm{E}+07$ & $1.13 \mathrm{E}+07$ & $3.81 \mathrm{E}+01$ \\
\hline 48 & $5.20 \mathrm{E}+07$ & $5.50 \mathrm{E}+07$ & $5.30 \mathrm{E}+07$ & $5.33 \mathrm{E}+07$ & $1.52 \mathrm{E}+06$ & $2.85 \mathrm{E}+00$ \\
\hline 72 & $5.40 \mathrm{E}+07$ & $5.70 \mathrm{E}+07$ & $5.35 \mathrm{E}+07$ & $5.48 \mathrm{E}+07$ & $1.89 \mathrm{E}+06$ & $3.44 \mathrm{E}+00$ \\
\hline 96 & $5.10 \mathrm{E}+07$ & $5.20 \mathrm{E}+07$ & $5.10 \mathrm{E}+07$ & $5.13 \mathrm{E}+07$ & $5.77 \mathrm{E}+05$ & $1.12 \mathrm{E}+00$ \\
\hline 120 & $5.00 \mathrm{E}+07$ & $5.10 \mathrm{E}+07$ & $4.50 \mathrm{E}+07$ & $4.86 \mathrm{E}+07$ & $3.21 \mathrm{E}+06$ & $6.60 \mathrm{E}+00$ \\
\hline
\end{tabular}




\section{REFERENCES}

Adney, B., Baker, J., and National Renewable Energy Laboratory (U. S.) (2008). Measurement of cellulase activities [electronic resource]: laboratory analytical procedure (LAP): issue date, 08/12/1996 / B. Adney and J. Baker (Golden, Colo. :: National Renewable Energy Laboratory).

Allcock, E.R., Reid, S.J., Jones, D.T., and Woods, D.R. (1982). Clostridium acetobutylicum Protoplast Formation and Regeneration. Appl Environ Microbiol 43, 719-721.

Birrer, G.A., Chesbro, W.R., and Zsigray, R.M. (1989). Protoplast formation, L-colony growth, and regeneration of\&lt;i\&gt;Clostridium beijerinckii\&lt;/i\&gt; NRRL B-592 and B-593 and\&lt;i\&gt;Clostridium acetobutylicum\&lt;/i\&gt; ATCC 10132. Journal of Industrial Microbiology \& Biotechnology 4, 325-331.

Dahman, Y., Jayasuriya, K.E., and Kalis, M. (2010). Potential of Biocellulose Nanofibers Production from Agricultural Renewable Resources: Preliminary Study. Applied Biochemistry and Biotechnology 162, 1647-1659.

Dashtban, M., Maki, M., Leung, K.T., Mao, C., and Qin, W. (2010). Cellulase activities in biomass conversion: measurement methods and comparison. Crit. Rev. Biotechnol. 30, 302-309.

Dellomonaco, C., Fava, F., and Gonzalez, R. (2010). The path to next generation biofuels: successes and challenges in the era of synthetic biology. Microbial Cell Factories 9, 3.

Dien, B.S., Jung, H.-J.G., Vogel, K.P., Casler, M.D., Lamb, J.F.S., Iten, L., Mitchell, R.B., and Sarath, G. (2006). Chemical composition and response to dilute-acid pretreatment and enzymatic saccharification of alfalfa, reed canarygrass, and switch grass. Biomass and Bioenergy 30, 880-891.

Dürre, P. (1998). New insights and novel developments in clostridial acetone/butanol/isopropanol fermentation. Applied Microbiology and Biotechnology 49, 639-648. 
Ezeji, T.C. (2004). Acetone butanol ethanol (ABE) production from concentrated substrate: reduction in substrate inhibition by fed-batch technique and product inhibition by gas stripping. Applied Microbiology and Biotechnology 63, 653-658.

Ezeji, T., Qureshi, N., and Blaschek, H.P. (2007). Butanol production from agricultural residues: Impact of degradation products on Clostridium beijerinckii growth and butanol fermentation. Biotechnol. Bioeng. 97, 1460-1469.

Ezeji, T.C., Qureshi, N., and Blaschek, H.P. (2004). Acetone butanol ethanol (ABE) production from concentrated substrate: reduction in substrate inhibition by fed-batch technique and product inhibition by gas stripping. Appl. Microbiol. Biotechnol. 63, 653-658.

Formanek, J., Mackie, R., and Blaschek, H.P. (1997). Enhanced Butanol Production by Clostridium beijerinckii BA101 Grown in Semidefined P2 Medium Containing 6 Percent Maltodextrin or Glucose. Appl. Environ. Microbiol. 63, 2306-2310.

Harper, S.H.T., and Lynch, J.M. (1981). The chemical components and decomposition of wheat straw leaves, internodes and nodes. Journal of the Science of Food and Agriculture 32, 1057-1062.

Herrero, A.A., Gomez, R.F., and Roberts, M.F. (1985). 31P NMR studies of Clostridium thermocellum. Mechanism of end product inhibition by ethanol. J. Biol. Chem. 260, 7442-7451.

Huang, W.-C., Ramey, D.E., and Yang, S.-T. (2004). Continuous production of butanol by Clostridium acetobutylicum immobilized in a fibrous bed bioreactor. Appl. Biochem. Biotechnol. 113-116, 887898.

Inderwildi, O.R., and King, D.A. (2009). Quo vadis biofuels? Energy \& Environmental Science 2, 343. Jin, C., Yao, M., Liu, H., Lee, C.F., and Ji, J. (2011). Progress in the production and application of nbutanol as a biofuel. Renewable and Sustainable Energy Reviews 15, 4080-4106.

Joe Shaw, A., Jenney Jr., F.E., Adams, M.W.W., and Lynd, L.R. (2008). End-product pathways in the xylose fermenting bacterium, Thermoanaerobacterium saccharolyticum. Enzyme and Microbial Technology 42, 453-458. 
Jones, D.T., and Woods, D.R. (1986a). Acetone-butanol fermentation revisited. Microbiol Rev 50, 484-524.

Jones, D.T., and Woods, D.R. (1986b). Acetone-butanol fermentation revisited. Microbiol Rev 50, 484-524.

Jones, D.T., Jones, W.A., and Woods, D.R. (1985). Production of Recombinants after Protoplast Fusion in Clostridium acetobutylicum P262. J Gen Microbiol 131, 1213-1216.

Kahar, P. (2013). Synergistic Effects of Pretreatment Process on Enzymatic Digestion of Rice Straw for Efficient Ethanol Fermentation. In Environmental Biotechnology - New Approaches and Prospective Applications, M. Petre, ed. (InTech),.

Kumar, M., and Gayen, K. (2011). Developments in biobutanol production: New insights. Applied Energy 88, 1999-2012.

Ladisch, M.R., and Svarczkopf, J.A. (1991). Ethanol production and the cost of fermentable sugars from biomass. Bioresource Technology 36, 83-95.

Lee, S.Y., Park, J.H., Jang, S.H., Nielsen, L.K., Kim, J., and Jung, K.S. (2008). Fermentative butanol production by Clostridia. Biotechnol. Bioeng. 101, 209-228.

Levin, D.B., Islam, R., Cicek, N., and Sparling, R. (2006). Hydrogen production by Clostridium thermocellum 27405 from cellulosic biomass substrates. International Journal of Hydrogen Energy $31,1496-1503$.

Liu, S., and Qureshi, N. (2009). How microbes tolerate ethanol and butanol. N Biotechnol 26, 117-121.

Liu, Z., Ying, Y., Li, F., Ma, C., and Xu, P. (2010). Butanol production by Clostridium beijerinckii ATCC 55025 from wheat bran. J. Ind. Microbiol. Biotechnol. 37, 495-501.

Lynd, L.R., Weimer, P.J., Van Zyl, W.H., and Pretorius, I.S. (2002). Microbial cellulose utilization: fundamentals and biotechnology. Microbiol. Mol. Biol. Rev. 66, 506-577, table of contents.

Lynd, L.R., Van Zyl, W.H., McBride, J.E., and Laser, M. (2005). Consolidated bioprocessing of cellulosic biomass: an update. Curr. Opin. Biotechnol. 16, 577-583. 
Maddox, I.S., Qureshi, N., and Roberts-Thomson, K. (1995). Production of acetone-butanol-ethanol from concentrated substrate using clostridium acetobutylicum in an integrated fermentation-product removal process. Process Biochemistry 30, 209-215.

Maddox, I.S., Steiner, E., Hirsch, S., Wessner, S., Gutierrez, N.A., Gapes, J.R., and Schuster, K.C. (2000). The cause of "acid-crash" and "acidogenic fermentations" during the batch acetone-butanolethanol (ABE-) fermentation process. J. Mol. Microbiol. Biotechnol. 2, 95-100.

Maki, M., Leung, K.T., and Qin, W. (2009). The prospects of cellulase-producing bacteria for the bioconversion of lignocellulosic biomass. Int J Biol Sci 5, 500-516.

Modig, T., Lidén, G., and Taherzadeh, M.J. (2002). Inhibition effects of furfural on alcohol dehydrogenase, aldehyde dehydrogenase and pyruvate dehydrogenase. Biochem J 363, 769-776.

Mosier, N., Wyman, C., Dale, B., Elander, R., Lee, Y.Y., Holtzapple, M., and Ladisch, M. (2005). Features of promising technologies for pretreatment of lignocellulosic biomass. Bioresour. Technol. $96,673-686$.

Murray, P.R., and American Society for Microbiology (1995). Manual of clinical microbiology. (Washington, D.C.: ASM Press).

Naik, S.N., Goud, V.V., Rout, P.K., and Dalai, A.K. (2010). Production of first and second generation biofuels: A comprehensive review. Renewable and Sustainable Energy Reviews 14, 578-597.

Nakayama, S., Kiyoshi, K., Kadokura, T., and Nakazato, A. (2011). Butanol Production from Crystalline Cellulose by Cocultured Clostridium thermocellum and Clostridium saccharoperbutylacetonicum N1-4. Appl. Environ. Microbiol. 77, 6470-6475.

Palmqvist, E., and Hahn-Hägerdal, B. (2000). Fermentation of lignocellulosic hydrolysates. II: inhibitors and mechanisms of inhibition. Bioresource Technology 74, 25-33.

Peberdy, J.F. (1980). Protoplast fusion - a tool for genetic manipulation and breeding in industrial microorganisms. Enzyme and Microbial Technology 2, 23-29. 
Pessani, N.K. (2011). Simultaneous saccharification and fermentation of switch grass by thermotolerant Kluyveromyces marxianus IMB3| Effect of enzyme loading, temperature and operating mode. Oklahoma State University.

Pienkos, P.T., and Darzins, A. (2009). The promise and challenges of microalgal-derived biofuels. Biofuels, Bioproducts and Biorefining 3, 431-440.

Qureshi, N., and Blaschek, H. (2001). ABE production from corn: a recent economic evaluation. Journal of Industrial Microbiology and Biotechnology 27, 292-297.

Qureshi, N., and Ezeji, T.C. (2008). Butanol, “a superior biofuel” production from agricultural residues (renewable biomass): recent progress in technology. Biofuels, Bioproducts and Biorefining 2, 319330.

Qureshi, N., Saha, B.C., and Cotta, M.A. (2007). Butanol production from wheat straw hydrolysate using Clostridium beijerinckii. Bioprocess Biosyst Eng 30, 419-427.

Qureshi, N., Saha, B.C., Hector, R.E., Hughes, S.R., and Cotta, M.A. (2008a). Butanol production from wheat straw by simultaneous saccharification and fermentation using Clostridium beijerinckii: Part I-Batch fermentation. Biomass and Bioenergy 32, 168-175.

Qureshi, N., Ezeji, T.C., Ebener, J., Dien, B.S., Cotta, M.A., and Blaschek, H.P. (2008b). Butanol production by Clostridium beijerinckii. Part I: Use of acid and enzyme hydrolyzed corn fibre. Bioresource Technology 99, 5915-5922.

Qureshi, N., Saha, B.C., Hector, R.E., Dien, B., Hughes, S., Liu, S., Iten, L., Bowman, M.J., Sarath, G., and Cotta, M.A. (2010). Production of butanol (a biofuel) from agricultural residues: Part II - Use of corn stover and switch grass hydrolysates. Biomass and Bioenergy 34, 566-571.

Radakovits, R., Jinkerson, R.E., Darzins, A., and Posewitz, M.C. (2010). Genetic Engineering of Algae for Enhanced Biofuel Production. Eukaryotic Cell 9, 486-501.

Reilly, P.M., and Rogers, P. (1987). Regeneration of cells from protoplasts of\&lt;i\&gt;Clostridium acetobutylicum\&lt;/i\&gt; B643. Journal of Industrial Microbiology \& Biotechnology 1, 329-334. 
Sadeghi, H.M.M., Rajaei, R., Moazen, F., Rabbani, M., and Jafarian-Dehkordi, A. (2010). Mutating Asn-666 to Glu in the O-helix region of the taq DNA polymerase gene. Res Pharm Sci 5, 15-19.

Saha, B.C. (2003). Hemicellulose bioconversion. J. Ind. Microbiol. Biotechnol. 30, 279-291.

Shaw, A.J., Hogsett, D.A., and Lynd, L.R. (2009). Identification of the [FeFe]-Hydrogenase Responsible for Hydrogen Generation in Thermoanaerobacterium saccharolyticum and Demonstration of Increased Ethanol Yield via Hydrogenase Knockout. J. Bacteriol. 191, 64576464.

Sims, R.E.H., Mabee, W., Saddler, J.N., and Taylor, M. (2010). An overview of second generation biofuel technologies. Bioresource Technology 101, 1570-1580.

Sun, Y., and Cheng, J.J. (2005). Dilute acid pretreatment of rye straw and bermudagrass for ethanol production. Bioresour. Technol. 96, 1599-1606.

Taherzadeh, M.J., and Karimi, K. (2008). Pretreatment of Lignocellulosic Wastes to Improve Ethanol and Biogas Production: A Review. Int J Mol Sci 9, 1621-1651.

Tashiro, Y., Shinto, H., Hayashi, M., Baba, S.-I., Kobayashi, G., and Sonomoto, K. (2007). Novel high-efficient butanol production from butyrate by non-growing Clostridium saccharoperbutylacetonicum N1-4 (ATCC 13564) with methyl viologen. J. Biosci. Bioeng. 104, $238-240$.

Torget, R., Werdene, P., Himmel, M., and Grohmann, K. (1990). Dilute acid pretreatment of short rotation woody and herbaceous crops. Applied Biochemistry and Biotechnology 24-25, 115-126.

Tsai, S.-L., Oh, J., Singh, S., Chen, R., and Chen, W. (2009). Functional Assembly of Minicellulosomes on the Saccharomyces cerevisiae Cell Surface for Cellulose Hydrolysis and Ethanol Production. Appl Environ Microbiol 75, 6087-6093.

D. V. Gokhale, (1993). U.S.P. Protoplast fusion: A tool for intergeneric gene transfer in bacteria. Biotechnology Advances 199-217. 
Wood, T.M., and Bhat, K.M. (1988). Methods for measuring cellulase activities. In Biomass Part A: Cellulose and Hemicellulose, (Academic Press), pp. 87-112.

Wood, S.M., Layzell, D.B., and BIOCAP Canada Foundation (2003). A Canadian biomass inventory [electronic resource]: feedstocks for a bio-based economy : final report. (Kingston, Ont: BIOCAP Canada Foundation).

Wyman, C. (1996). Handbook on Bioethanol: Production and Utilization (Taylor \& Francis).

Wyman, C.E., Dale, B.E., Elander, R.T., Holtzapple, M., Ladisch, M.R., and Lee, Y.Y. (2005). Coordinated development of leading biomass pretreatment technologies. Bioresour. Technol. 96, $1959-1966$.

Yu, E.K.C., Chan, M.K.-H., and Saddler, J.N. (1985). Butanol production from cellulosic substrates by sequential co-culture of\&lt;u\&gt;Clostridium\&lt;/u\&gt;\&lt;u\&gt;thermocellum\&lt;/u\&gt; and\&lt;u\&gt;C\&lt;/u\&gt;.\&lt;u\&gt;acetobutylicum\&lt;/u\&gt; Biotechnology Letters 7, 509-514.

Zverlov, V.V., Berezina, O., Velikodvorskaya, G.A., and Schwarz, W.H. (2006). Bacterial acetone and butanol production by industrial fermentation in the Soviet Union: use of hydrolyzed agricultural waste for biorefinery. Appl. Microbiol. Biotechnol. 71, 587-597. 